\title{
COMUNICACIONES ORALES
}

\section{IMPACTO DE LOS ACTIVIRALES DE ACCIÓN DIRECTA EN EL TRATAMIENTO DE PACIENTES CON INFECCIÓN CRÓNICA VHC. ANÁLISIS DE RESULTADOS TRAS UN AÑO DE EXPERIENCIA}

Trigás Ferrín M, Pastor de Celis Rubí E, Ferreira González L, García Alén D, Lorenzo Álvarez J. MEDICINA INTERNA, COMPLEJO HOSPITALARIO UNIVERSITARIO DE FERROL.

INTRODUCCIÓN Y OBJETIVOS: Desde Abril de 2015 disponemos de nuevos fármacos para el tratamiento de la infección crónica por virus C (VHC) denominados antivirales de acción directa (AAD) que han conseguido en los estudios tasas de respuesta viral superiores al 90\% lo que constituye una mejoría significativa con respecto al tratamiento estándar con Peginterferon / Rivabirina (PEG/RV).

MATERIAL Y MÉTODOS: Se han analizado todos los pacientes con infección crónica por VHC tratados con AAD descle Abril 2015 a Abril 2016 en la consulta de Hepatología de nuestro servicio (sólo pacientes monoinfectados). Se han recogido datos demográficos, características de la infección, tratamientos previos, tratamiento actual, respuesta viral y seguridad. Los resultados se han analizado con el paquete estadístico SPSS

RESULTADOS: Se han tratado 156 pacientes (63.5 \% varones) con una edad media de 60 años (19-86 años). El $51 \%$ de los casos con fibrosis avanzada (Fibroscan $>14 \mathrm{Kpa}$ ) siendo el genotipo 1 el más prevalente (75\%). El $59 \%$ había recibido tratamiento antiviral previo (24\% null responder) y $8(4,4 \%)$ habían fracasado a tratamientos que incluyeron antivirales orales. El $66.6 \%$ de los pacientes recibieron tratamiento con sofosvubir /ledipasvir (SOF/LDV) con /sin RV; $14.8 \%$ SOF/Daclatasvir (DC) con/sin RV; 8\% 3D y SOF/Simeprevir (SIM) con /sin RV. El 82\% ha finalizado el tratamiento en el momento del análisis y disponemos del RNA realizado a las 12 semanas de su finalización en el $65 \%$ siendo en el $64 \%$ indetectable ( $98.5 \%$ de eficacia). Tres pacientes han presentado recaída. No se han encontrado diferencias estadisticamente significativas al comparar el tipo de tratamiento y la respuesta viral a las 12 semanas. El 37\% de los pacientes recibieron Rivabirina el $45 \%$ de los cuales presentaron efectos secundarios ( $34 \%$ anemia) frente al $4 \%$ de los pacientes tratados sin Rivabirina. $(p<0.005)$. El $35 \%$ de los pacientes presentaron posibles interacciones farmacológicas (10\% antihipertensivos, 8\% IBP $3 \%$ estatinas). No hubo interacciones graves. En un $9.6 \%$ de los caso fue necesario suspender modificar el tratamiento para evitar interacciones. Dos pacientes fallecieron por causas no relacionadas con el tratamiento ni con la enfermedad hepática.

CONCLUSIONES: El tratamiento con AAD para la infección por VHC es eficaz, con tasas de respuesta viral elevadas (en nuestro grupo sólo 1.9\% de recaídas), seguro sin presentar efectos adversos importantes y sin dificultad en el manejo de las interacciones farmacológicas.

\section{ARTERITIS DE CÉLULAS GIGANTES. \\ UTILIDAD DEL 18F-FDG PET/TC EN UN SUBGRUPO DE PACIENTES CON MANIESTACIONES ATÍPICAS}

Alende V, Sopeña B, García Villafranca A, Páez Guillán E, Macía Rodríguez C, González-Quintela A. MEDICINA INTERNA, COMPLEO HOSPITALARIO UNIVERSITARIO DE SANTIAGO DE COMPOSTELA.

INTRODUCCIÓN: Algunos pacientes con arteritis de células gigantes y afectación de grandes vasos (GV-ACG) no presentan síntomas craneales típicos (C-ACG) y la biopsia de arteria temporal (BAT) es negativa. A menudo son diagnosticados tardíamente, lo que conlleva un retraso en el tratamiento y en ocasiones, un tratamiento inadecuado. Asimismo, los pacientes con BAT positiva y elevación aislada de VSG pueden ser identificados erróneamente como recaída, intensificando el tratamiento esteroideo. En estos pacientes el 18F-FDG PET/CT puede ser útil.

OBJETIVOS: estudiar si el PET/TC con 18F-FDG puede ser de utilidad para el diagnóstico de casos difíciles de GV- ACG y para evaluar recaídas en pacientes diagnosticados de C-ACG y elevación de reactantes de fase aguda.

MÉTODOS: Estudio prospectivo de dos subgrupos de pacientes desde enero de 2012 a junio de 2015. El Grupo 1 incluyó pacientes con sospecha de C-ACG y biopsia de arteria temporal negativa y/o pacientes con síndrome general de origen inflamatorio o fiebre de origen desconocido que no cumplían criterios para C-ACG. El grupo 2 incluyó pacientes diagnosticados de C-ACG con VSG persistentemente elevada y sospecha de recaída. En los dos casos se realizó un 18F-FDG PET/TC.

RESULTADOS: se incluyeron 22 pacientes; 17 fueron mujeres (77\%) con una edad media de 72 Grupo 1 ( $n=18$ ): Las quejas principales fueron: síntomas constitucionales en $13(72 \%)$, FOD en $7(39 \%)$, neuritis óptica en 1 y polimialgia reumática (PMR) en otro. Síntomas de claudicación de miembros superiores o inferiores se presentaron en 8 (44\%) y 1 (6\%) respectivamente; dolor abdominal severo en 4 (22\%); ningún evento isquémico. 4 pacientes (todos con BAT negativa) presentaron anormalidad en la exploración de la arteria temporal. Se objetivó anemia en 10 pacientes (55\%) y una VSG > 50 en 18. La biopsia de arteria temporal se realizó en 9 pacientes y fue negativA. EI PET demostró captación vascular sugestiva de GV-ACG sin involucrar a la arteria temporal en 16/18 (89\%). Ningún paciente con PET negativo presentaba GV-ACG. En e paciente diagnosticado de PMR se objetivó compromiso vascular, lo que tuvo implicaciones en el tratamiento. En casos con dolor abdominal se objetivó captación a nivel de la aorta abdominal. En el grupo 2, los pacientes presentaron una VSG $>100 \mathrm{~mm} / \mathrm{h}$. Uno de los pacientes presentaba síntomas de PMR y los otros 3 estaban asintomáticos. Sin embargo, 2 de los pacientes recibieron tratamiento intermitente con esteroides. El PET/TC fue negativo para arteritis en estos tres pacientes que fueron seguidos durante una media de 16.5 meses. En el otro cao, el PET/TC fue típico para PMR (sin signos de GV-ACG) y respondieron a baja dosis de esteroides
CONCLUSIONES: El correcto uso del PET/TC fue útil en el diagnóstico y el manejo de casos seleccionados de GV-ACG, así como para evitar el tratamiento inadecuado con esteroides en pacientes sin evidencia de recaída o vasculitis.

\section{COINFECCIÓN POR EL VIRUS DE LA HEPATITIS C E INCIDENCIA DE CÁNCER EN PACIENTES VIH}

Mena A (1), Meijide H (1,2), Pértega S (3), Rodríguez-Osorio I (1), Castro A (1), Pernas B (1), Rodríguez G (4), Poveda E (1).

(1) GRUPO DE VIROLOGÍA CLIINICA, INSTITUTO DE INVESTIGACIÓN BIOMÉDICA DEA CORUÑA (INIBIC)-COMPLEXO HOSPITALARIO UNIVERSTTARIO DEA CORUÑA (CHUAC), SERGAS. UNIVERSIDADE DA CORUÑA (UDC). (2) SERVICIO DE MEDICINA INTERNA, HOSPITAL QUIRON, A CORUÑA. (3) UNIDAD DE EPIDEMIOLOGÍA CLIIIICAY BIOESTADISTICA, INSTITUTO DE INVESTIGACIÓN BIOMÉDICA DE A CORUÑA (INBIC)-COMPLEXO HOSPITALARIO UNIVERSITARIO DEA CORUÑA (CHUAC), SERGAS. UNIIERSIDADE DA CORUÑA (UDC). (4) UNIDAD DEADMIISIÓN Y DOCUMENTACIÓN CLIINICA. COMPLEXO HOSPITALARIO UNIVERSITARIO DEA CORUNNA (CHUAC), SERGAS. A CORUÑA., CHUAC.

OBJETIVOS: Determinar la incidencia de cáncer en pacientes VIH según la presencia o no de coinfección por el virus de la hepatitis C (VHC), y compararla con la incidencia en población general. MÉTODOS: Estudio de seguimiento ambispectivo de pacientes VIH diagnosticados en el periodo 1985-2013 y seguidos en el Complexo Hospitalario Universitario A Coruña. La variable principal fue el diagnóstico de cáncer (tumores definitorios de SIDA y tumores no definitorios) en el seguimiento, que se extendió hasta Julio de 2015. Se calculó la tasa de incidencia de cáncer cruda y ajustada por el método indirecto, utilizando los datos de incidencia de cáncer en España publicados en el informe GLOBOCAN 2012. Para comparar la incidencia observada con la publicada en población general, se calculó la razón de incidencias estandarizada (SRI) y su intervalo de confianza al 95\%. Para analizar la incidencia acumulada de cáncer en el seguimiento tras el diagnóstico de VIH se aplicó una metodología de riesgos competitivos, considerando la muerte por cualquier causa como evento que "compite" con la incidencia de cáncer.

RESULTADOS: Se incluyeron $n=2318$ pacientes $(75.8 \%$ hombres, edad media al diagnóstico del VIH 32,3 $\pm 10,1$ años), que dieron lugar a 26.580 personas-año de seguimiento. De ellos, $857(37,0 \%)$ eran pacientes coinfectados por VHC y $1461(63,0 \%)$ pacientes monoinfectados por VIH. Durante el seguimiento, se diagnosticaron 185 tumores, con una tasa de incidencia (TI) de 696 tumores por 100.000 personas/año, significativamente más elevada que en población general (SIR=3,8; 95\% IC 3,3-4,4). La incidencia de tumores no definitorios de SIDA fue de 349,4 tumores/100.000 personas/año, más elevada en pacientes coinfectados $(T \mid=415,0 ; \mathrm{SIR}=3,4)$ que en monoinfectados (TI=377,3; SIR=1,8). La incidencia de tumores definitorios, por el contrario, fue más elevada en pacientes monoinfectados $(T \mid=442,2 ; \mathrm{SIR}=37,4)$ que en pacientes coinfectados $(T \mid=127,2 ; S I R=27,2)$. La incidencia acumulada de cáncer es del 3,6\% a los 5 años del diagnóstico de VIH, del $5,5 \%$ a los 10 años y del $10,4 \%$ a los 20 años. Un 50,2\% de los pacientes siguen vivos y libres de tumores a los 20 años tras el diagnóstico. Tras ajustar por edad al diagnóstico, sexo y vía de transmisión, los pacientes coinfectados por VHC presentan significativamente una mayor incidencia de tumores no definitorios de SIDA (HR ajustado $=1,7 \cdot 95 \% \mathrm{IC}=1,1-2,8)$ y meno incidencia de tumores definitorios ( $\mathrm{HR}$ ajustado $=0,44 ; 95 \% \mathrm{IC}=0,25-0,74$ ).

CONCLUSIONES: Los pacientes VIH presentan una incidencia de cáncer superior a la de la población general. La coinfeccion por VHC se asocia a una mayor tasa de incidencia de tumores no definitorios de SIDA.

\section{EVALUACIÓN NO INVASIVA DE LA FIBROSIS EN PACIENTES CON HEPATITIS B}

Fernández Fernández FJ, Arca Blanco A, Lamas Ferreiro JL, González Portela C, Vázquez López S, Camba Estévez M, de la Fuente Aguado J.

MEDICINA INTERNA, POVISA.

INTRODUCCIÓN: La evaluación de la fibrosis es indispensable en los pacientes con hepatitis B para establecer el pronóstico. Existen diferentes métodos no invasivos para estimar la fibrosis. OBJETIVOS: Evaluar la prevalencia de fibrosis significativa y cirrosis mediante elastografía de transición (ET) en una población con infección crónica por hepatitis B. Analizar las variables que se correlacionan con una puntuación mayor en la ET. Evaluar si existe correlación entre los índices bioquímicos de fibrosis y la ET.

MATERIAL Y MÉTODO: Se incluyeron todos los pacientes entre 18 y 80 años con HBsAg en suero durante $>6$ meses a seguimiento en nuestro hospital Se recogieron datos clínicos y radiológicos, y se realizó una ET con FibroScan $囚$. Se emplearon los marcadores bioquímicos de fibrosis FIB-4, APRI y FORNS. Se tomaron como valores de corte de referencia: $\leq 6 \mathrm{kPa}$ fibrosis no significativa 6-9 kPa zona gris, 9-12 kPa fibrosis significativa $y \geq 12 \mathrm{kPa}$ cirrosis.

RESULTADOS: 76 pacientes tenían una infección crónica por hepatitis B: el 30\% hepatitis crónica ( $56 \%$ de ellos HBeAg positivo) y el $70 \%$ portadores inactivos del virus

La edad media fue de 50 años (rango 20-75), 66\% varones. El 26\% refería consumo habitual de alcohol, aunque sólo 1 paciente > 2 UBE diarias. El IMC medio fue de $27 \mathrm{~kg} / \mathrm{m} 2$ (48\% sobrepeso y $19 \%$ obesidad). El $32 \%$ de los pacientes tenía al menos una comorbilidad asociada, y 4 pacientes tenían infección por VIH. El 17\% de los pacientes tenía trombopenia. El 33\% de los pacientes tenía el DNA del VHB indetectable, la mayor parte bajo tratamiento antiviral. El 67\% tenía una ecografía normal, el $17 \%$ esteatosis y el $17 \%$ datos ecográficos sugestivos de hepatopatía crónica. El valor medio de la ET fue de 6.6 (rango 3-32.8); el 9\% de los pacientes tenía un valor $>9 \mathrm{kPa}$, indicativo de fibrosis significativa o cirrosis. Los factores relacionados con un valor de ET superior a 6 fueron el sexo (varones), consumo de alcohol, presencia de HBeAg, cifra menor de plaquetas, valores más elevados de GOT, GPT y la existencia de alteraciones ecográficas. En el estudio multivariante 
Ios factores relacionados con un valor de ET superior fueron las mayores cifras de GOT y GPT, e consumo de alcohol y la existencia de alteraciones ecográficas. Existió una correlación positiva (rho de Spearman) entre los índices bioquímicos de fibrosis y los valores medidos mediante ET, moderada para APRI y FORNS, y baja para FIB-4. La fuerza de la concordancia (índice kappa) de los índices bioquímicos fue débil en el grupo de pacientes con un grado de fibrosis no significativa. CONCLUSIONES: La mayor parte de los pacientes con infección crónica por hepatitis B tienen fibrosis poco significativa evaluada mediante ET. Existe concordancia entre los métodos bioquímicos y la ET para la evaluación de la fibrosis, aunque sólo moderada. La elevación de enzimas hepáticas el consumo de alcohol y la existencia de alteraciones ecográficas se correlacionan con un mayor grado de fibrosis.

\section{TUBERCULOSIS ÓSEA EN GALICIA}

Alves-Pereira D (1), Alende Castro V (2), Lorenzo R (3), Piñeiro Parga P (4), Pérez González (5), Dalama López T (6), Piñeiro Fernández JC (7), González Noya A (8), Anibarro L (1). SERVICIO DE MEDICINA INTERNA, COMPIEJO HOSPITALARIO DE PONTEVEDRA (1), HOSPITAL CLÍNICO UNIVERSITARIO DE SANTIAGO DE COMPOSTELA (2), HOSPITAL XERAL, VIGO (3), COMPLEXO HOSPITALARIO UNIVERSITARIO DEA CORUÑA (4), HOSPITAL DO MEIXOEIRO, VIGO (5), COMPLEJO HOSPITALARIO ARQUITECTO MARCIDE-PROFESOR NOVOA SANTOS, FERROL (6), COMPLEJO HOSPITALARIO XERAL- CALDE, LUGO (7). COMPLEJO HOSPITALARIO DE OURENSE (8). GRUPO REGAMI.

INTRODUCCIÓN: En general en nuestro medio se ha observado un descenso de la incidencia de tuberculosis (TB) respiratoria, aunque no ocurre así con algunas formas de TB extrapulmonar. La TB osteoarticular es la 3ra forma más frecuentes de localización, tras la pleural y ganglionar. OBJETIVO: Analizar características de la TB osteoarticular en Galicia.

MATERIAL Y MÉTODOS: Estudio retrospectivo multicéntrico en 8 hospitales gallegos, de los pacientes adultos diagnosticados de TB osteoarticular desde abril-2009 a mayo-2014 RESULTADOS: Se diagnosticaron 87 casos de TB osteoarticular, se pudieron analizar 85 de ellos. $62 \%$ eran hombres. La edad media fue de 63+/-19,5 años. Solo 4 pacientes habían nacido fuera de España. 53 (62,4\%) pacientes presentaban algún tipo de inmunosupresión, aunque solo 6 coinfección con VIH. Únicamente $14 \%$ de pacientes presentaban anemia $(\mathrm{Hb}<10 \mathrm{~g} / \mathrm{dl})$ y 11 pacientes (13\%) presentaban leucocitosis (recuento >10.500) al momento del diagnóstico. El síntoma más frecuente fue el dolor (88\%), mientras que se objetivó fiebre en el $36 \%$. La localización más frecuente fue la vertebral: 67,1\%. 35 enfermos presentaban también TB activa de localización extraósea. Se obtuvo confirmación microbiológica en el 87,9\% de los pacientes de los que se tomaron muestras. No se encontraron diferencias en la detección de M. tuberculosis de las muestras de biopsia frente a las de la PAAF ( $82,4 \%$ vs $84,6 \%, p=N S)$. La media de demora de inicio de tratamiento tras el inicio de los síntomas fue de $23,6+/-11$ semanas, sin que fuera diferente en función de la localización axial (23,4 semanas) frente a la extraaxiales (23,9 semanas), p=NS, ni en los casos de TB con otra localización extraósea (20,6 semanas vs 26,1 en los pacientes con localización únicamente osteoarticular; $p=N S)$. El 37,6\% precisaron tratamiento ortopédico, todos ellos con afectación vertebral $(p<0,001)$. En 18 pacientes $(21,2 \%)$ se objetivó algún tipo de déficit neurológico (29,8\% en los pacientes con afectación axial vs 3,6\% en pacientes sin esta localización; $p=0,003$ ). Se realizó seguimiento de los pacientes hasta la finalización del tratamiento. En 10 pacientes se consideró una situación final insatisfactoria: tres pacientes fallecieron por causa atribuible a la TB, otros cinco por causas distintas de la TB y dos abandonaron el tratamiento. Los otros 75 pacientes $(88,2 \%)$ finalizaron el tratamiento de manera correcta. La única variable relacionada con la mala evolución fue la hipoalbuminemia basal $(p=0,03)$.

CONCLUSIONES: La TB osteoarticular es aún relativamente frecuente en nuestro medio. La rentabilidad microbiológica de la toma de muestras en nuestros pacientes es elevada, siendo la localización vertebral la más frecuente y con mayor complicación. La hipoalbuminemia es un factor de mal pronóstico.

\section{ENFERMEDAD TROMBOEMBÓLICA INCIDENTAL EN PACIENTES CON CÁNCER}

Vázquez Vázquez B, Fernández Bouza E, Mella Pérez C, Buño Ramilo B. MEDIIINA INTERNA, COMPLEJO HOSPITALARIO UNIVERSITARIO DE FERROL.

INTRODUCCIÓN: La enfermedad tromboembólica venosa (ETV) incidental es un hallazgo frecuente en los pacientes con cáncer que realizan pruebas de imagen durante el seguimiento de su enfermedad. Su prevalencia depende del tipo de tumor, estadío, modalidad de tratamiento y métodos utilizados para el diagnóstico. Se ha observado que la ETV incidental afecta significativamente al pronóstico y por ello se recomienda actualmente un tratamiento similar a los eventos sintomáticos en estos pacientes. Objetivos: Analizar las características de la ETV incidenta en pacientes con cáncer remitidos a consulta de Medicina Interna en cuanto a características demográficas, clínicas y tratamiento

MATERIAL Y MÉTODOS: Se registraron los datos de 90 pacientes con cáncer y ETV seguidos en consulta monográfica desde Julio de 2012 a Enero 2016. Se consideró ETV incidental cuando esta era hallada en una TC de rutina y no existían síntomas previos compatibles en el seguimiento. RESULTADOS: De los 90 pacientes con ETV y cáncer se encontraron 31 eventos incidentales (34,4\%), de los cuales el 64\% (20) eran hombres. La distribución de la ETV incidental fue: 41,9\% (13) embolismo pulmonar (EP), 16,1\% (5) trombosis venosa visceral, 16,1\% (5) trombosis asociada a catéter, 9,6\% (3) trombosis en vena cava, 6,4\% (2) trombosis femoral y 3,2\% (1) trombosis de tronco braquiocefálico en relación con compresión local tumoral. El EP se consideró de riesgo intermedio/alto en 13\% (4) de los casos, fue bilateral el 32,3\% (10) y de localización lobar 16,1\% (5). Se consideraron otros factores de riesgo encontrándose antecedentes de cirugía abdomina reciente en $6,4 \%$ (2) y ETV previa en 3,2\%(1). En lo referente a la enfermedad neoplásica 38,7\%(12) de los pacientes presentaban cáncer colo-rectal..29\% (9) pulmón, 9,7\%(3) mama, y $9,7 \%(3)$ ginecológico. Se encontró enfermedad metastásica diseminada en $71 \%$ (22) de los casos, siendo la histología mas frecuente adenocarcinoma en 64,5\% (20). El 45,2\% (14) recibían quimioterapia en el momento del diagnóstico y se anticoagularon con HBPM como tratamiento inicial el $93,5 \%$ (29) de los pacientes.

CONCLUSIONES: La tasa de ETV incidental es elevada en los pacientes con cáncer seguidos en la consulta, en parte debida a las características asistenciales propias del centro. El EP fue el evento incidental mas frecuente y se observó una elevada proporción de pacientes con enfermedad neoplásica avanzada y en tratamiento con quimioterapia de acuerdo con lo descrito en la literatura.
La gran mayoría de los pacientes recibio anticoagulación conforme a las recomendaciones actuales de las guias de práctica clinica en estos pacientes.

\section{HOSPITALIZACIONES POR INSUFICIENCIA CARDIACA EN GALICIA. ESTIMACIONES A 10 AÑOS. COMPARACIÓN CON ESPAÑA}

Montes-Santiago J (1), Pérez A, Machado B, Rey-García G (2).

(1)MEDICINA INTERNA (2) DOCUMENTACIÓN CLÍNICA, COMPLEJO HOSPITALARIO UNIVERSITARIO. VIGO.

OBJETIVO: En Galicia, debido al envejecimiento poblacional, se registran de forma más acusada que en el resto de España, mayores tasas de hospitalizaciones y mortalidad por insuficiencia cardiaca (IC). Por ello, es importante poder estimar sus tendencias en los próximos años, a fin de poder habilitar los recursos adecuados para afrontar tal problema. El presente trabajo realiza un modelo de predicción hasta el año 2025 para cuantificar dichas altas en Galicia comparándolas con el resto de España.

MÉTODOS: Se examinaron los datos correspondientes a las altas por IC de la Encuesta Naciona Anual de Morbilidad Hospitalaria del Instituto Nacional de Estadística (EMH, INE, www. ine. es/jaxi/). Tal encuesta es mucho más completa que los datos proporcionados por el CMBD del Servicio Nacional de Salud (SNS) y recoge el 99,2\% del total de altas hospitalarias. Se analizó la Categoría 428 (IC como diagnóstico principal) según la Clasificación Internacional de Enfermedades (CIE9MC) para España y para Galicia durante el periodo 2004-2014 Para el cálculo de costes se utilizaron los atribuidos a tal categoría 428 por el SNS y Servicio Gallego de Salud (SERGAS). Con dichos datos se elaboró una gráfica de regresión y se obtuvo por extrapolación los valores previstos para el año 2025. En investigaciones previas determinamos que modelos predictivos semejantes estimaban cifras distanciadas $<3 \%$ de las altas reales producidas.

RESULTADOS: En 2014 las tasas de hospitalización de IC por 100000 h fueron de 26,3 (Galicia) y 26,1 (España). En comparación la tasa de mortalidad por 100000 h. fue 57 (Galicia, la más alta de España) y 36 (España). Tales hospitalizaciones ocasionaron unos costes de 31,3 millones (SERGAS) y 485,2 millones (SNS).

La curva de regresión lineal fue la mejor ajustada a datos reales [SNS: R2=0,991; SERGAS: $\mathrm{R} 2=0,848]$. Dicha línea es creciente y no hay datos ni en Galicia ni en España que muestren ralentización o límite en tales hospitalizaciones. Por tanto, si las altas por IC siguen la tendencia lineal robusta mostrada, se estiman para 2025 unas 162000 altas anuales por IC en España y 10000 en Galicia.

CONCLUSIONES: Se sigue observando una tendencia creciente en las altas por IC en España y Galicia. Por tanto, en los próximos años dicha proceso seguirá constituyendo un desafío sanitario de primera magnitud. Se calculan unas 10000 hospitalizaciones anuales en el SERGAS y 162000 en el SNS dentro de la próxima década.

\section{FACTORES DE COMORBILIDAD ASOCIADOS A LA ENFERMEDAD TROMBOEMBÓLICA VENOSA NO PROVOCADA. ESTUDIO ETVGA}

Matesanz Fernández M, Pombo Vide B, Díaz Peromingo JA, Puerta Louro R, Barbagelata López C, Fernández Bouza E Nuñez Fernández M, Jiménez Martínez JL Montes Santiago J. MEDICINA INTERNA, HOSPITAL LUCUS AUGUST.

INTRODUCCIÓN: La enfermedad tromboembólica venosa (ETEV) no provocada supone entre un $25-45 \%$ del total de casos de ETEV. No está claro cuál es la influencia de la comorbilidad asociada a estos casos ni qué factores se asocian al riesgo de recurrencia a medio y largo plazo.

OBJETIVO: estudiar los factores de comorbilidad y epidemiológicos asociados a la ETEV no provocada, dentro de un estudio más amplio (Estudio ETVGA-enfermedad tromboembólca venosa en Galicia) que intenta determinar además los factores predictores de evolución clínica a medio plazo

MATERIAL Y MÉTODO: estudio multicéntrico, observacional y prospectivo, en el ámbito de servicios de Medicina Interna de Galicia, sobre enfermos con ETEV no provocada consecutivos, iniciado en septiembre de 2015. Se han registrado datos epidemiológicos, clínicos, analíticos, evolutivos y terapéuticos, dentro de práctica clínica habitual. En este trabajo se muestran los datos clínicos basales después de 6 meses de reclutamiento y parciales a los 3 meses de seguimiento.

RESULTADOS: Se registraron 70 pacientes con ETEV no provocada (HULA 22, CHUS 15, POVISA 8. CHUAC 7, CHUF 5, CHOP 5, CHUO 5, CHUVI 3). El 61.4\% fueron hombres, edad 68,4 (DS 14.6). La ETEV se presentó como trombosis venosa profunda (TVP) proximal en $54(77.1 \%)$ pacientes (11 con embolia pulmonar (EP) asociada y 3 con TVP distal), EP aislada en 9 (12.9\%) y TVP distal en 7 (10\%), 2 de ellos con EP asociada. El 5.7\% tenían antecedentes de ETEV en familiares de primer grado y el 13\% historia personal de ETEV (6 TVP, 2 EP, 1 TVP+EP). E 10\% tenían antecedentes de cardiopatía, 10\% diabetes, $7.1 \%$ cáncer remoto o en remisión completa, $7 \%$ infección aguda reciente, $4.3 \%$ EPOC y el 5.71\% enfermedad inflamatoria crónica. Presentaban varices en miembros inferiores 37 pacientes (52.8\%) y síndrome postrombótico e 10\% Solo 2 casos (2.8\%) tenían demencia y 4 enfermedad psiquiátrica (5.7\%). El 85\% tenían un índice de Charlson menor de 3 puntos y el Barthel medio fue 94.3 (DS 18.8). La Hb fue 13.8 $\mathrm{mg} / \mathrm{dl}$ (DS 1.6) y el CKD-EPI 75.6 (19.7). Todos los casos salvo 1 fueron tratados inicialmente con heparina sc. Se disponen de los datos de revisión a los 3 meses de 37 pacientes (52.8\%), sin casos de recidiva de TVP. Se realizó eco de control a 17 enfermos, de los cuales el $47 \%$ tenía trombosis residual. Se practicó estudio de trombofilia en 14 casos, con resultado positivo en 6 ( 2 anticoagulante lúpico y 4 heterocigosis para factor $V$ Leiden).Durante el seguimiento se detectaron 2 tumores (neoplasia de pulmón y pólipo de colon). A los 3 meses, todos los enfermos revisados recibían anticoagulación (56\% antivitamina K, 27\% heparina sc, 16.2\% anticoagulantes de acción directa).

CONCLUSIÓN: El perfil del paciente con ETEV no provocada es un varón, no anciano independiente funcional y con poca comorbilidad. La presencia de trombosis residual a los 3 meses es significativa. 


\section{FACTORES EPIDEMIOLÓGICOS Y SOCIODEMOGRÁFICOS ASOCIADOS AL SINDROME DE ANBSTINENCIA ALCOHÓLICA COMPLICADO}

Monte-Secades R (1), Sánchez-Lora FJ (2), Díaz-Peromingo JA (3), Sanvisens A (4), Martín-González MC (5), Barbosa A (6), Gómez-Méndez R (1), Rosón-Hernández B (7), Epelde F (8), Tejero A (9), Puerta-Louro R (10), García-Pereña L (11).

SERVICIOS DE MEDICINA INTERNA, HOSPITAL UNIVERSITARIO LUCUS AUGUSTI. LUGO (1). HOSPITAL

CLINICO UNIVERSITARIO VIRGEN DE LA VICTORIA. MALAGA (2). COMPLEJO HOSPITALARIO UNIVERSITARIO SANTIAGO DE COMPOSTELA (3). HOSPITAL UNIVERSITARIO GERMAN TRIAS Y PUJOL. BADALONA (4). HOSPITAL UNIVERSITARIO DE CANARIAS. SAN CRISTOBAL DE LA LAGUNA (5). HOSPITAL UNIVERSITARIO DE SALAMANCA (6). HOSPITAL UNIVERSITARIO DE BELLVITGE (7). HOSPITAL UNIVERSITARIO PARC TAUU. SABADELL (8). HOSPITAL DE CABUEÑES. GIJÓN (9). POVISA. VIGO (10). HOSPITAL SAN CECILIO. GRANADA (11).

INTRODUCCIÓN: Existe una gran variabilidad en la presentación del síndrome de abstinencia alcohólica (SAA). Los factores que determinan su evolución clínica no están bien caracterizados y son probablemente múltiples: genéticos, epidemiológicos, clínicos, sociodemográficos, etc. OBJETIVOS: analizar la influencia de los factores epidemiológicos y sociodemográficos disponibles en el momento del ingreso hospitalario en el desarrollo de un SAA complicado

MATERIAL Y MÉTODO: estudio multicéntrico, observacional, prospectivo, en el ámbito de 12 servicios de Medicina Interna de hospitales españoles, sobre enfermos consecutivos ingresados con SAA, desde el 1 de enero de 2013 hasta el 31 de diciembre de 2014. Se registraron datos sociodemográficos, epidemiológicos, clínicos y evolutivos. Se definió SAA complicado como aque que había cursado con crisis comiciales o delirium tremens (DT)

RESULTADOS: Se estudiaron 228 episodios de SAA en 219 pacientes. La edad media fue 54.5 (DS 11.6), $90.1 \%$ hombres. EI SAA fue la causa de la hospitalización en el 39.9\%. El $26.7 \%$ de los casos presentaron crisis comiciales (tipo gran mal 80\%). Considerando el final del ingreso, 82 episodios (35.9\%) cursaron con DT. Precisaron ingreso en UCl 49 enfermos (21.9\%) y la mortalidad fue de 2.1\%. La cantidad ingerida de alcohol media fue 18 UBEs (DS 21.6), con 29.2 años de consumo (DS 13.7) y 16.8 años de dependencia (DS 11.2). El patrón de abuso de alcohol fue regular en el $82 \%$. El $17 \%$ habían presentado anteriormente un SAA con ingreso. Procedían de núcleos de población de menos de 10.000 habitantes el $38.6 \%$. Vivían casados o en pareja el $35.5 \%$ y e $51.2 \%$ tenía hijos. Un $76.2 \%$ estaba en paro o era pensionista. Se recogieron datos referentes a nivel de estudios alcanzado en 193 enfermos: el 68.9\% no habían pasado de estudios primarios. El $5 \%$ consumía cannabis, $6 \%$ cocaína y $3.5 \%$ opiáceos.

Los siguientes factores se asociaron significativamente con el riesgo de SAA complicado en e análisis univariante: menor edad, cantidad diaria de ingesta, $n^{\circ}$ de SAA previos, ingreso por SAA nivel bajo de estudios y consumo de cocaína. Las variables independientes identificadas en e análisis multivariante fueron: edad <55 (OR 2.8; IC 95\% 1.4-5.6), bajo nivel de estudios (OR 3,7; IC 95\% 1.3-10.3) y el ingreso por SAA (OR 3.3; IC 95\% 1.6-6.6). El área ROC del modelo fue 0.726 (IC 95\% 0.648-0.805).

CONCLUSIONES: es difícil identificar factores ligados al hábito de consumo de alcohol con el desarrollo de SAA complicado. En cambio, variables como la edad o el nivel bajo de estudios pueden ayudar en la identificación de pacientes de riesgo. La capacidad predicitiva de este modelo es baja.

\section{INFECCIONES POR KLEBSIELLA PNEUMONIAE PRODUCTORA DE CARBAPENEMASAS EN EL ÁREA DEL BARBANZA}

Martínez-Braña L (1), Rodríguez-Fernández S (1), Rodríguez-Cordero M (1). Barbeito G (2), Rodríguez-Framil M (1), Molinos-Castro S (1), Pesqueira-Fontán P (1).

(1) SERVICIO MEDICINA INTERNA, HOSPITAL DA BARBANZA; (2) SERVICIO DE MICROBIOLOGÍA CLIINICA, C.H. UNIVERSITARIO DE SANTIAGO DE COMPOSTELA, HOSPITAL DA BARBANZA.

INTRODUCCIÓN: Cada vez es más frecuente la presencia de gérmenes multirresistentes implicados en las infecciones relacionadas con la asistencia sanitaria. En los últimos años se comunica un número creciente de infecciones por Klebsiella pneumoniae productora de carbapenemasas (KPC). OBJETIVO: Conocer el número de infecciones y colonizaciones por KPC en el Hospital da Barbanza las características clínicas y microbiológicas de los pacientes afectados y los factores que se asocian a mayor mortalidad.

MATERIAL Y MÉTODOS: Estudio retrospectivo, observacional, descriptivo y analítico, que incluye los pacientes ingresados en nuestro servicio, entre enero 2015 y abril 2016, en los que se constata infección o colonización por KPC, realizando la búsqueda a través del registro de altas y datos de Microbiología. Se recogieron datos demográficos, características clínicas, comorbilidad, tipo y localización de la infección y antecedentes de atención sanitaria (ingresos previos, sondaje urinario catéter venoso, etc.). Para el estudio descriptivo se utilizó la media (desviación típica) o mediana (rango intercuartil) dependiendo de la normalidad de las variables, y en el estudio de factores asociados a la mortalidad se realizó un análisis bivariante, aplicando test no paramétricos (Fisher para variables cualitativas, $U$ de Mann-Whitney para cuantitativas). Para el análisis estadístico hemos utilizado el paquete informático SPSS, versión 22 en español.

RESULTADOS: Se incluyeron 13 episodios, 11 infecciones por KPC (8 urinarias y 3 respiratorias, incidencia 3 casos/1000 ingresos/año) y 2 colonizaciones. Las características basales antecedentes de los pacientes se muestran en la tabla 1 y las variables relacionadas con los episodios se recogen en la tabla 2. Fallecieron 2 pacientes por infección por KPC. Durante el seguimiento (mediana de 102 días) fallecieron 4 pacientes más, por causas no relacionadas. № hemos podido demostrar diferencias estadísticamente significativas en cuanto a la mortalidad, a final del seguimiento, con las variables estudiadas.

CONCLUSIONES: 1) La infección por KPC afecta en nuestro medio a pacientes de edad avanzada, pluripatológicos, con hospitalización, sondaje vesical y antibioterapia de amplio espectro recientes. 2) En nuestros aislamientos observamos una elevada frecuencia de resistencias a Fosfomicina y aminoglucósidos, con buena sensibilidad a Colistina. 3) Existe una gran variabilidad en las pautas terapéuticas empleadas. A pesar de ello, se ha constatado la curación del episodio en el 80\% de casos. 4) Son necesarios estudios futuros para poder identificar factores de riesgo que permitan mejorar la prevención y manejo de estas infecciones.

\section{FIEBRE Q EN EL ÁREA SANITARIA DE SANTIAGO DE COMPOSTELA}

Macía-Rodríguez C, Alende-Castro V, García Fernández X, Paez Guillán E, García Villafranca A, Vázquez Agra N, Novo-Veleiro I, González-Quintela A.

MEDICINA INTERNA, COMPLEXO HOSPITALARIO UNIVERSITARIO DE SANTIAGO DE COMPOSTELA.

INTRODUCCIÓN: La fiebre $Q$ es una zoonosis de distribución mundial, endémica en algunas zonas de España. En Galicia no existían hasta el momento series de casos descritas. Su forma de presentación variable (fiebre, hepatitis, neumonía) hace que pueda pasar inadvertida durante el proceso diagnóstico y responda a tratamientos habituales en la práctica clínica diaria.

OBJETIVOS: analizar y describir los casos de fiebre Q diagnosticados en el Área Sanitaria de Santiago de Compostela con la finalidad de conocer e identificar mejor la forma de presentación y características clínicas de esta enfermedad en nuestra área.

PACIENTES Y MÉTODOS: Se recogieron los pacientes con determinación serológica de Coxiella burnetii entre el 1/1/2011 a 30/6/2015. Se identificaron: resultados negativos, serologías positivas no relacionadas con infección actual y casos confirmados. Se recogieron variables epidemiológicas, clínicas, analíticas, terapéuticas y de evolución.

RESULTADOS: Se incluyeron 121 serologías positivas: 87 serologías positivas no relacionadas con infección actual $(71,9 \%$ ) y 34 pacientes diagnosticados de Fiebre Q (28\%). De estos últimos 24 $(70,6 \%)$ fueron varones, con una edad media de $73,1 \pm 14,1$ años. La actividad laboral fue: $1(2,9 \%)$ trabajador en un petrolero, $1(2,9 \%)$ carpintero, $1(2,9 \%)$ cantero, $1(2,9 \%)$ labrador y $24(70,6 \%)$ jubilados; se desconoce el empleo en los demás casos. No se identificó agente de exposición en 32 pacientes $(94,1 \%)$; los otros $2(5,9 \%)$ refirieron contacto con animales. La distribución en medio rural, semiurbano y urbano fue $55,9 \%, 35,3 \%$ y $5,9 \%$ respectivamente; se desconoce el domicilio de un paciente por ser turista. La mayoría de los casos $(n=21 ; 61,8 \%)$ correspondieron al 2015; 11 casos (32.4\%) en 2014 y los restantes en 2011 y 2012, sin haber agrupación de estos casos por municipio. El 100\% de los casos cursaron como forma aguda y sólo 2 pacientes presentaron cronificación del cuadro. En cuanto a la forma de presentación, $31(91,2 \%)$ fueron neumonias, 2 (5,9\%) síndromes febriles y $1(2,9 \%)$ cuadro diarreico. En lo referido al tratamiento, $11(32,4 \%)$ pacientes recibieron tratamiento con doxiciclina, 17 con una fluoroquinolona $(50,0 \%)$ los 6 restantes (17,6\%) fueron tratados como neumonia adquirida en la comunidad con buena evolución clínica. La duración media del tratamiento fue de 13,8 \pm 14,1 días. La mortalidad total fue del $14,7 \%$ (5 pacientes). El 100\% de los pacientes presentaron serología de fase II positiva, con títulos superiores a 1/256.

CONCLUSIONES: En nuestra área los pacientes diagnosticados de Fiebre $Q$ se presentaron de forma aguda (neumonia), evolucionando favorablemente en la mayoria de los casos con tratamiento con levofloxacino o doxiciclina. Los resultados de este estudio ponen de manifiesto la necesidad de realizar serología de Coxiella burnetii en los pacientes con neumonia adquirida en la comunidad, dado que este cuadro infeccioso puede desarrollarse en pacientes sin claro exposición de riesgo.

\section{TROMBOEMBOLISMO PULMONAR EN PACIENTE MUY ANCIANO: CARACTERÍSITICAS CLÍNICAS Y MORTALIDAD}

Vares M, Barbagelata C, Llinares D, Piñeiro P, Clavero E, Blanco C, Bouza L, Arévalo A, Rodríguez A, Freire $S$.

MEDICINA INTERNA, COMPLEJO HOSPITALARIO UNIVERSITARIO A CORUÑA.

INTRODUCCIÓN: Los pacientes (p) de edad avanzada con tromboembolismo pulmonar (TEP) están poco representados en los estudios que abalan las guías clínicas, por lo que se conoce poco sobre las características de la enfermedad en esta población.

OBJETIVOS: Conocer los datos demográficos, las comorbilidades y la evolución del TEP en los $p \geq 80$ años.

MÉTODOS: Estudio descriptivo retrospectivo en $p \geq 80$ años diagnosticados de ETV entre 01/01/2013 y 31/12/2013 en el CHUAC, realizándose un seguimiento de las complicaciones hasta el 31/01/2016.

RESULTADOS: Se incluyeron 70 p. Se excluyeron 10 p fallecidos con diagnóstico de TEP no confirmado mediante prueba de imagen $65.7 \%$ fueron mujeres, $34.3 \%$ hombres, la edad media fue de 85 años. El índice de Charlson tuvo una media de 6 y el de Barthel de 72 (valor mínimo de 5, máximo de 100). Presentaron IC el 21\%, IVC el 10\%, cáncer activo el 17\%, catéter central el $1.4 \%$, inmovilización, fractura o cirugía previa el $33,5.7$ y $4.4 \%$ respectivamente Todas las fracturas registradas fueron de fémur. Se había realizado tromboprofilaxis durante el ingreso en cirugía en todos los p. La presión de 02 media fue de $62 \mathrm{mmHg}$. El peso sólo se registró en la mitad de los p. Se objetivó TVP sintomática en el 20\% de los p. El diagnóstico de TEP se realizó mediante angioTC pulmonar en el $98.6 \%$. EI TEP fue bilateral en el 35\% y unilateral en el mismo porcentaje. El trombo afectó al tronco de la arteria pulmonar en el 10.7\%, a las arterias pulmonares en el $28.6 \%$, a las lobares en $14.3 \%$, a las segmentarias en el $35.7 \%$ y a las subsegmentarias en el 10.7\%. Se realizó ecocardiograma en el 17\%; sólo un caso presentó TAPSE menor de 18. La cifras medias de hemoglobina, plaquetas, creatinina y filtrado glomerular fueron respectivamente $12 \mathrm{~g} / \mathrm{dL}, 249.000,1.3 \mathrm{mg} / \mathrm{dL}$ y $52 \mathrm{~mL} / \mathrm{min} / 1.73 \mathrm{~m} 2$. No se realizaron dímeros $\mathrm{D}$ en el $40 \%$ de Ios $p$, siendo la mediana en los casos realizados de 2000. EI PESI simplificado fue siempre de alto riesgo, presentando el $37 \%$ una puntuación de 1 y el $40 \%$ una de 2 I a estancia media hospitalaria fue de 14 días. La mortalidad global a dos años fue del 40\%. Se consideró en relación probable o posible con el TEP en el $32 \%$. En dichos casos el fallecimiento fue precoz, frente a los casos en los que la mortalidad no se consideró asociada con la ETV, siendo la diferencia estadísticamente significativa. No se objetivó relación entre la mortalidad asociada, la inestablidad hemodinámica, la localización del TEP o el PESI del p, aunque estos datos posiblemente estén condicionados por el pequeño tamaño muestra.

CONCLUSIONES: 1. En población muy anciana se objetivó un predominio del TEP en mujeres. 2. Dentro de los factores predisponentes destacó la inmovilización, la IC y el cáncer. 3. El Charlson y el Barthel no fueron muy elevados. 4. El PESI fue siempre de alto riesgo riesgo sin que se viese una asociación con la mortalidad, por lo que parece necesario validar nuevas escalas pronósticas en este subgrupo de población. 


\section{INCIDENCIA DE SARCOIDOSIS EN OURENSE EN 10 AÑOS. REVISIÓN DE LOS CASOS}

Lorenzo Vizcaya AM, González Noya A, Barreiro Rivas A, Latorre Díez A, López Mato P, Gómez Fernández $R$.

MEDICINA INTERNA., COMPLEXO HOSPITALARIO UNIVERSITARIO DE OURENSE.

INTRODUCCIÓN: La sarcoidosis es una enfermedad multisistémica de causa desconocida resultado de la acción de un agente externo que desencadena la respuesta inmunitaria en individuos genéticamente predispuestos, favoreciendo la formación de granulomas no caseificantes en diversos órganos, siendo las principales dianas: pulmonar, cutánea y ocular.

La sarcoidosis presenta predominio del sexo femenino, siendo el pico de mayor incidencia entre los 20 y los 29 años. La mitad de los casos cursan de manera asintomática y son detectados tras observar alteraciones típicas en la radiografía de tórax.

OBJETIVO: Conocer la epidemiología de sarcoidosis en Ourense de Enero de 2005 a Diciembre de 2015), así como sus características clínicas, manejo terapéutico y evolución.

MATERIAL Y MÉTODOS: Estudio descriptivo retrospectivo donde se ha analizado la incidencia de pacientes diagnosticados de sarcoidosis en 10 años en la provincia de Ourense, así como las cacterísticas clínicas y la evolución de los casos detectados. Los datos fueron aportados por el Servicio de Documentación Clínica. En todos Ios análisis consideramos estadísticamente significativas las diferencias con $p<0.05$. Los análisis se realizaron utilizando SPSS 15.0.

\section{COMUNICACIONES POSTER}

\section{HIPOACUSIA NEUROSENSORIAL Y DÉFICIT VISUAL COMO MANIFESTACIONES DE DEBUT DE SÍNDROME DE SUSAC}

Gondar Barcala T (1), Valle Feijoó L (1), Armenteira Santos E (2), Ramos Rúa L (3), De la Fuente Aguado J (1).

MEDICINA INTERNA (1), RADIODIAGNÓSTICO (2), NEUROLOGÍA (3), POVISA.

INTRODUCCIÓN: El síndrome de Susac es una microangiopatía cócleorretinocerebral muy poco frecuente. Se caracteriza por la tríada clínica de hipoacusia neurosensorial, déficit visual encefalopatía subaguda. El inicio del cuadro puede ser heterogéneo y debutar como un síndrome incompleto lo que dificulta su diagnóstico. La afectación del cuerpo calloso en la RMN cerebral junto con la evaluación vascular de la retina juegan un papel crucial en la confirmación diagnóstica. CASO CLÍNICO: Mujer de 42 años sin antecedentes médicos de interés que consulta por disminución brusca de la audición en el oído derecho con extensión al izquierdo en 48 horas. La audiometría confirmó una hipoacusia neurosensorial bilateral en frecuencias medias y bajas más acentuada en el oído derecho. Los potenciales auditivos tronco-encefálicos fueron normales y la RMN cerebral mostró lesiones multifocales en fibras centrales de cuerpo calloso potenciadas en las secuencias Flair y T2. El análisis del LCR mostró discreta proteinorraquia, sin bandas oligoclanes. Se excluyeron infecciones virales, borreliosis, brucelosis, neurosífilis, sarcoidosis, patología autoinmune, trombofilia y trastornos hematológicos. Seis meses después refirió pérdida súbita de visión del ojo derecho detectándose en la exploración un escotoma en cuadrante nasal superio por lo que se le realizó una angiografía fluresceínica retiniana que confirmó la existencia de una oclusión de una rama de la arteria retiniana macular y de algunas ramas periféricas. Diagnosticada de síndrome de Susac, inició tratamiento antiagregante y corticoterapia. Posteriormente recibió inmunoglobulinas endovenosas tras presentar una crisis vertiginosa refractaria a sedantes vestibulares y empeoramiento de lesiones cerebrales, con excelente respuesta. Ocho semanas después presentó ataxia y aparición de 2 microinfartos en sustancia blanca. Actualmente, tras 2 pulsos de rituximab, continúa con corticoterapia, sin nuevas reagudizaciones.

DISCUSIÓN: El síndrome de Susac es una entidad rara probablemente infradiagnosticada debido a la dificultad que entraña su reconocimiento clínico. La demora en el diagnóstico y el diagnóstico erróneo es frecuente ya que fácilmente puede confundirse con otros síndromes con afectación central como la esclerosis múltiple o el lupus eritematoso sistémico. Hasta la fecha se han publicado poco más de 300 casos en el mundo. No existe un tratamiento estandarizado. En el período agudo el empleo de altas dosis de corticosteroides es la estrategia más aceptada. Inmunosupresores como ciclofosfamida, metotrexato 0 azatioprina e inmunoglobulinas intravenosas también se han utilizado. En casos resistentes pueden resultar útiles el rituximab, etanercept o ciclosporina A. La enfermedad generalmente presenta un curso monofásico y autolimitado y a menudo se estabiliza entre los 2 a 4 años de evolución. Se pueden producir recaídas tardías y también una evolución crónica progresiva.

\section{INTOXICACIÓN POR PLOMO EN UN PACIENTE CON DOLOR ABDOMINAL}

Estévez M, Argibay A, Pérez A, Diéguez P, Machado B, Val N, Baroja A, Fernández-Martín J, Crespo M.

MEDICINA INTERNA, COMPLEXO HOSPITALARIO UNIVERSITARIO DE VIGO

INTRODUCCIÓN Y OBJETIVOS: El plomo (Pb) es un metal tóxico conocido desde la antigüedad. La mayor fuente de exposición proviene de su utilización en actividades industriales, si bien fuera del ámbito laboral el origen alimentario es la causa principal.

MÉTOD0: Descripción de un caso y revisión de la literatura.

RESULTADOS: Varón de 40 años derivado a consultas externas de Medicina interna por dolor abdominal, anemia e hiperbilirrubinemia. No presentaba antecedentes de interés, reconocía ingesta moderada de vino de fabricación casera y era fumador. Refería cuadro de 9 meses de evolución de dolor articular migratorio, astenia sensación distérmica, cefalea frontal con sonofobia y dolor abdominal recurrente. El dolor era tipo cólico de predominio en región umbilical acompañado de náuseas, vómitos biliosos y estreñimiento. La ecografia abdominal, las serologías y estudios
RESULTADOS: De los 46 pacientes registrados, $26(57,8 \%)$ son mujeres y la edad media en el momento del diagnóstico fue de 55,6 años (DS+16,04). El 51,1\% de los pacientes no presentaba exposición a factores de riesgo, el 22,2\% sí presentaban exposición, la mayoría a canteras; y en el $26,7 \%$ no constaban datos. La forma más frecuente de debut fue la disnea en el 37,8\%. El 17,8\% estaban asintomáticos (siendo un hallazgo casual) y el 15,6\% presentaron artralgias. En función de la radigrafía de tórax, se clasificaron en estadios, siendo el más frecuente el II con 41,9\%. En cuanto al estudio histológico, fue realizado en el 75,6\%. De ellos, el 87,4\% mostraron hallazgos patológicos compatibles con sarcoidosis. Se solicitaron los niveles de ECA en 43 pacientes, con una mediana de 74 [17-350]. Fueron tratados 35 pacientes (77,8\%). De ellos, el 75,7\% presentaron mejoría o resolución; el 8,1\% no mejoría o estabilidad; y en el 16,2\% no consta evolución tras el tratamiento. De los 46 pacientes registrados, se hizo estudio de función pulmonar pre y pos tratamiento a 10 pacientes; de ellos, los valores de difusión pulmonar (DLCO) aumentaron en 9,96 puntos de forma significativa.

CONCLUSIONES: En Ourense hay mayor afectación de la población femenina, con edad media al diagnóstico de 55,6 años. No se asocia mejoría tras el tratamiento con ninguna de las variables estudiadas. El valor de DLCO aumentó en 9,96 puntos en los pacientes en los que se realizó estudio de función pulmonar antes y después del tratamiento. En nuestra serie se observaron resultados similares en cuanto a sexo y edad a los de la literatura publicada. Tras el tratamiento hubo mejoría en la función pulmonar, siendo el incremento de cifras de DLCO estadísticamente significativo.

endoscópicos solicitados fueron normales. Ante la recurrencia de la clínica se decidió ingreso hospitalario. En la exploración destacaba ictericia conjuntival y abdomen distendido, discretamente timpánico y leve dolor a la palpación en fosa iliaca derecha. La analítica mostró una anemia hemolítica en torno a $9 \mathrm{gr} / \mathrm{dl}$. y deterioro leve de la función renal. Se solicitó TC abdominal en el que se objetivó un colon distendido con abundante líquido hasta sigma-recto, sin datos de patología obstructiva, inflamatoria, vascular o neoplásica. El frotis sanguíneo fue informado como un intenso punteado basófilo, por lo que se solicitó expresamente la determinación sérica de Pb, siendo los niveles superiores a $100 \mathrm{mcg} / \mathrm{dl}$. Se instauró tratamiento con Calcio- Sodio- EDTA, con buena tolerancia y con una franca mejoría clínica de manera progresiva.

DISCUSIÓN Y CONCLUSIONES: Se considera intoxicación por Pb niveles sanguíneos superiores a $10 \mathrm{mcg} / \mathrm{d}$, aunque las manifestaciones severas aparecen por encima de $80 \mathrm{mcg} / \mathrm{dl}$. En pacientes con exposición crónica se pueden constatar valores entre 30 y $70 \mathrm{mcg} / \mathrm{dl}$. El tratamiento quelante está indicado con niveles $>80 \mathrm{mcg} / \mathrm{dl}$ y se sugiere en pacientes sintomáticos con niveles entre 50 y $80 \mathrm{mcg} / \mathrm{dl}$. En nuestro caso se consideró como probable fuente de exposición la utilización de cubiertos de Peltre (aleación compuesta por estaño, cobre, antimonio y Pb). No obstante en nuestro entorno, es muy habitual el uso de utensilios de plomo para la fabricación de vino y aguardiente casera. Ante un paciente con dolor abdominal y anemia regenerativa debe realizarse una anamnesis dirigida exhaustiva y revisar la extensión de sangre periférica, en busca de un punteado basófilo (no presente en todos los casos). Además se deben solicitar niveles de $\mathrm{Pb}$ en sangre con lo que obtendremos el grado de exposición en las últimas semanas.

\section{SÍNDROME DE LEMMEL}

Bravo Blázquez I, Lijó Carballeda C, García Alén D, Dalama López T, Martul Pego E, Fernández Bouza E, Sesma Sanchez P.

MEDICINA INTERNA, COMPLEXO HOSPITALARIO UNIVERSITARIO DE FERROL.

INTRODUCCIÓN: Descripción de un caso de ictericia obstructiva en relación con divertículo duodenal.

CASO CLÍNICO: Mujer de 80 años, colecistectomizada y claustrofóbica, que acude al servicio de Urgencias por cuadro clínico de 72 horas de evolución de dolor abdominal en hipocondrio derecho, predominantemente postprandial, de tipo cólico, asociado a náuseas y a algún episodio de vómito alimentario. No refería fiebre ni escalofríos. En la exploración física destacaban: tinte subictérico y abdomen doloroso a la palpación profunda de hipocondrio derecho. Se solicitaron hemograma y bioquímica, destacando: bilirrubina total $1.9 \mathrm{mg} / \mathrm{dL}$, GOT $566 \mathrm{UI} / \mathrm{L}$ y GPT $455 \mathrm{UI} / \mathrm{L}$. La ecografía abdominal mostró una marcada dilatación de la vía biliar intra y extrahepática (colédoco 12,8 mm) sin que se lograse evidenciar la causa de la misma.

Se ingresó a la enferma con el diagnóstico de sospecha de coledocolitiasis residual. Pasadas 24 horas se realizaron análisis de control en los que se evidenciaba un franco empeoramiento de los parámetros de colestasis y citolisis (bilirrubina total $4.3 \mathrm{mg} / \mathrm{dL}$, fosfatasa alcalina $1611 \mathrm{UI} / \mathrm{L}$, GOT 1047 UI/L, GPT 1260 UI/L y GGT 704 UI/L). Se hizo TC abdominal, en la que se visualizaba dilatación de la via biliar intra y extrahepática (colédoco $12 \mathrm{~mm}$ ) sin evidencia de cálculos en su interior, así como la presencia de un divertículo en la segunda porción duodenal que comprimía el colédoco a nivel de su porción más distal. Se procedió a la realización de esfinterotomía endoscópica, alcanzándose tras la misma una rápida y significativa mejoría, tanto clínica como analítica.

DISCUSIÓN: Después del colon el duodeno constituye la localización más frecuente del tracto digestivo sobre la que asientan los divertículos. La prevalencia de la diverticulosis duodenal está en torno al $20 \%$ y aunque suele tratarse de un hallazgo incidental, hasta en un $10 \%$ de los casos puede dar lugar a complicaciones. Entre ellas destacan: coledocolitiasis, colangitis, ictericia obstructiva, pancreatititis, sangrado, perforación, diverticulits u obstrucción intestinal. El Síndrome de Lemmel relaciona los divertículos duodenales con las complicaciones pancreatobiliares derivadas de los mismos y su tratamiento de primera línea lo constituyen las técnicas endoscópicas (Colangiopancreatografía retrógrada endoscópica).

CONCLUSIÓN: El síndrome de Lemmel constituye una causa inusual de ictericia obstructiva que debe ser incluida en el diagnóstico diferencial de ésta, siempre que los divertículos duodenales se encuentren presentes. 


\section{LOS ANTIVIRALES DE ACCIÓN DIRECTA EN PACIENTES MAYORES DE 65 AÑOS: ¿SON TAN SEGUROS COMO PENSAMOS?}

Rodríguez-Osorio I (1, 2), Cid P (1), Mena Á (1, 2), Morano L (3), Castro Á (1, 2), Meijide H (1, 4), Suárez M (3), Delgado M (1), Margusino L (1), Pernas B (1, 2), Tabernilla A (1), Poveda E (1), Pedreira JD $(1,2)$

(1) GRUPO DE VIROLOGÍA CLIINICA, INSTITUTO DE INVESTIGACIÓN BIOMÉDICA DEA CORUÑA (INIBIC)-COMPLEXO HOSPITALARIO UNIVERSITARIO DEA CORUÑA (CHUAC), SERGAS. UNIVERSIDADE DA CORUÑA (UDC), SPAIN. (2) SERVICIO DE MEDICINA INTERNA, COMPLEJO HOSPITALARIO UNIVERSITARIO DEA CORUÑA (CHUAC). (3) SERVICIO DE MEDICINA INTERNA, HOSPITAL QUIRÓN A CORUÑA. (4) UNIDAD DE PATOLOGIÁ INFECCIOSA, HOSPITAL UNIVERSITARIO ÁLVARO CUNQUEIRO, VIGO (SPAIN)., (1) GRUPO DE VIROLOGÍA CLÍNICA, INSTITUTO DE INVESTIGACIÓN BIOMÉDICA DE A CORUÑA (INIBIC)-COMPLEXO HOSPITALARIO UNIVERSITARIO DEA CORUÑA (CHUAC) SERGAS UNIIVERSIDADE DA CORUÑA (UDC) SPAIN. (2) SERVICIO DE MEDICINA INTERNA, COMPIEJO HOSPITALARIO UNIVERSITARIO DEA CORUÑA (CHUAC). (3) SERVICIO DE MEDIIINA INTERNA, HOSPITAL QUIRÓNA CORUÑA. (4) UNIDAD DE PATOLOGÍA INFECCIOSA, HOSPITAL UNIIERSITARIO ÁLVARO CUNQUEIRO, VIGO (SPAIN). INTRODUCCIÓN/OBJETIVOS: Los nuevos antivirales de acción directa (AADs) son seguros y bien tolerados. Por ello, los pacientes mayores de 65 años (>65), en quienes las comorbilidades y tratamientos crónicos son frecuentes, se pueden beneficiar de estas terapias. Puesto que se trata de una población poco representada en los ensayos clínicos de desarrollo de los AADs, e objetivo de este estudio es evaluar la eficacia y seguridad de estos fármacos en esta población. MATERIAL-MÉTODOS: Se seleccionaron pacientes con VHC > 65 en seguimiento en 2 hospitales de tercer nivel en tratamiento con AADs entre agosto2012-octubre2015. Se recogieron variables epidemiológicas, clínicas, de laboratorio, estadío de fibrosis, tratamiento antiviral y perfil farmacoterapéutico. Se realizó un análisis descriptivo y test t-Student para comparar variables cuantitativas.

RESULTADOS: Se incluyeron un total de 121 pacientes monoinfectados por VHC y $>65$. E $52,9 \%$ eran mujeres de 72,6 años. El genotipo 1 fue el más frecuente: 95,9\% (G1b: 87,1\%). Un $64,1 \%$ eran F4 y el $43 \%$ habían fracasado previamente a un tratamiento. La Tabla 1 describe las combinaciones terapéuticas utilizadas. El 61,2\% recibió RBV ajustada al peso, necesitando reducción de dosis el 42,9\%. Sólo el 9,9\% recibieron INF. El 86,8\% de los pacientes recibían medicación crónica y el 33,9\% de ellos precisó ajuste de dosis antes de iniciar la terapia. El 43,8\% presentaron eventos adversos ( $E A)$ siendo los más frecuentes: astenia (37,2\%) y anemia $(34,7 \%)$. Sólo 3 pacientes suspendieron terapia por EA y en 2 casos relacionados con IFN. Ningún paciente falleció. Tras 4 semanas de tratamiento hubo una disminución significativa de las transaminas (GOT basal y final respectivamente, mediana [rango]: 76 [24-354] UI/L; 28 [14-65] UI/L; GPT basal y final respectivamente, mediana [rango]: 81 [18-408] UI/L; 22 [8-59] UI/L). En la semana 12 de tratamiento el 95,1\% alcanzaron respuesta viral sostenida (RVS).

CONCLUSIÓN: Los AADs son muy eficaces (95,1\% RVS) en $>65$. Aunque los EA fueron frecuentes (43,8\%), sólo el $2,4 \%$ tuvo que abandonar tratamiento. El $42,9 \%$ de los pacientes que recibían regímenes con RBV necesitaron una reducción de dosis y 33,9\% de los pacientes con medicación crónica concomitante necesitaron modificaciones de la misma. Estos hallazgos, apoyan la necesidad de un seguimiento más estrecho en pacientes $>65$ en tratamiento con AADs especialmente en aquellos que reciben RBV.

\section{GRANULOMATOSIS NO NECROTIZANTE (GNN). ANÁLISIS DE LAS MUESTRAS TISULARES DE GNN EN UN HOSPITAL UNIVERSITARIO}

Alende-Castro V Sopeña B, González-Quintela A

MEDICINA INTERNA, COMPLEXO HOSPITALARIO UNIVERSTTARIO DE SANTIAGO DE COMPOSTELA.

INTRODUCCIÓN: Para la mayoría de los clínicos, el diagnostico anatomopatológico de Granulomatosis no necrotizante (GNN) en cualquier muestra tisular es casi sinónimo de sarcoidosis. Sin embargo, son muchas las enfermedades infecciosas, neoplásicas e inflamatorias que pueden compartir dicha descripción histológica. Existen muy pocas series en la literatura que detallen e espectro de enfermedades que pueden causar GNN, por lo que, a excepción de la sarcoidosis son poco conocidas.

OBJETIVO: El estudio ha sido diseñado para describir las enfermedades que pueden causar GNN los tejidos más frecuentemente afectados y si el tipo de tejido analizado puede orientar sobre la causa de la GNN.

MATERIAL Y MÉTODOS: Se analizaron todas las muestras histológicas informadas como inflamación granulomatosa no necrotizante desde el 1 de enero de 2010 hasta el 31 de diciembre de 2014 en el Complexo Hospitalario Universitario de Santiago de Compostela. Se recogieron variables demográficas, analíticas y tipo de tejido estudiado. Los pacientes fueron seguidos en el tiempo y se recogió el diagnóstico final que causó la GNN.

RESULTADOS: Se incluyeron 290 muestras tisulares correspondientes a 207 pacientes (50,7\% mujeres) con una edad media de 51,23 años. En lo relativo a la procedencia de las muestras, la distribución fue la siguiente: piel 68 (32,9\%), adenopatías 55 (26,6\%), biopsia transbronquia $30(14,5 \%)$, pulmón $12(5,8 \%)$ y otras $42(20,2 \%)$. El diagnóstico al final del seguimiento fue: sarcoidosis en 124 (59,9\%); infecciones en 16 pacientes $(7,7 \%)$ de los cuales $8(4 \%)$ fueron finalmente diagnosticados de tuberculosis e infección por micobacterias atípicas otros $3(1,4 \%)$; reacción a cuerpo extraño 13 (6,3\%); neoplasia 12 (5,9\%); enfermedad autoinmune $5(2,5 \%)$, dos de las cuales (0.9\%) fueron Granulomatosis de Wegener; rosácea $3(1,4 \%)$; enfermedad de Crohn $2(0,9 \%)$; granuloma anular $2(0,9 \%)$ : bocio multinodular $2(0,9 \%)$; queilitis $2(0,9 \%)$ y amiloidosis $1(0,5 \%)$. Finalmente, no se logró diagnóstico en 12 pacientes $(5,9 \%)$. Al analizar la prevalencia de sarcoidosis en función del tejido estudiado se observó que estuvo presente en un 83\% de las biopsias transbronquiales y en un $78 \%$ de las adenopatías. Sin embargo en otros tejidos como la piel (48.5\%), hígado, tiroides, intestino ( $0 \%$ ) la frecuencia de sarcoidosis fue sensiblemente inferior. CONCLUSIONES: Casi un 50\% de los pacientes con inflamación granulomatosa no necrotizante no tenían sarcoidosis. El diagnóstico alternativo más frecuente fueron las infecciones incluida la tuberculosis. En un 95\% de los pacientes con GNN se alcanzó un diagnóstico etiológico definitivo.

\section{PROGRAMA DE CONCILIACION DEL TRATAMIENTO EN EL PACIENTE PLURIPATOLOGICO: EXPERIENCIA PILOTO}

Mella Pérez C (1), Rodríguez Legazpi I (2), Montero Hernández A (2), Buño Ramil B (1), Fernández Bouza E (1), Vázquez Vázquez B (1), Bravo Blázquez I (1), Rodríguez Penin I (2), Sesma Sánchez P (1). (1) MEDICINA INTERNA (2) FARMACIA, CHUF, FERROL, A CORUÑA.

INTRODUCCIÓN: El perfil de los pacientes atendidos en nuestro sistema sanitario es cada vez más complejo, siendo la edad avanzada y la presencia de varias enfermedades crónicas, características muy habituales. Los errores en la medicación son una de las principales causas de morbilidad en los pacientes hospitalizados. La mitad de los errores en la medicación se producen en la transición asistencial y con los cambios en los responsables del paciente.

OBJETIVOS: Describir un programa piloto de conciliación de la medicación (CM) al ingreso y a alta en una planta de medicina interna, en un proyecto conjunto entre el $S^{\circ}$ de Medicina Interna y Farmacia, para detectar discrepancias de medicación entre las distintas transiciones asistenciales y obtener un perfil farmacoterapéutico lo más actualizado.

MATERIAL: Estudio prospectivo (último trimestre de 2015) en el que se incluyeron pacientes $\geq 65$ años y con más de cinco medicamentos como tratamiento domiciliario, ingresados en una planta de medicina interna en un hospital de segundo nivel. Se revisó la historia clínica electrónica (HCE) y se realizó entrevista al paciente y/o familiares. Se elaboró el historial farmacoterapéutico de paciente, con posterior registro electrónico en el episodio de hospitalización(HCE). Si se detectaban discrepancias se contactaba con el médico responsable. Al alta el facultativo contactaba con el farmacéutico, realizándose de nuevo CM, y entregando a cada paciente un impreso horario personalizado con el tratamiento completo actualizado (tambien en HCE).

MÉTODOS: Se recogieron 58 pacientes (62\% hombres), edad media de 78,8 años. La estancia media fue de 10 días. Cuatro fueron exitus y 3 pérdidas. Las causas principales de ingreso: disnea y dolor torácico. La estratificación de los pacientes según la "Estratexia Galega de Atención Integral a la Cronicidad do SERGAS" fue: ciudadano sano (3,4\%), paciente con alguna enfermedad crónica estable (20,7\%), paciente crónico complejo (39,7\%), paciente con alto riesgo y complejidad (36,2\%). Número medio de medicamentos/paciente al ingreso: 10,4. Se realizaron 132 intervenciones farmacéuticas (IF): 77 al ingreso/alta (omisión 36, la más frecuente) y 55 en e-receta y atención primaria (bloqueo de la e-receta, 39 , la más frecuente). Al alta se suspendieron 88 medicamentos (56 modificados y 126 inciados). El número medio de medicamentos/paciente al alta: 11,1

CONCLUSIÓN: La implantación de estrategias multidisciplinares se han mostrado como un elemento beneficioso para mejorar la seguridad en los tratamientos, la minimización de riesgos y reducción de costes y gasto sanitario. En la instauración de este programa piloto la selección de pacientes es adecuada (el $75.9 \%$ muy complejos). La CM es una estrategia valiosa, pero compleja y clave al alta. El elevado número de intervenciones corrobora el papel del farmacéutico en este aspecto, logrando así una atención multidisciplinar centrada en la seguridad del paciente y ayudando a incrementar la adherencia al tratamiento.

\section{TOXICIDAD POR INTERACCIÓN MEDICAMENTOSA ENTRE AZATIOPRINA Y ALOPURINOL EN PACIENTE CON ENFERMEDAD DE CROHN}

Dalama López T (1), Echarri Piudo A (2), Lijó Carballeda C (1), García Alén D (1), Bravo Blázquez I (1), Martul Pego E (1), Fernández Bouza E (1), Sesma Sánchez P (1). (1)SERVICIO DE MEDICINA INTERNA. (2)UNIDAD DE EICI., COMPIEXO HOSPITALARIO UNIVERSITARIO DE FERROL (A CORUÑA)..

INTRODUCCIÓN: Se describe un caso de anemia grave secundaria a interacción entre azatioprina y alopurinol.

CASO CLíNIC0: Mujer de 45 años, con seguimiento en Consultas Externa de Digestivo por enfermedad de Crohn pancólica y perianal, desde 2008 debutando con brote grave. Recibió tratamiento con Infliximab hasta 2010, suspendido por pérdida de efecto, iniciándose tratamiento con Azatioprina y Adalimumab, este último suspendido en 2013. Desde entonces tratada con Azatioprina (250mg/día). Seguimiento conjunto con la Unidad de Reumatología por artralgias en el contexto de enfermdad inflamatoria intestinal (EII). En marzo de 2015 se detecta incidentalmente hiperuricemia, prescribiéndose alopurinol. Tras 5 semanas de tratamiento desarrolla astenia grave, detectándose hemoglobina de $6.2 \mathrm{~g} / \mathrm{dL}$, sin evidenciarse hemorragia a ningún nivel. La determinación de nucleótidos de la 6-tioguanina (6-TGN) mostró cifras superiores a la normalidad (710) confirmando el diagnóstico de anemia secundaria a interacción entre ambos fármacos. Se decidió la suspensión temporal del tratamiento, resolviéndose el cuadro.

DISCUSIÓN: La azatioprina y su metabolito, la 6-mercaptopurina (6-MP), son análogos de las purinas con actividad inmunosupresora, utilizados en el tratamiento de diversas patologías autoinmunes, entre las que se encuentra la Ell. La azatioprina se convierte en 6-MP. posteriormente puede metabolizarse de 3 modos: Metilación, a través de tiopurina metiltransferasa (TPMT); oxidación, mediante xantina oxidasa a ácido tioúrico o catabolización hacia 6-TGN a través de la hipoxantina-guanina fosforribosil transferasa. Los metabolitos activos responsables de la eficacia del fármaco y también de la mielotoxicidad son los 6-TGN. Niveles muy elevados de 6-TGN se relacionan con un mayor riesgo de toxicidad, mientras que niveles bajos se relacionan con una baja eficacia del fármaco. Por otra parte, el alopurinol es inhibidor de la xantina oxidasa, que es una de las vías por las que se metaboliza la azatioprina favoreciendo indirectamente el incremento de los niveles de 6-TGN e incrementando por tanto el riesgo de toxicidad y mielosupresión. Los niveles de 6-TGN pueden determinarse en el interior de los eritrocitos mediante cromatografía de alta resolución. Esta medición estaría indicada cuando se decide tratar a un paciente con ambos fármacos. También sería importante conocer la actividad de la TPMT, porque los pacientes con baja actividad de la misma también tienen riesgo de toxicidad.

CONCLUSIONES: La azatioprina y el alopurinol son dos fármacos que actúan a nivel del metabolismo de las purinas, el segundo impide la degradación de metabolitos del primero provocando toxicidad como se ha visto en nuestra paciente. La monitorización de los niveles de 6-TGN puede ayudar cuando se manejan estos dos fármacos juntos para el correcto ajuste de dosis. Se recomienda disminuír la dosis de azatioprina en un 70-75\% al inicio del tratamiento con alopurino. 


\section{ALOPECIA AREATA COMO SÍNDROME PARANEOPLÁSICO DE UN CÁNCER GÁSTRICO}

Álvarez Otero J (1), Fernández Fernández FJ (1), Martínez Rodríguez C (2), Gondar Barcala T (1), García Pouton N (1), Fernández Castro I (1), de la Fuente Aguado J (1).

MEDICINA INTERNA (1) RADIOLOGÍA (2), HOSPITAL POVISA.

INTRODUCCIÓN: La alopecia areata se relaciona con enfermedades autoinmunes, estrés o antecedentes familiares. Se han descrito casos que ponen de manifiesto la asociación de esta entidad con neoplasias hematológicas, con un tumor del estroma gastrointestinal de origen esofágico y con un adenocarcinoma gástrico.

OBJETIVOS: Incidir en la posibilidad de que la alopecia areata sea la manifestación inicial de una neoplasia.

MATERIAL Y MÉTODO: Presentamos el caso de un paciente con alopecia areata que se presentó como síndrome paraneoplásico de un adenocarcinoma gástrico.

RESULTADOS: Varón de 38 años que presentó de forma brusca pérdida de pelo en el cuero cabelludo de forma parcheada y circular, por lo que se inició tratamiento con corticoides tópicos. Dos meses después comenzó con dolor lumbar de características mecánicas, por lo que recibió tratamiento con antiinflamatorios. Posteriormente asoció dolor abdominal de localización en hipogastrio, vómitos e ictericia. En los análisis destacaba G0T 328 U/L, GPT 995 U/L, GGT 406 U/L, FA $469 \mathrm{U} / \mathrm{L}$ y bilirrubina total $7,12 \mathrm{mg} / \mathrm{dL}$ con predominio de directa. Se realizó una RM lumbar que mostró múltiples lesiones óseas blásticas sugestivas de enfermedad metastásica y una TC abdominal en la que se observó engrosamiento del fundus gástrico y múltiples adenopatías retrocrurales, en ángulos cardiofrénicos, retroperitoneo y raíz de mesenterio. La endoscopia digestiva alta mostró una lesión subcardial sugestiva de neoplasia y la anatomía patológica confirmó la existencia de un adenocarcinoma con células en anillo de sello. En la colangiografía percutánea se apreció afectación difusa del árbol biliar y de la vía biliar periférica secundaria a lesiones sólidas. El paciente presentó mala evolución con fallecimiento un mes después del diagnóstico.

CONCLUSIONES: Consideramos que la alopecia areata puede estar relacionada con trastornos malignos subyacentes, por lo que es necesario tenerlo en cuenta a la hora de manejar a estos pacientes

\section{¿SÍNDROME DE SNEDDON: UNA ENTIDAD INFRADIAGNOSTICADA?}

Soto-Peleteiro A, Freire M, Sousa A, Lorenzo R, Machado B, Gómez-Sousa J, Argibay AB, Rivera A, Crespo $M$.

UNIDAD DE TROMBOSIS Y VASCULITIS. SERVICIO MEDICINA INTERNA., COMPLEXO HOSPITALARIO UNIVERSITARIO DEVIGO.

INTRODUCCIÓN Y OBJETIVOS: En 1965 Sneddon describió la asociación de enfermedad cerebrovascular, fundamentalmente por isquemia en la arteria cerebral media o posterior, livedo reticularis intensa (livedo racemosa). La incidencia anual de este síndrome se estima en 4/1.000.000 y afecta con mayor frecuencia a mujeres entre los 20 y 40 años de edad. En la mitad de los casos se detectan anticuerpos antifosfolipído circulantes pero la otra mitad es seronegativa, mostrando en la histología una vasculopatía trombótica no inflamatoria característica.

MATERIAL Y MÉTODO: Presentación de un caso clínico y revisión de la literatura.

RESULTADOS: Mujer de 39 años con antecedentes de hipertensión arterial sin tratamiento médico. Estudiada desde los 30 años de edad y con múltiples ingresos en neurología por distintos déficits neurológicos (síndrome parietal izquierdo, crisis parciales motoras, neuritis óptica bilateral hipoacusia neurosensorial y parálisis facial izquierda periférica) con estudio completo sin objetivarse causa de los cuadros. Además la paciente refería episodios de púrpura en extremidades de años de evolución y livedo reticularis. En su historial obstétrico constaba un parto a término y un aborto programado a las 20 semanas de gestación por oligoamnios severo. La analítica era normal incluyendo la negatividad de ANAs, crioglobulinas, anticoagulante lúpico, anticardiolipinas y B2glicoproteina, repetidos en varias ocasiones. La RMN cerebral mostró pequeños focos de alteración de señal en sustancia blanca y múltiples lesiones sin focos de restricción de la difusión. El doppler carotídeo, EEG y ecocardiograma transtorácico fueron normales. Se realizaron 2 punchs coincidiendo con brotes cutáneos: en el segundo se observó a nivel de la dermis extravasación de hematíes e hiperplasia muscular en los vasos de la dermis reticular sin necrosis ni trombos. La paciente fue diagnosticada de síndrome de Sneddon y se inició tratamiento con IECAS y antiagregación.

CONCLUSIONES: El síndrome de Sneddon es diagnosticado por criterios clínicos en pacientes con lesiones cerebrovasculares y livedo racemosa, pero es fundamental distinguir el asociado a un síndrome antifosfolipídico del seronegativo, tanto por las implicaciones pronósticas como por su diferente manejo terapéutico. En el grupo seronegativo la realización de una biopsia cutánea sobre la zona blanca de la livedo es la única prueba diagnóstica definitoria, mostrando una proliferación vascular en la dermis con un típico engrosamiento e hiperplasia de la media. Parece probable que se trate de una entidad diferente de etiología desconocida y manejo controvertido, sin habe mostrado beneficio la inmunosupresión ni la anticoagulación, aunque sí parecen de utilidad la antiagregación y el uso de IECAs.

\section{SÍNDROME DE LAMBERT EATON Y POLINEUROPATÍA AXONAL MOTORA PARANEOPLÁSICOS SIMULTÁNEOS}

Álvarez Otero J (1), Sánchez Conde P (1), Lorenzo González JR (2), Santomé Couto L (3), Gondar Barcala T (1), García Pouton N (1), Fernández Castro I (1), de la Fuente Aguado J (1) MEDICINA INTERNA (1), NEUROLOGIA (2), ONCOLOGÍA (3), HOSPITAL POVISA.

INTRODUCCIÓN: Los síndromes paraneoplásicos neurológicos son un grupo heterogéneo de trastornos poco frecuentes que afectan al sistema nervioso, cuya patogenia está usualmente relacionada con un mecanismo inmunomediado.

OBJETIVOS: Presentar dos síndromes paraneoplásicos neurológicos simultáneos, siendo la polineuropatía axonal motora muy poco frecuente, e incidir en la importancia de su reconocimiento por sus implicaciones pronósticas.
MATERIAL Y MÉTODOS: Presentamos el caso de una paciente con dos síndromes neurológicos paraneoplásicos, síndrome de Lambert Eaton y polineuropatía axonal motora simultáneos, que precedieron al diagnóstico de un carcinoma microcítico pulmonar.

RESULTADOS: Mujer de 49 años que acudió a nuestro centro por cuadro de tres meses de evolución de pérdida de fuerza inicialmente en extremidades inferiores y posteriormente superiores. Refería también astenia y pérdida de peso de 10 kgs. En el último mes asociaba disfagia para sólidos y dificultad para la apertura ocular por la mañana, que mejoraba a lo largo del día. Era fumadora y no presentaba otros antecedentes médicos de interés. En la exploración destacaba una tetraparesia con hiporreflexia generalizada y una discreta ptosis palpebral que disminuía con la contracción mantenida. La sensibilidad estaba conservada y no presentaba fasciculaciones. Se realizó un electromiograma que mostró una polineuropatía axonal motora grave y un electromiograma con estimulación repetitiva del nervio cubital que mostró a 3 hz respuestas decrementales significativas y a $30 \mathrm{hz}$ postejercicio incremento en la respuesta, compatible con síndrome de Eaton Lambert. Los anticuerpos anti canales de calcio fueron positivos así como la banda anti Sox 1, mientras que los anti Hu, anti Ri, anti Yo y anti GM1 fueron negativos. Ante la sospecha de síndrome paraneoplásico se solicitó TC tórax-abdomen que mostró un nódulo pulmonar localizado en lóbulo inferior derecho con adenopatías hiliares derechas y subcarinales. La anatomía patológica de una muestra obtenida por punción percutánea confirmó la presencia de un carcinoma de pulmón de células pequeñas. Se administró tratamiento con inmuglobulinas y se inició quimioterapia según protocolo CDDP-VP16 y radioterapia externa con una dosis total de 3000 cGy. La paciente presentó mejoría neurológica tras el primer ciclo de quimioterapia. En el seguimiento un año después no hay evidencia de enfermedad tumoral.

CONCLUSIONES: El reconocimiento y diagnóstico precoz de los síndromes paraneoplásicos neurológicos es de gran importancia puesto que tiene implicaciones pronósticas.

\section{TUMORACIÓN DE PARTES BLANDAS. NO SIEMPRE LO PEOR ES CIERTO}

Suárez Varela MM, Rada Soto MA, Montes Santiago J, Baroja Basanta AL, Lorenzo Castro R, Vilas Pio B, Val Domínquez N. Dieguez Pena P, Soto Peleteiro A, Gómez Sousa J.

MEDICINA INTERNA, HOSPITAL ÁLVARO CUNQUEIRO, VIGO.

INTRODUCCIÓN: La enfermedad por arañazo de gato (EAG) es producida por un bacilo gram negativo denominado Bartonella henselae. Se transmite por arañazo o mordedura generalmente de gatos aparentemente sanos. Su presentación clásica incluye fiebre y adenopatía regional satélite al sitio de inoculación.

OBJETIVOS: Describir una forma atípica de la EAG, y enfatizar la importancia de la historia clínica en el proceso diagnóstico.

MATERIAL Y MÉTODOS: Presentación de un caso clínico.

RESULTADOS: Varón de 39 años sin antecedentes médicos de interés, valorado en la consulta de Cirugía por tumoración axilar de al menos 3 meses de evolución y crecimiento progresivo. A la exploración física se palpa una masa de $3 \mathrm{~cm}$ de diámetro mayor, adherida a planos profundos. La resonancia magnética evidenció una lesión irregular con metástasis ganglionar locorregiona e infiltración de piel y grasa subcutánea que contactaba con el paquete vasculonervioso axilar, sugestiva proceso maligno con alta sospecha de sarcoma de partes blandas. La analítica básica fue normal. Ante dicho hallazgo es remitido al centro de referencia de sarcomas. La anatomía patológica de la pieza quirúrgica no confirmó malignidad y describe un ganglio linfático con arquitectura folicular preservada, objetivando organización de tipo granulomatoso sin necrosis. No se realizaron tinciones específicas para microorganismos ni cultivo. Con el diagnóstico de Linfadenitis granulomatosa reactiva es remitido a la consulta de Medicina Interna seis meses después del inicio del proceso, encontrándose éste resuelto. Una historia clínica detallada puso de manifiesto sintomatología de fiebre y deterioro general simultaneo a la aparición de la tumoración descrita, la cual había presentado drenaje espontáneo al inicio. Como dato de interés el paciente posee un gato como mascota. La serología para B.henselae fue positiva con título de lg G 1/128 y determinación de lg M negativa. No fue posible recuperar las muestras histológicas para realizar PCR. Se descartaron otras posibilidades etiológicas.

Con el antecedente de contacto con gato, la presencia de linfadenopatía supurativa con histología compatible y resultados serológicos positivos se establece el diagnóstico de Enfermedad por Arañazo de Gato. El paciente no ha vuelto a presentar sintomatología relacionada con dicho diagnóstico. Como complicación mantiene dolor en la zona de la incisión quirúrgica por el que precisa control en la Unidad del dolor

CONCLUSIONES: La historia clínica detallada es el pilar fundamental para efectuar un diagnóstico. Si bien la sospecha radiológica de sarcoma de partes blandas apoya la exéresis en bloque de la tumoración, es necesario realizar un diagnóstico diferencial amplio con el fin de evitar procedimientos médicos invasivos no exentos de complicaciones.

\section{ENDOCARDITIS INFECCIOSA. REVISIÓN DE CASOS EN EL COMPLEXO HOSPITALARIO UNIVERSITARIO DE OURENSE EN 5 AÑOS.}

González Noya A, Lorenzo Vizcaya AM, Latorre Díez A, Barreiro Rivas A, López Mato P. MEDICINA INTERNA, CHU OURENSE.

INTRODUCCIÓN: La endocarditis infecciosa (EI) es una enfermedad con elevada morbimortalidad, que afecta a determinados grupos de riesgo, tales como pacientes con valvulopatía previa. Su etiología más frecuente son las infecciones estafilocócicas y suele cursar con una presentación clínica diversa. Su diagnóstico se establece basándose en los criterios de Duke modificados. OBJETIVO: Estudiar las características epidemiológicas, clínicas, la terapéutica aplicada y la evolución de los pacientes diagnosticados de El ingresados en el Hospital de Ourense durante 5 años (2011- 2015).

MÉTODOS: Se realizó un análisis descriptivo retrospectivo. Los análisis se realizaron utilizando SPSS 15.0.

RESULTADOS: Se registraron 53 pacientes, de ellos 36 (67,9\%) eran hombres. La edad media fue de los pacientes fue de $71,94(+14,46)$ años. El $73,6 \%$ de los pacientes ingresaron en el Servicio de Medicina Interna. Cuatro de los casos reconocía manipulación dental previa y dos eran 
portadores de catéter venoso central para hemodiálisis. Un 49,1\% de los pacientes presentaban valvulopatía previa. La clínica de debut fue fiebre en el $41,5 \%$ de los pacientes. El tiempo medio de diagnóstico fue de 8,58 días $(+8,1)$. Los gérmenes más frecuentemente aislados pertenecían a las especies Staphylococcus (19 casos). En un 13,2\%\% de los pacientes los hemocutivos fueron negativos. La válvula aórtica se afectó en el 47,2\%. La pauta antibioterápica más utilizada estaba compuesta por fármacos en combinación (se utilizaron dos fármacos en el 43,4\%). Los antibióticos más utilizados fueron: gentamicina (52,8\%), ceftriaxona (35,8\%) y cloxacilina (24,5\%). La duración del tratamiento fue de 4,5 semanas [2-66]. Las complicaciones más frecuentes evidenciadas fueron la presencia de émbolos sépticos. Precisaron intervención quirúrgica el 39,6\% de los pacientes. En cuanto a los éxitus, de los hombres diagnosticados de El, 15 (41.7\%) fallecieron, frente al $11,8 \%$ de las mujeres, siendo esta diferencia estadísticamente significativa $(p=0.028)$. DISCUSIÓN: En nuestro estudio se confirma la mayor incidencia en varones y en población de mayor edad. Los gérmenes más frecuentemente implicados son el Staphylococcus aureus, seguido de estreptococos del grupo viridans y enterococos. Las válvulas más frecuentes implicadas fueron as válvulas nativas izquierdas. También observamos que se prefiere la combinación de fármacos. En el curso de la enfermedad, destaca la presencia de complicaciones y la necesidad de cirugía cardíaca en un número considerable de pacientes en relación a disfunción de la válvula afecta. Cabe destacar en cuanto a la evolución, la mayor mortalidad observada (32,1\%), respecto a lo descrito en otras series, siendo esta mayor en varones. En conclusión, la El es una patología que ingresa en nuestro Servicio de Medicina Interna. Es importante una buena anamnesis y elevada sospecha clínica que nos puedan conllevan a un diagnóstico precoz y quizás contribuya a mejorar la supervivencia.

\section{HELICOBACTER CINAEDI, UN PATÓGENO EMERGENTE: COMUNICACIÓN DE UN CASO}

García Poutón N, Fernández Fernández FJ, Vidal Rey J, Pérez Castro S, Villanueva Campos AM Potelo Alvarellos C, Álvarez Otero J, de la Fuente Aguado J. MEDICINA INTERNA, POVISA.

INTRODUCCIÓN: Los microorganismos más frecuentemente implicados en los aneurismas micóticos son Staphylococcus, Salmonella y Streptococcus. Helicobacter cinaedi es un bacilo gram negativo que ha sido descrito como agente causal de aneurismas aórticos, fundamentalmente en Japón.

OBJETIVOS: Descripción de las características epidemiológicas, clínicas y terapéuticas de $\mathrm{H}$. cinaedi.

MATERIAL Y MÉTODOS: Presentamos el caso de un varón con un aneurisma micótico causado por $\mathrm{H}$. cinaedi y revisamos los casos previamente descritos en la literatura.

RESULTADOS: Un hombre de 68 años con antecedentes de hipertensión arterial y dislipemia consulta por dolor suprapúbico de 10 días de evolución. Había estado en Japón y Hungría en os meses previos La exploración física era normal. En TC abdominal se observaron hallazgos compatibles con un aneurisma micótico. Se extrajeron hemocultivos y urocultivo (con resultado posterior negativo) y se inició terapia antibiótica empírica con ceftriaxona y vancomicina. A los diez días se solicitó nueva TC abdominal que mostró rotura contenida del aneurisma, por lo que se decidió intervención quirúrgica. Se realizó resección y desbridamiento del aneurisma con implante de prótesis de poliéster revestida de plata/colágeno impregnada en rifampicina. El cultivo del tejido aórtico fue negativo y la PCR tisular positiva para H. cinaedi. La evolución posterior fue favorable y completó tratamiento con cefditoreno durante 6 semanas. En la revisión de la literatura se han descrito cuatro pacientes con aneurisma micótico por $\mathrm{H}$. cinaedi. Todos los pacientes eran varones inmunocompetentes con una edad media de 67 años. La presentación clínica más frecuente fue dolor abdominal, y menos de la mitad presentaron fiebre. Únicamente un caso tuvo hemocultivos positivos, mientras que el resto fueron diagnosticados por PCR. El tratamiento estándar fue cirugía y antibioterapia, con evolución favorable en todos los pacientes. $\mathrm{H}$. cinaed puede colonizar el sistema enterohepático de humanos y animales y la vía de contagio posible es la transmisión fecal-oral. Debido a su complejidad para el cultivo en medios convencionales resulta de gran ayuda disponer de técnicas de PCR para su identificación. La mayoría de los casos se han descrito en Japón, Los primeros casos fueron descritos en pacientes inmunodeprimidos o con graves enfermedades subyacentes. Sin embargo, recientemente, y de manera creciente se ha visto implicado en infecciones en sujetos inmunocompetentes, principalmente en Japón. H. cinaedi parece tener un particular tropismo cardiovascular, ya que se ha comunicado asociación de este patógeno con la enfermedad aterosclerótica cardiovascular y con las arritmias auriculares. CONCLUSIÓN: H. cinaedi debe ser sospechado en pacientes con aneurismas micóticos aórticos, con cultivo negativo, principalmente si el paciente procede o ha viajado a Japón.

\section{A PROPÓSITO DE UN CASO DE CLOROPSIA}

González Vázquez L, Pérez Sánchez B (1), Gondar Barcala T, Arca Blanco A, Valle Feijoó L, Alonso Parada M, de la Fuente Aguado J.

MEDICINA INTERNA, MEDICINA FAMILIARY COMUNITARIA (1), POVISA.

INTRODUCCIÓN: la cromatopsia se define como un trastorno de la visión que consiste en percibir os objetos con una coloración que no existe, es decir que la mayoría de la población ve como blancos. En su patogenia se cree que está implicada la deficiencia de uno o más conos de la retina o la alteración de los circuitos nerviosos que transmiten los impulsos asociados al color a la corteza cerebral. Existen varios tipos de cromatopsias: 1) la eritropsia (color rojo) descrita tras cirugía de cataratas, en hemorragias del globo ocular, intoxicación por setas, por monóxido de carbono y en exposición prolongada al sol: 2) la cianopsia (color azul) descrita en la intoxicación por alcohol, en la ingesta de anticonceptivos orales o de anfetaminas; 3) la xantopsia (amarillo) en la intoxicación por digital; 4) la cloropsia (verde) en la intoxicación por absenta.

OBJETIVOS: describir un caso de cloropsia que se presentó tras ingerir absenta de modo subrepticio.

MATERIAL Y MÉTODOS: presentación del caso clínico y revisión de la literatura.

RESULTADOS: paciente de 22 años que acude a urgencias traída por el 061 por sospecha de intoxicación etílica. Le han administrado vitamina B1 y diazepam 5 mgrs por vía intramuscular. En sus antecedentes personales consta epilepsia y trastorno de personalidad histriónica en tratamiento con valproato, Clonazepam, zonisamida y fluoxetina. Refiere haber salido a da una vuelta, durante la cual se encuentra con unos franceses, con los que bebe vino, licor café y alguna otra bebida que desconoce. Poco después inicia un cuadro consistente en ver a las personas de color verde. En la exploración fisica presentaba fetor enólico, una tension arteria de $130-90 \mathrm{~mm} / \mathrm{Hg}$, estaba afebril y la frecuencia cardiaca era de 92 latidos por minuto. La auscultación cardiopulmonar, la palpación abdominal y la exploración de las extremidades no mostraron alteraciones. Neurológicamente, las pupilas eran midriáticas y normorreactivas a la luz; el resto de pares craneales y de la exploración neurológica fueron normales. Se realizó una determinación de tóxicos en orina que fue negativa, incluyendo benzodiacepinas. Fue dada de alta el diagnóstico de intoxicación por absenta y, al no existir un tratamiento específico, con vigilancia por su familia en domicilio.

CONCLUSIONES: la cloropsia es un síntoma asociado al consumo de absenta, que cede en pocas horas de forma espontánea y que es conveniente conocer, especialmente para los médicos que trabajan en los servicios de urgencias

\section{FACTORES RELACIONADOS CON FIBROSIS HEPÁTICA AVANZADA EN PACIENTES COINFECTADOS VIH/VHB EN TRATAMIENTO ANTIVIRAL}

Rodríguez-Osorio I, Mena Á, Meijide H, Castro-Iglesias Á, Pernas B, Baliñas J, Poveda E. GRIPO DEVIROLOGIA CLIIIICA. INSTITUTO DE INVESTIGACIÓN BIOMÉDICA DE A CORUÑA INIBIC)-COMPLEJO HOSPITALARIO UNIVERSTTARIO DE A CORUÑA (CHUAC), SERGAS, UNIVERSIDADE DE A CORUÑA (UDC), A CORUÑA. CHUAC

INTRODUCCIÓN: Existen pocos datos sobre el desarrollo de fibrosis en pacientes con infección crónica VIH/VHB en tratamiento antirretroviral (TAR). El presente estudio evalúa la prevalencia de fibrosis avanzada medida por elastografía (FS) y su relación con factores virológicos, epidemiológicos y metabólicos.

MÉTODOS: Estudio de cohortes trasversal que incluyó pacientes coinfectados VIH/VHB en TAR en seguimiento clínico en un hospital de referencia. Se definió fibrosis avanzada si FS $>7.5 \mathrm{kPa}$ síndrome metabólico (SM) de acuerdo con criterios de la Federación Internacional de Diabetes. Se estudiaron factores relacionados con fibrosis avanzada mediante un análisis de regresión logística. El análisis estadístico se realizó con SPSS (v19.0)

RESULTADOS: Se incluyeron 65 pacientes VIH/VHB de los que 61 (93.8\%) tenían valores óptimos de fibrosis $(8.8 \pm 4.7 \mathrm{kPa})$. El $70.5 \%$ eran varones, con edad media de $46 \pm 9$ años; el $95.1 \%$ europeos; $68.8 \%$ fumadores y $9.8 \%$ tenían un consumo de alcohol $>40 \mathrm{gr} / \mathrm{d}$. La media de seguimiento fue de $13 \pm 5$ años. Todos los pacientes recibían TAR con una media de $9.8+5$ años de tratamiento: $95.1 \%$ tenofovir/emtricitabina y $4.9 \%$ entecavir y lamivudina. El $95.1 \%$ tenían carga viral indetectable para VIH y VHB con una media CD4 534 \pm 210 cells/ $\mu \mathrm{L}$, siendo el $41 \%$ categoría CDC-C. La distribución por genotipos fue: A-43.4\%, B-9.4\%, D-26.4\%, E-7.5\%, F-3.8\%, G-3.8\% y H-5.7\%. El 19.7\% presentaba anticuerpos frente a VHD, 27.9\% frente $\mathrm{VHC}$ y $45.9 \% \mathrm{HBeAg}+$. La prevalencia global de SM fue del 32.8\% (22.3- 45.3). Se observó un incremento de la prevalencia de SM con la edad (18.4\% en $<40$ años, $28.3 \%$ en $41-60$ años y $60.0 \%$ en $>60$ ). El $32.3 \%$ recibía terapia hipolipemiante, $13.1 \%$ antidiabéticos orales y $10.8 \%$ antihipertensivos. La prevalencia de fibrosis avanzada fue del $57.4 \%$ (44.9-69.0). E análisis multivariado identificó como factores asociados a fibrosis (OR, Cl95\%, p): presencia de anti-VHB-Ab+ $(4.88,1.90-15.76,0.01)$, persistencia de HBeAg $(4.04,1.50-17.16,0.01)$ $\mathrm{SM}(3.35,1.20-11.40,0.04)$ y tiempo de seguimiento $(2.10,1.104 .60,0.04)$. No se observó asociación con niveles de transaminasas, recuento de plaquetas, genotipo de VHB ni la edad. CONCLUSIONES: El $57,4 \%$ de pacientes coinfectados VIH/NHB con un adecuado control virológico presentaron fibrosis avanzada siendo la coinfección por VHD y la persistencia de HBeAg los principales factores asociados. El SM podría relacionarse también con el desarrollo de fibrosis en esta población. Por tanto, en pacientes VIH/VHB aún con un control adecuado de la carga viral, tanto la fibrosis como los desórdenes metabólicos deben ser monitorizados, especialmente en pacientes $\mathrm{HBeAg}+$ y coinfección por VHD.

\section{EMBOLIA PARADÓJICA INMINENTE}

Gondar Barcala T (1), Valle Feijoó ML (1), Delgado Gracián C (2), Alonso Fernández V (3), Fernández Castro I (1), García Poutón N (1), Álvarez Otero J (1), de la Fuente Aguado J (1) MEDINA INTERNA (1), RADIODIAGNÓSTICO (2), CARDIOLOGÍA (3), POVISA.

INTRODUCCIÓN: La persistencia del foramen oval permeable (FOP) es relativamente frecuente en la población general, siendo la prevalencia de hasta el $25 \%$ en series de autopsias. En la mayoría de los casos es asintomática y constituye un hallazgo ecocardiográfico incidental. La presencia de un trombo en tránsito atrapado en un FOP que avanza hacia las cavidades izquierdas recibe e nombre de embolia paradójical inminente (EPI) y constituye una forma extremadamente inusual de enfermedad tromboembólica con elevado potencial de embolización arterial.

CASO CLÍNICO: Varón de 66 años que acude a urgencias por disnea de inicio súbito y mareo sin pérdida de conocimiento. Niega dolor torácico, hemoptisis o palpitaciones. Refiere encamamiento la semana previa por un proceso catarral. Es exfumador y se ha intervenido de varices hace años. Niega procesos trombóticos previos así como antecedentes familiares relevantes. No toma tratamientos farmacológicos. Está taquipneico a $28 \mathrm{rpm}$ y taquicárdico a $111 \mathrm{lpm}$. TA $100 / 50 \mathrm{mmHg}$ y Ta $^{\mathrm{a}}$ 36.5 C. Normohidratado y normoperfundido. Funciones cerebrales superiores conservadas. No presenta IVY a 45․ AC: Rítmica, sin soplos. AP: murmullo vesicular conservado. Abdomen: Blando, depresible, no doloroso, con ruidos hidroaéreos. EEll: sin edemas y Homan negativo. La bioquímica básica y hemograma no presentan alteraciones. Mioglobina y CPK normales. Troponina I: $0.09 \mathrm{ng} / \mathrm{mL}$ (0,0 0,045); Dímero D: $9.202 \mathrm{ng} / \mathrm{ml}$, Gasometría arterial: $\mathrm{pH}$ : 7.46, pC02: 30 mmHg, p02:55,8 mmHg, HCO3: 23,2, Sp02: 90,8\%. Posteriormente se solicita un estudio de trombofilia que es normal. El ECG revela una taquicardia sinusal con patrón S103T3 y datos de sobrecarga derecha. Se confirma la existencia de un tromboembolismo pulmonar (TEP) masivo bilateral en la TC torácica. Se inicia anticoagulación con HBPM y se realiza un ecocardiograma transtorácico (ETT) en el que se visualiza una masa móvil en la aurícula izquierda (Al) altamente sugestiva de trombo, además de una dilatación de cavidades derechas con disfunción sistólica y signos indirectos de hipertensión pulmonar. En la TC cardíaca se confirma la existencia de una lesión serpiginosa en el interior de la Al de $5 \mathrm{~cm}$ que parte del septo interauricular y está anclada al foramen oval, compatible con un trombo. El paciente es trasladado a UCI donde permanece estable hemodinámicamente iniciando tratamiento con heparina sódica. A las 24 horas es intervenido realizando trombectomía arterial pulmonar, cierre del foramen oval y revisión de 
la Al sin encontrar el trombo. La evolución es favorable desapareciendo los datos de sobrecarga en el ETT de control.

CONCLUSIÓN: El aumento de presión en las cavidades cardíacas derechas secundario a TEP masivo es la causa de la EPI en pacientes con FOP. Presenta una elevada morbimortalidad y se trata de una emergencia quirúrgica por su riesgo de fragmentación y embolización sistémica si se emplean fibrinolíticos y la necesidad del cierre del FOP

\section{HEMATOMAS MUSCULARES ESPONTÁNEOS EN RELACIÓN A LA ANTICOAGULACIÓN: PRESENTACIÓN DE UNA SERIE DE 10 CASOS}

Rivero de Aguilar Pensado A*, Martínez Rey C, Rodríguez Méndez ML, García Suárez F, Suárez Dono J, Novo Veleiro I, Pose Reino A, González Quintela A.

SERVICIO DE MEDICINA INTERNA. *SERVICIO DE NEUROLOGÍA. HOSPITAL DE CONXO. COMPLEJO HOSPITALARIO UNIVERSITARIO DE SANTIAGO DE COMPOSTELA.

INTRODUCCIÓN: El riesgo individual de desarrollar fibrilación auricular (FA), así como el de sufri alguna complicación embólica, se incrementa con la edad. Con el progresivo envejecimiento poblacional se ha producido una generalización de la anticoagulación oral, tratamiento no exento de riesgos. Entre sus posibles complicaciones figura el desarrollo de hematomas musculares espontáneos (HME), un sangrado cuyo diagnóstico se puede demorar si no se mantiene una sospecha clínica elevada

OBJETIVOS: Conocer las características epidemiológicas de los pacientes que desarrollan HME durante el ingreso en nuestra planta

MATERIAL: Se revisaron los pacientes hospitalizados en el S. de Medicina Interna del H. de Conxo (Santiago de Compostela) desde noviembre de 2014 a noviembre de 2015 que desarrollaron HME durante el ingreso

MÉTODO: 10 pacientes ingresados durante dicho período de tiempo sufrieron HME. Su media de edad fue de 81.1 años y su predominio femenino (70\%). Asociaban importantes comorbilidades (Charlson medio: 6.4), 7 de ellos presentaban FA, todos con un riesgo tromboembólico alto segú la escala CHA2DS2-VASc ( $\geq 2$ ). El riesgo hemorrágico era también elevado en los 7 según la escala HEMORR2HAGES ( $\geq 2$ ), pero solo en 3 según la escala HAS-BLED $(\geq 3)$. En todos los casos el motivo de ingreso fue distinto al hematoma. Éste solía producirse al $6^{\circ}$ día de ingreso, siendo e síntoma inicial más frecuente el dolor (90\%). Las localizaciones más habituales fueron por igua el retroperitoneo el recto anterior del abdomen y el muslo. En un único caso se produjo en el glúteo medio. Al momento del sangrado todos los pacientes recibían tratamiento con heparinas de bajo peso molecular (HBPM) (7 a dosis anticoagulantes y 3 a dosis profilácticas). 1 había recibido anticoagulación oral en las 48 horas previas al sangrado y 2 antiagregación en la última semana. 3 de los pacientes tenía un filtrado glomerular estimado menor de $30 \mathrm{~mL} / \mathrm{min} / 1.73 \mathrm{~m} 2$ y, solo 1 , una cifra de plaquetas inferior a $100.000 / \mathrm{mm}^{3}$. Ninguno presentaba alteraciones significativas en los parámetros de coagulación. El 70\% de los pacientes precisaron tratamiento transfusional con 20 más concentrados de hematíes. 1 de ellos falleció durante el propio ingreso y otro fue trasladado a la UCl. El alta hospitalaria se produjo una media de 14.4 días tras el evento agudo, mientras que la mortalidad a los 6 meses fue del $30 \%$.

CONCLUSIONES: En nuestra pequeña serie de casos hemos observado que los HME se produjeron mayoritariamente en pacientes con FA a tratamiento con HBPM a dosis anticoagulantes y que se acomparon de una importante morbimortalidad. La puntuación al ingreso según la escala HEMORR2HAGES clasificó como de alto riesgo hemorrágico a la totalidad de los pacientes con FA que posteriormente sangraron, frente al $43 \%$ según la escala HAS-BLED. En cualquier caso, se debería sospechar de HME ante todo paciente anticoagulado que presente de forma aguda dolo abdominal, inguinal o en el muslo, acompañado de anemización e inestabilidad hemodinámica

\section{ENTEROPATÍA POR OLMESARTÁN}

Fernández Castro l: Paz Ferrín J: Sánchez Conde P: Páramo de la Vega M; Gondar Barcala T; Álvarez Otero J: García Pouton N; de la Fuente Aguado J. MEDICINA INTERNA, POLICLÍNICO POVISA.

OBJETIVOS: En julio de 2013 la FDA alertó de la relación entre el olmesartán y una enteropatía similar al esprúe celíaco. El objetivo es exponer dos casos en los que describimos dicha patología y sus características.

MATERIAL Y MÉTODOS: Estudio y descripción de dos pacientes diagnosticados de enteropatía asociada a olmesartán en el Hospital

Policlínico Povisa en 2014 y 2015. Revisión bibliográfica en PubMed de los casos publicados en España.

RESULTADOS: Caso 1: Paciente de 79 años que acudió a nuestro centro por cuadro de diarrea de 6 semanas de evolución, de hasta 20 deposiciones diarias, sin moco ni sangre, con leve dolor abdominal y pérdida de $10 \mathrm{~kg}$. El paciente era hipertenso a tratamiento con olmesartán/ hidroclorotiazida 40/12.5 mg. Las pruebas complementarias fueron normales salvo la anatomía patológica, con ileítis crónica inespecífica con hiperplasia folicular linfoide sin datos de colitis. Durante el ingreso se suspendió el olmesartán, con progresiva resolución del cuadro.

Caso 2: Varón de 78 años que acudió a nuestro centro por cuadro de deposiciones líquidas de dos meses de evolución de hasta 15 veces/día de coloración amarilla sin sangre ni moco, con náuseas y vómitos ocasionales sin dolor abdominal ni fiebre y que no respetaba el sueño ni mejoraba con el ayuno. Pérdida de $8 \mathrm{Kg}$ de peso sin pérdida de apetito. El paciente era hipertenso a tratamiento con olmesartán/hicroclorotiazida 40/25 mg y atorvastatina $20 \mathrm{mg}$. Las pruebas complementarias no mostraron alteraciones y la anatomía patológica del colon informaba de hiperplasia folicula linfoide ileal sin datos de colitis y la biopsia duodenal que informó de inflamación crónica en la lámina propia, atrofia focal moderada de vellosidades y linfocitosis intraepitelial CD3 positivas. Durante el ingreso se suspendió el olmesartán con desaparición completa de la clínica.

DISCUSIÓN: El olmesartán es un fármaco ampliamente utilizado en el control de la HTA que puede producir enteropatía severa, con diarrea importante y pérdida de peso. Como mecanismo fisiopatológico se postula una reacción inmune mediada por células basada en la alteración de mecanismo de regulación intestinal que normalmente suprime la actividad de los linfocitos T CD8. La presencia en las biopsias duodenales de un gran número de CD8 apoya esta hipótesis. En España hay publicados 7 casos y la aparición de la clínica no parece tener relación con el sexo o la edad. Es clínicamente indistinguible de la enteropatía celíaca, y en la anatomía patológica se aprecia linfocitosis intraepitelial y atrofia de vellosidades como hallazgo más frecuente. La diferencia radica en la negatividad de los autoanticuerpos y en la ausencia de respuesta a dieta sin gluten. La resolución del cuadro se produce con la suspensión del tratamiento con olmesartán. CONCLUSIONES: Ante un paciente con síndrome diarreico crónico sin datos de alarma y a tratamiento con olmesartán, se debe suspender el fármaco previamente a realizar procedimientos invasivos

\section{TUBERCULOSIS PULMONAR MILIAR: NUESTRA REALIDAD DEL SIGLO XXI}

García Villafranca A, Páez Guillán E, Macía Rodríguez C, Alende Castro V, Vázquez Agra N, González Quintela A.

MEDICINA INTERNA, COMPLEXO HOSPITALARIO UNIVERSITARIO DE SANTIAGO DE COMPOSTELA (A CORUÑA).

INTRODUCCIÓN: La tuberculosis con diseminación hematógena y/o linfática tanto a nivel pulmonar como extrapulmonar es un problema vigente.

OBJETIVOS: Analizar las características clínicas y epidemiológicas en el subgrupo de pacientes diagnosticados de tuberculosis pulmonar miliar (diseminación intrapulmonar) y su mortalidad en un seguimiento de dos años

MATERIAL Y MÉTODO: Estudio retrospectivo de los casos de tuberculosis miliar pulmonar diagnosticados en el CHUS entre el 1/1/2006 y el 31/12/2015. Se realizó un estudio descriptivo. RESULTADOS: Se incluyeron 27 pacientes (70.4\% mujeres) con una edad media de $61.26 \pm$ 19.71 años. En cuanto a los antecedentes: el $22 \%$ eran fumadores, el $14.8 \%$ consumo de alcohol, el $14.8 \%$ diabéticos, el 18.5\% neoplasia, el 11.3\% infección por virus hepatotropos, el $7.4 \%$ infección por VIH, el $18.5 \%$ recibía corticoterapia y el $14.8 \%$ otros inmunosupresores. El 91. 9\% se diagnosticaron en planta de hospitalización ,3,7\% en Urgencias y 3,7\% post-mortem. La mayor incidencia fue en 2015 con un 18,5\%. El 63\% presentó exclusivamente afectación pulmonar. La afectación extrapulmonar: ganglionar en el $14.1 \%$, meníngea en el $7.4 \%$, faríngea en el $3.7 \%$, medular 3.7\%, ganglionar y medular (simultáneamente) 3.7\% y genitourinaria $3.7 \%$. La sospecha diagnóstica fue por imagen en el $85.1 \%$ tras resultado microbiológico en el $11.7 \%$ y por histología en el $18,5 \%$. Se realizó PPD en el $14.8 \%$, resultando positivo en el $75 \%$. Los resultados microbiológicos positivos fueron: BAAR en esputo en el $40.7 \%$, cultivo de esputo en el 81.5\%, PCR en el esputo en el 59.3\% y BAAR en orina en el $25.9 \%$. IGRA-Quantiferon se realizó en el $3.7 \%$, resultando positivo. El cultivo de LCR se solicitó en el $18.5 \%$, siendo positivo en el $3.7 \%$. Se realizó cultivo de médula ósea en el $11.1 \%$, siendo positivo el $3.7 \%$. Las especies de Mycobacterium aisladas fueron: tuberculosis (88.9\%), bovis (7.4\%) y avium (3.7\%). En el $22.2 \%$ se realizó biopsia. El tratamiento recibido fue: rifampicina, isoniacida y pirazinamida (92.6\%), etambutol (41.2\%), quinolonas (11.1\%), aminoglucósidos y protionamida (3.7\%). Se apreciaron multirresistencias a los antituberculostáticos de primera línea en el 3.7\%. La estancia media fue de $32.2 \pm 22.2$ días. La duración del tratamiento antituberculostático fue de $267.2 \pm 127.4$ días. La supervivencia a dos años fue del $85.0 \%$.

CONCLUSIONES: En nuestro subgrupo de pacientes con tuberculosis pulmonar miliar destaca el aumento de supervivencia con respecto a estudios previos, mayormente, debido al avance en la terapéutica antituberculostática. En cuanto a características clínicas, factores predisponentes y resultados microbiológicos, se superpone a la de estudios anteriores, exceptuando la edad, que es mayor, en probable relación al aumento de supervivencia y envejecimiento de la población más notable en nuestra comunidad. Destaca la menor tasa de multirresistencia bacteriana $3.7 \%$ de los casos), siendo mayor del $4 \%$ en la población mundial.

\section{NEUMONÍA POR LEGIONELLA EN EL PERIODO DE 2001-2015 EN EL HOSPITAL UNIVERSITARIO LUCUS AUGUSTI}

Romay-Lema EM, Ventura-Valcárcel P, Fernández-Piñeiro JC, López-Reboiro ML, Suárez-Gill $R$ Gómez-Méndez R, Pedrosa-Fraga C, Rabuñal-Rey R.

MEDICINA INTERNA, HOSPITAL UNIVERSTARIO IUCUS AUGUST.

OBJETIV0: conocer el perfil clínico de los pacientes con Neumonía por Legionella atendidos en nuestro hospital.

MÉTOD0: estudio retrospectivo de pacientes diagnosticados de Enfermedad del Legionario atendidos en nuestro hospital en el periodo 2001-2015. Se consideró el diagnóstico de NAC por Legionella en pacientes con clínica y patrón radiológico compatible y antígeno urinario para L. Pneumophila serogrupo 1 positivo. Los pacientes con antigenuria positiva en ausencia de infiltrado pulmonar se diagnosticaron de Fiebre de Pontiac. Se analizaron datos epidemiológicos, factores de riesgo, clínica, patrón radiológico y analítico, antibiótico recibido y evolución. El análisis estadístico se realizó con el SPSS18.

RESULTADOS: Se registraron 145 pacientes con antigenuria positivas, de los cuales 136 presentaban neumonía y se incluyeron en el estudio. En 121 la presentación fue esporádica y 15 fueron adscritos a un brote. Casi un 50\% tuvo lugar en los meses de septiembre, octubre y noviembre. Se observó un aumento progresivo de la incidencia a lo largo del periodo analizado.

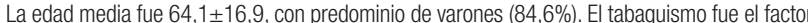
de riesgo más común (60\%) seguido por EPOC y alcoholismo (ambos 22\%). En cuanto a la

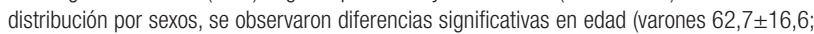
mujeres $71,9 \pm 17,3$ _ y en el consumo de alcohol (varones $26,1 \%$; mujeres $0 \%$ ) y tabaco (varones $67,8 \%$; mujeres $14,3 \%$ ). Los síntomas más frecuentes fueron la fiebre $(96 \%)$, mialgias $(51,5 \%)$ y tos $(57,4 \%)$. No obstante, un 30\% no cursó con clínica respiratoria. Un 50\% presentó hiponatremia, siendo leve en la mayoría de casos, y un 54,4\% hipertransaminasemia. La imagen radiológica más frecuente fue la consolidación unilobar (70,6\%) con derrame pleural asociado en un 8\%. Casi un $60 \%$ se diagnosticó en las primeras 24 horas. La mayoría recibieron un antibiótico adecuado con una duración entre 10 y 15 días, siendo el más empleado el levofloxacino. Se asoció un segundo fármaco activo frente a legionella en un 13\%. Un 85\% necesitó ingreso con una estancia media de 11 días. Un 53,7\% fueron clasificadas como neumonías FINE IV-V un 12,5\% precisó ingreso en UC y un $14 \%$ falleció. En el análisis univariante se asociaron con evolución desfavorable (ingreso en UCI o muerte) la presencia de Tabaquismo, Consumo de alcohol, EPOC, Disnea, Síntomas neurológicos, 
SO2 baja, FINE $\geq I V$ y Demora diagnóstica. De ellos, solo edad<65 años, EPOC, Saturación 02 a ingreso $<90 \%$ y FINE $\geq I V$ fueron factores de riesgo independientes en el análisis multivariante. CONCLUSIONES: La incidencia de la neumonía por legionella en nuestra área sanitaria ha aumentado en el periodo estudiado. Los factores de riesgo más frecuentes son el tabaquismo, el consumo de alcohol y el EPOC. Aunque el cuadro clínico es atípico, el patrón radiológico es similar al de la neumonía neumocócica. Se asociaron a peor pronóstico edad<65 años, EPOC, Saturación 02 al ingreso $<90 \%$ y FINE $\geq I V$.

\section{RIESGO CARDIOVASCULAR Y ENFERMEDAD CEREBRAL VASCULAR: CÓMO ANTICIPARNOS A LA ENFERMEDAD}

Alves Pereira ED.

MEDICINA INTERNA, COMPLEJO HOSPITALARIO DE PONTEVEDRA.

INTRODUCCIÓN: Las enfermedades cardiovasculares son una de las principales causas de morbimortalidad en los países desarrollados. Siendo el ictus la segunda causa de muerte en la población mundial y, la tercera en el mundo occidental, así como la primera causa de invalidez en la edad adulta. La enfermedad cerebrovascular (ECV) es de etiología multifactorial y se implican múltiples factores de riesgo cardiovascular (FRCV).

OBJETIVOS: Analizar casos de ictus en nuestra área sanitaria; con el objetivo detectar FRCV modificables y así intervenir en el manejo de la enfermedad, tanto prevención primaria como secundaria. Objetivos secundarios: analizar descriptivamente factores de riesgo inmodificables relacionados y pronóstico.

MATERIAL Y MÉTODOS: Estudio descriptivo restrospectivo de nuevos casos de ECV en Complexo Hospitalario de Pontevedra, entre Enero-Junio del 2014 y su evolución en un año. El análisis estadístico se ha hecho en SPSS 15.0

RESULTADOS: 222 pacientes, edad media: $77.35 \pm 12.05$ años, $49.10 \%$ varones. $87.38 \%$ fueron ictus isquémico y AlTs, $67.52 \%$ no cardioembólica, aterotrombóticos e indeterminados y 32,38\% cardioembólicos,12.61\% hemorrágicos. 62.16\% presentaban hipertensión arterial (HTA); 88.4\% desarrollaron ictus isquémico/AlT, siendo 69.54\% no cardioembólicos, 30.46\% cardioembólicos 11.6\% hemorrágicos. Previo al ingreso el tratamiento de HTA, 7.9\% era medidas higiénicodietéticas/cambios en estilo de vida, $55.79 \%$ tratados con un fármaco, dos fármacos: $21.01 \%$ y con tres o más fármacos: $15.21 \%$. Los hipertensos que precisaban más fármacos para su contro fueron los isquémico/AIT no cardioembólica: 1.43 fármacos. Al alta precisaron ajuste de tratamiento 46.4\%.33.78\% presentó dislipemia (DLP). La cifra media de colesterol total (CT): 178.18+48.88, C-HDL 46.37 \pm 16.38 , c-LDL107.54 \pm 39.54 , la cifra media de triglicéridos (TG) fue 121.16 \pm 66.34 siendo mayores en el grupo isquémico/AIT no cardioembólico con CT medio: 181.95 \pm 48.24 (46.22 $16.57 \mathrm{HDL}, 109.5+41.38 \mathrm{LDL}$ y TG medio: $132.17+77.63 .22 .97 \%$ tenian diabetes mellitus (DM), la media de HbA1c: 7.41+1.6, más prevalente en el isquémico/AIT, 84.32\%, de los cuales $74.41 \%$ al no cardioemblólico y 25.69\% al cardioembólico. 12.61\% tabaquismo activo $82.14 \%$ debutó como ictus isquémico no cardioembólico. Las comorbilidades: 17.11\% ictus previo $15.76 \%$ cardiopatía isquémica y $6.3 \%$ arteriopatía periférica La estancia media fue 9.24 días+/-9.15. 13.09\% fallecieron durante el ingreso hospitalario. La mortalidad acumulada al año ue del $23.42 \%$, el $84,31 \%$ al grupo de isquémico/AIT (47.06\% no cardioembólicos y $37.25 \%$ cardioembólicos) y 15.68\% al hemorrágico.

CONCLUSIÓN: LOS FRCV están implicados de forma significativa en el desarrollo de la ECV especialmente la patología isquémica aterotrombótica. La HTA es el más frecuentemente asociado. Con la detección precoz de los FRCV y su tratamiento, se podrían evitar nuevos eventos, de esa manera se reduciría una de las mayores causas de morbimortalidad.

\section{TUMORES NEUROENDOCRINOS GASTROINTESTINALES: \\ 2010-2015}

Fernández Bouza E, Lijó Carballeda C, García Alén D, Bravo Blázquez I, Dalama López T, Martul Pego E, Durana Tonder C (1). Sesma Sánchez P.

MEDICINA INTERNA, ANATOMÍA PATOLÓGICA (1), COMPIEXO HOSPITAL ARIO UNIIVRSITARIO DE FERROL.

INTRODUCCIÓN: Ios tumores neuroendocrinos gastrointestinales (TNE) son infrecuentes, de crecimiento lento y frecuentemente se diagnostican de forma incidental. Su comportamiento se relaciona con el grado de malignidad.

Objetivo: se pretende analizar las características de estos tumores en el área sanitaria de Ferrol. MATERIAL Y MÉTODOS: revisión retrospectiva de las historias clínicas de los pacientes diagnosticados de TNE entre los años 2010 y 2015 a partir de los diagnósticos aportados por los Servicios de Anatomía patológica y Admisión. Se analizaron variables epidemiológicas, clínicas histológicas. Se usó el paquete estadístico SPSS versión 21.

RESULTADOS: se diagnosticaron 39 casos (22 mujeres) con edad media 62 años (22-85, DS15). a incidencia fue de 3.2/100.000 habitantes-año. El grado histológico fue I en 18 (46\%), II en 13(33\%), y III en 8 (20\%). El estadio clínico fue I en 14 (35\%), II en 6, III en 6 (15\%) y IV en 12 $30 \%)$. La localización del primario fue intestino delgado $(11,28 \%)$, páncreas $(9,23 \%)$, colon (6, $15 \%)$, estómago (6,15\%), apéndice $(5,12 \%)$ y desconocida $(2,5 \%)$. El hallazgo fue incidental en 14 pacientes (36\%). Sólo un paciente manifestó síndrome carcinoide y uno afectación cardíaca. El síntoma más frecuente fue dolor abdominal $(16,41 \%)$. Fueron sometidos a cirugía curativa $21(53 \%)$ y citorreductora $2(5 \%)$, y a exéresis endoscópica 5 (12\%). Recibieron tratamiento con análogos de somatostatina 11(28\%) everólimus $3(7 \%)$ y quimioterapia 4 (10\%). Fallecieron 11 pacientes (28\%); de ellos el tumor primario asentaba en pàncreas (4), colon (3), se desconoce en 2, estómago en 1 e intestino delgado 1.La probabilidad de supervivencia es del $76 \%$ al año, de $72 \%$ a los 2 años y del $67 \%$ a los 3 años. El grado histológico y el estadio clínico se relacionaron de forma estadísticamente significativa con la supervivencia. Los pacientes con grado histológico I tienen supervivencia del $87 \%$ al año, mientras que es del $73 \%$ en el grado || y del $12 \%$ en el grado III. En el estadio clínico la supervivencia es del $91 \%$ al año, del $83 \%$ en los estadios II y || del $42 \%$ en el estadio IV.

CONCLUSIONES: Ios TNE en nuestra área tienen una incidencia ligeramente más baja que la cescrita en la literatura. Frecuentemente son un hallazgo incidental quirúrgico, endoscopico o de magen. La cirugía es el tratamiento más eficaz. El grado histológico más agresivo y el estadio clínico más avanzado son condiciones que comportan un peor pronóstico.

\section{TRATAMIENTO DE LA ANEMIA CRÓNICA EN UN HOSPITAL DE DÍA DE MEDICINA INTERNA: FACTORES ASOCIADOS A EVOLUCIÓN Y MORBILIDAD}

Páez Guillán EM (1), García Villafranca A (1), Alende Castro V (1), Macía Rodríguez C (1), Vázquez Agra N (1), Novo Veleiro I (1), González Quintela A (1).

(1): SERVICIO DE MEDICINA INTERNA, COMPLEJO HOSPITALARIO UNIVERSITARIO DE SANTIAGO DE COMPOSTELA.

INTRODUCCIÓN: La anemia ferropénica es una patología muy prevalente (6\% de la población), llegando al 20\% por encima de los 80 años, lo que la convierte en una de los principales problemas de la Medicina Interna, por lo que se han creado unidades específicas para su estudio y tratamiento.

OBJETIVOS: Analizar las características de los pacientes con anemia atendidos en un Hospital de Día de Medicina Interna, distinguiendo entre los diferentes tratamientos disponibles, así como los factores asociados a su evolución y morbimortalidad

MATERIAL Y MÉTOD0: Estudio retrospectivo en el cual se incluyeron los pacientes con anemia tratados en Hospital de Día entre 01/01/12 y 30/06/15. Se recogieron variables epidemiológicas, clínicas y analíticas, y se realizó un análisis descriptivo y univariante.

RESULTADOS: Se incluyeron 104 pacientes: un $51.9 \%$ mujeres y un $48.1 \%$ hombres. La edad media fue de $79 \pm 17$ años. Presentaron una $\mathrm{Hb}$ media de $8.2 \mathrm{~g} / \mathrm{dl}$. Un $31.7 \%$ fueron derivados de la planta hospitalaria, un 31.7\% de consultas de Medicina Interna, un 9.8\% de otras Consultas Externas, un $8.7 \%$ de Atención Primaria y un 4.8\% de Urgencias. Las comorbilidades fueron: $71.2 \%$ HTA, 42.3\% insuficiencia cardiaca, 39.4\% FA, 38.5\% insuficiencia renal crónica, 27.9\% DM y $23.1 \%$ neoplasias. Un $81.7 \%$ recibieron IBP, un $34.6 \%$ AINEs, un $32.7 \%$ antiagregantes, un $29.8 \%$ anticoagulantes orales y un $28.2 \%$ heparina de bajo peso molecular. La etiología de la anemia fue: digestiva en el $37.5 \%$, multifactorial en el $25 \%$ y tumoral en el $11.5 \%$. El $69.2 \%$ recibió al menos una trasfusión sanguínea. El $47.1 \%$ fue tratado con hierro sacarosa y el $21.2 \%$ con hierro carboximaltosa. Un 80,8\% recibió además tratamiento con hierro oral. La mortalidad a fecha de diciembre de 2015 fue del $37.5 \%$, siendo menor en los tratados con hierro intravenoso: $20.4 \%$ hierro sacarosa y $31.8 \%$ en carboximaltosa. La mortalidad fue mayor en los pacientes con menor hemoglobina: $42,8 \%$ con $\mathrm{Hb} \leq 7.5 \mathrm{~g} / \mathrm{dl}$. Factores asociados fueron neoplasia e ICC. La cifra media de hemoglobina mejoró durante el estudio en $2.4 \mathrm{~g} / \mathrm{dl}$. Tras un año, el número de ingresos se redujo en un $60.4 \%$, las trasfusiones en un $53.2 \%$ y las asistencias a Urgencias en un $72 \%$ de los pacientes. Estas cifras, en los pacientes que recibieron tratamiento con hierro sacarosa y carboximaltosa, fueron del $57.2 \%$ y $82.4 \%$ para reingresos y del $76.2 \%$ y $64.7 \%$ para asistencias a Urgencias, respectivamente.

CONCLUSIONES: La anemia crónica es una patología de difícil manejo cuyos pacientes se benefician del tratamiento en Hospital de Día. Se han obtenido mejores resultados clínicos y de mortalidad con hierro intravenoso que con trasfusiones periódicas. El tratamiento con hierro carboximaltosa es especialmente efectivo en pacientes de difícil manejo, que han fracasado en el tratamiento con hierro sacarosa y con escasa disponibilidad para acudir a Hospital de Día. La insuficiencia cardiaca y la neoplasia se han identificado como factores de riesgo de mortalidad en nuestro estudio.

\section{ACVA ISQUÉMICO CON TRANSFORMACIÓN HEMORRÁGICA: REVISIÓN ANUAL DE CASOS Y COMPLICACIONES EN EL CHUO}

López Mato P, González Noya A, Barreiro Rivas A, Latorre Díez A, Lorenzo Vizcaya A MEDICINA INTERNA., COMPLEXO HOSPTTALARIO UNIVERSITARIO DE OURENSE (CHUO)

INTRODUCCIÓN: La transformación hemorrágica es una complicación potencial del accidente cerebrovascular agudo (ACVA) isquémico, a la que se asocia un aumento de mortalidad en determinadas series. Esto cobra especial relevancia en los pacientes ingresados en Medicina Interna, cuya edad avanzada y multimorbilidad condicionan una mayor dificultad en el manejo clínico, así como un peor pronóstico.

OBJJETIVOS: Analizar las características epidemiológicas de los pacientes ingresados en Medicina Interna con transformación hemorrágica de ACVA isquémico, centrándose en el estudio de la posible fuente embolígena y en el tratamiento anticoagulante recibido.

MATERIAL Y MÉTODOS: Estudio descriptivo de los casos registrados en CHUO entre enero diciembre de 2015, realizando seguimiento de los casos hasta 30 abril de 2016 para valorar complicaciones médicas. Los datos fueron obtenidos a través de Documentación Clínica. RESULTADOS: Se registraron 17 casos, de los cuales el 65\% fueron mujeres. La edad media fue de 82 años, con un índice de Charlson superior a 4 puntos en el $88 \%$ casos. Se conocía arritmia cardíaca (FA o flutter) en el momento del evento isquémico en 5 pacientes, estando anticoagulados 4 de ellos ( 3 con antivitaminas $K$ y 1 con heparina); asimismo, durante el ingreso se detectó arritmia supraventricular en 3 pacientes. Todos tenían CHA2DS2VASc mayor de 2 puntos, y el 76\% casos presentaba HASBLED superior a 3 puntos.. La confirmación de transformación hemorrágica se realizó mediante resonancia magnética (RMN) en 9 pacientes (53\%). En el momento de la detección, el 23,5\% del total se encontraba anticoagulado con heparina a dosis terapéutica y un $47 \%$ a dosis profiláctica. El principal territorio afectado fue la arteria cerebral media derecha (9 pacientes). El 18\% casos fueron exitus; en aquellos que sobrevivieron al evento, el 36\% fueron dados de alta con anticoagulación, iniciando uno de ellos tratamiento con antagonista directo de trombina (rivaroxaban); no se retiró anticoagulación a aquellos que ya la tenían previamente. A los 6 meses de seguimiento, ningún paciente precisó nuevo ingreso por aparición de focalidad neurológica o complicaciones hemorrágicas.

CONCLUSIONES: En Medicina Interna la transformación hemorrágica del ACVA isquémico se produce en pacientes de edad avanzada y elevada murtimorbilidad, lo que condiciona la expectativa de vida independientemente del evento cerebrovascular ocurrido. Existían criterios de anticoagulación en los pacientes con arritmia confirmada, pero sólo en un caso se planteó el uso de nuevos anticoagulantes orales tras la transformación hemorrágica. Son necesarios nuevos estudios para ver la evolución de estos pacientes a largo plazo, así como la mortalidad asociada a esta patología y las posibles nuevas indicaciones de inicio, retirada 0 ajuste de anticoagulación según evolución clínica. 


\section{PERFIL DE PACIENTES IDENTIFICADOS COMO PALIATIVOS EN HOSPITALIZACIÓN A DOMICILIO (HADO) DEL HOSPITAL DE BARBANZA 2014}

Iglesias Gallego M (1), Gayol Fernández MC (1), Abad Lustres N (2), Pesqueira Fontan P (1), Guerra Corredoira JC (2), Caaveiro Ageitos D (2), Piñeiro Davila S (2). (1) FACULTATIVOSY (2) DUES DE UNIDAD DE HOSPITALIZACIÓN A DOMICILIO, HOSPITAL DA BARBANZA. INTRODUCCIÓN: En 2013 el SERGAS implementó el programa de identificación de pacientes paliativos (programa NECPAL Galicia).Se planteó la revisión de los pacientes ingresados en nuestra Unidad en 2014 identificados como tales.

OBJETIVO: Descripción de pacientes identificados como paliativos que ingresaron en en HADO del Hospital da Barbanza en 2014

MATERIALY MÉTODOS: Estudio retrospectivo informes de alta de HADO de Enero a Diciembre de 2014, donde consta identificación de pacientes que precisan atención paliativa y revisión de superviencia a 9/05/16

RESULTADOS: Identificados 101 pacientes con 126 ingresos, (46\% y 55\%), $38 \%$ de los ingresos de 2014. Edad media 79 años (52\% > 80a). De los oncológicos (46), 83\% previamente identificados (56\% Oncología) y 17\% en HADO. No oncológicos (55) 76\% En neurodecenerativa 9\% Pulmonar, 6\% Cardiopatía, $9 \%$ otras : 41 identificados en HADO $(76 \%$ con instrumento NECPAL CCOMS-ICOC), 9 Primaria (78\% NECPAL) y 5 otras especialidades. Alta el mismo día, 16 pacientes tras valoración para ajuste de tratamiento y control de síntomas (4 éxitus). El resto generaron estancia media de 9.8 días. Servicio procedencia: MI (35\%), Urgencias (28\%), AP (23\%), Oncología (8\%), otros (6\%). Motivo de ingreso: 55\% Infección (79\% respiratorio), $28 \%$ control síntomas (68\% dolor, $25 \%$ disnea)..Destino al alta: domicilio $48 \%$, consultas $9 \%$, éxitus $29 \%$ y traslado al hospital $14 \%$ (claudicación familiar 5 , infección 3, obstrucción intestinal 2, colocación tubo tórax 1, fractura patológica 1). A fecha 9/05/16 12 pacientes (12\%) seguían vivos. Período desde la identificación como paciente paliativo hasta el éxitus 0-841 días (Media 170 días). El 74\% (75) de los pacientes falleció antes del primer año tras su identificación. Lugar de éxitus: (58) 65\% en domicilio (36 con HADO) y (31) 35\% en el hospital (MIR 23, UPAL 2 y 6 en Urgencias)

CONCLUSIONES: Se trata de pacientes de edad avanzada, la mayoría no oncológicos (demencia) que suponen más del $25 \%$ de nuestra actividad. La mayoría proceden de Ml y Urgencias (motivo más frecuente infección respiratoria) siendo dolor y disnea los síntomas más frecuentes de los que ingresan para control de síntomas. Los pacientes oncológicos suelen ser identificados por los servicios que les diagnostican y siguen. El instrumento NECPAL CCOMS-ICO@, fue de utilidad en la identificación de pacientes no oncológicos. La mayoría de los pacientes fallecieron antes del primer año tras su identificación y en su domicilio con apoyo de HADO. Es fundamental la coordinación con Atención Primaria para optimizar seguimiento de pacientes con necesidades paliativas.

\section{SARCOIDOSIS ENDOBRONQUIAL, UNA MANIFESTACIÓN ATÍPICA}

García Poutón N, González Vázquez L, Paz Ferrín JM, Cobas Paz A, Corbacho Abelaira MD, Gondar Barcala T, Fernández Castro I, de la Fuente Aquado J.

MEDICINA INTERNA, POVISA.

INTRODUCCIÓN: La sarcoidosis se produce como consecuencia de una reacción granulomatosa exagerada en individuos genéticamente predispuestos. Puede manifestarse en distintos órganos, siendo los más frecuentemente implicados pulmones, ganglios linfáticos, ojos, piel e hígado. La afectación endobronquial es rara, descrita en un $5 \%$ de los casos.

CASO CLÍNICO 1: Varón de 33 años que acude por hallazgo incidental en RMN de hombro de lesiones pulmonares bilaterales en lóbulos superiores. Como único síntoma presentaba esputos verdes-grisáceos ocasionales. La exploración física era normal. La analítica básica no presentaba alteraciones, la ECA estaba elevada $(67.9 \mathrm{U} / \mathrm{L})$ y el calcio era normal. Se realizó Mantoux y baciloscopia en esputo que resultaron negativos. Se solicita TC tórax que muestra infiltrados bilaterales en lóbulos superiores y adenopatías en región paratraqueal derecha, prevascular e hilios pulmonares. Se continúa estudio con gammagrafía con galio que capta a nivel pulmonar y fibrobroncoscopia que muestra una mucosa de aspecto granular en los bronquios de LSI, LM y língula. El resultado histológico fue compatible con granulomas no necrotizantes y el lavado broncoalveolar indica un cociente T4/T8 de 3.8. Las pruebas funcionales respiratorias fueron normales.

CASO CLÍNICO 2: Mujer de 31 años que acude por tos persistente y expectoración amarillenta de 2 meses de evolución acompañada de fiebre de predominio vespertino, astenia e hiporexia. La exploración física era normal excepto por la existencia de lesiones máculopapulosas en región intermamaria, espalda y cuello. En la analítica destacaba una elevación de los reactantes de fase aguda (VSG $132 \mathrm{~mm} / \mathrm{h}$ y PCR $7.13 \mathrm{mg} / \mathrm{dl}$ ) y de la ECA(123.5 U/L) con el resto de parámetros dentro de la normalidad. Los hemocultivos, Mantoux y baciloscopia resultaron negativos. El TC tórax mostró múltiples adenopatías mediastínicas y nódulos milimétricos con tendencia a la confluencia de predominio en lóbulos superiores y pericisurales. La broncoscopia objetivó afectación del árbol bronquial derecho con implantes nodulares de predominio en LSD y carina segmentaria del LM y LID. La biopsia mostró inflamación crónica granulomatosa no necrotizante y el cociente T4/T8 resultó elevado. Desde el punto de vista funcional, la espirometría mostró un patrón mixto moderado con alteración moderada de la difusión. CONCLUSIÓN: La afectación endobronquial es muy poco frecuente y, a menudo, está infradiagnosticada. Se puede manifestar como eritema, granulación, edema, nódulos bronquiectasias o estenosis. Se afectan con mayor frecuencia los bronquios lobares, segmentarios o distales y con menor, la tráquea y los bronquios principales. Las pruebas funcionales suelen mostrar un patrón obstructivo y el uso de terapia esteroidea inhalada ha demostrado mejoría de la tos. En caso de pacientes sintomáticos se recomienda tratamiento con esteroides sistémicos.

\section{PAPEL DEL BEVACIZUMAB EN EL TRATAMIENTO DE LA ENFERMEDAD DE RENDU-OSLER-WEBER: A PROPÓSITO DE UN CASO}

Gómez Sousa JM, Rada Soto MA, Suárez Varela MM, Soto Peleteiro A, Lorenzo Castro R, Sousa Domínguez A, Argibay Filgueira AB, Rivera Gallego $A$ SERVICIO DE MEDICINA INTERNA, COMPLEJO HOSPITALARIO UNIVERSTTARIO DE VIGO (CHUVI).

INTRODUCCIÓN: La telangiectasia hemorrágica hereditaria (THH) o enfermedad de Rendu-OslerWeber es un trastorno vascular displásico multisistémico de herencia autosómica dominante, caracterizado por episodios recurrentes de epistaxis, teleangiectasias en piel y mucosas y malformaciones arteriovenosas viscerales. El diagnóstico se basa en la presencia de criterios clínicos compatibles y la historia familiar. En general el tratamiento es el de las complicaciones, aunque en los últimos años se ha ensayado el empleo de fármacos inhibidores de la angiogénesis en casos con afectación visceral con resultados prometedores.

OBJETIVOS: Descripción del caso clínico de un paciente con THH tratado con bevacizumab y revisión de la literatura

MATERIAL Y MÉTODOS: Revisión retrospectiva de la historia clínica de nuestro paciente y búsqueda relacionada en MEDLINE.

RESULTADOS: Varón de 77 años diagnosticado de THH en 1997 y que cumple criterios de Curaçao: historia familiar, epistaxis de repetición, teleangiectasias múltiples (cavidad oral, dedos) y afectación visceral (fístulas arteriovenosas hepáticas, teleangiectasias gastrointestinales). Presenta además hipertensión pulmonar confirmada por cateterismo derecho catalogada como secundaria a hiperafluio. Hasta el año 2014 presentaba anemia crónica moderada, controlada con hierro oral, secundaria a sangrados digestivos leves y epistaxis. Desde enero de 2015 la necesidad de soporte transfusional fue cada vez mayor. Ingresó reiteradamente por hemorragias digestivas amenazantes que precisaron tratamiento endoscópico y descompensaciones cardíacas por alto gasto. Fue tratado con ácido tranexámico sin éxito. En estas circunstancias se solicitó el tratamiento con bevacizumab fuera de ficha técnica, que fue autorizado e iniciado en noviembre de 2015. La respuesta fue excelente, con práctica remisión de los episodios de sangrado, manteniendo cifras de hemoglobina por encima de $10.5 \mathrm{~g} / \mathrm{dL}$. La periodicidad de administración inicial fue quincenal, espaciándola posteriormente con un intervalo máximo de 8 semanas. En la actualidad continúa e tratamiento en nuestro Hospital de Día sin efectos adversos.

CONCLUSIONES: El bevacizumab es un anticuerpo humano recombinante que inhibe los efectos del factor de crecimiento endotelial vascular, aumentado en los pacientes con THH. Existen varias series de casos donde ha sido empleado con éxito tanto a nivel local (intranasal) como sistémico, disminuyendo la necesidad de soporte transfusional. Recientemente un estudio prospectivo no aleatorizado evaluó su eficacia en pacientes con afectación hepática extensa y fallo cardíaco, logrando una reducción del gasto cardíaco en el 80\%. El trasplante es hasta ahora el único tratamiento curativo en los casos con afectación hepática. Según los datos disponibles en la literatura, bevacizumab podría emplearse en pacientes refractarios al tratamiento de soporte y aquellos con contraindicación para el trasplante.

\section{RECIDIVA SISTÉMICA DE MELANOMA COROIDEO}

Gómez Sousa JM, Soto Peleteiro A, Sousa Domínguez A, Lorenzo Castro R, Vilas Pío B, Val Domínguez N, Baroja Basanta AL, Rada Soto MA.

SERVICIO DE MEDICINA INTERNA, COMPLEJO HOSPITALARIO UNIVERSTARIO DEVIGO (CHUVI).

INTRODUCCIÓN: El melanoma coroideo es el tumor intraocular primario más frecuente en adultos. Suelen presentarse como una tumoración pigmentada, aunque también pueden ser amelanóticos. La propagación tumoral tiene lugar principalmente por extensión local y por diseminación hematógena dada la ausencia de vasos linfáticos en la úvea.

OBJETIVOS: Descripción del caso clínico de un paciente diagnosticado y tratado de melanoma coroideo amelanótico que recidivó años después y revisión de la literatura.

MATERIAL Y MÉTODOS: Revisión retrospectiva de la historia clínica de nuestro paciente y búsqueda relacionada en MEDLINE.

RESULTADOS: Varón de 50 años de edad, diagnosticado en 2011 de melanoma uveal amelanótico del ángulo supero-externo del globo ocular derecho. Remitido entonces a la Unidad de Retina Quirúrgica y Oncología Ocular del CHUS, donde se decidió tratamiento con braquiterapia. Desde entonces siguió rastreos periódicos, sin evidenciarse enfermedad a distancia. En marzo de 2016 es remitido por su Médico de Atención Primaria a nuestras Consultas Externas por la aparición en el último mes de múltiples lesiones nodulares subcutáneas en cuero cabelludo, tórax (incluyendo región retromamilar bilateral) y abdomen. Dichas lesiones eran móviles, no pigmentadas, de consistencia blanda y no presentaban signos inflamatorios. No existían otros hallazgos relevantes en la exploración física. Se contactó con el Servicio de Dermatología que biopsió una de las lesiones, cuyo estudio citopatológico fue compatible con melanoma metastásico de tipo epitelioide. El paciente fue derivado a Oncología Médica donde un estudio de extensión evidenció afectación ganglionar, cerebral, pulmonar, peritoneal, esplénica y músculo esquelética. Finalmente fue propuesto y aceptado para su inclusión en un ensayo clínico en fase II con inmunoterapia. CONCLUSIONES: Aunque poco frecuentes, es de interés el estudio y reporte de estos tumores debido a su alta malignidad y capacidad metastásica. En su mayoría son asintomáticos y cuando producen síntomas lo hacen en forma de disminución de la agudeza o defecto de campo visual. Las causas más frecuentes de muerte son la extensión extraescleral y las metástasis a distancia, con preferencia por pulmones e hígado. Como en otros tumores, las metástasis cutáneas constituyen un indicador de recurrencia y mal pronóstico. Todas estas manifestaciones pueden ocurrir tras un periodo prolongado y por ello se hace necesario un seguimiento estrecho periódico.

\section{SÍNDROME DE KLIPPEL-TRÉNAUNAY: DIAGNÓSTICO EN LA EDAD ADULTA}

Gómez Sousa JM, Vilas Pío B, Soto Peleteiro A, Suárez Varela MM, Sousa Domínguez A, Lorenzo Castro R, Baroja Basanta AL, Val Domínguez N, Rada Soto MA.

SERVICIO DE MEDICINA INTERNA, COMPLEJO HOSPITALARIO UNIVERSTTARIO DE VIGO (CHUVI).

INTRODUCCIÓN: El síndrome de Klippel-Trénaunay (SKT) es una rara condición presente al nacimiento y caracterizada por una tríada de manifestaciones clínicas: angiomatosis, varices 
venosas y/u otras malformaciones vasculares e hipertrofia ósea y de tejidos blandos. Es una entidad poco conocida entre los médicos, que puede llevar a un manejo inadecuado incluyendo la demora o no detección de manifestaciones asociadas.

OBJETIVOS: Descripción del caso clínico de una paciente diagnosticada en la edad adulta y revisión de la literatura.

MATERIAL Y MÉTODOS: Revisión retrospectiva de la historia clínica de nuestra paciente y búsqueda relacionada en MEDLINE.

RESULTADOS: Mujer de 26 años que ingresó por un cuadro de celulitis en costado derecho. La revisión minuciosa de la historia clínica y la exploración física evidenciaron detalles llamativos: desde el nacimiento presentaba una dismetría de extremidades, siendo unos 3 centímetros de mayor diámetro las derechas con un componente de linfedema a este nivel; le había sido extirpado un angioma arteriovenoso en la axila derecha a los 3 años y ya en la edad adulta fue valorada por Dermatología por la aparición de lesiones etiquedas de linfangiomas circunscritos. En 2013 presentó varios episodios de celulitis en el miembro superior derecho. En una angio-RM solicitada por este motivo se detectó la existencia de un linfangioma quístico a este nivel que finalmente fue intervenido. La revisión exhaustiva de la literatura sobre síndromes de crecimiento hemicorporal llevó al diagnóstico de SKT. La respuesta a la antibioterapia empírica fue satisfactoria y la paciente fue dada de alta en pocos días.

CONCLUSIONES: Se trata de una enfermedad con un curso habitualmente benigno, siendo las complicaciones más frecuentes las locales: tromboflebitis, trombosis venosas profundas y, como en el caso de nuestra paciente, celulitis y linfedema. Las complicaciones graves son mucho menos frecuentes y entre ellas se encuentran la coagulopatía de consumo (síndrome de Kasabach-Merritt), la angiomatosis visceral con el consiguiente riesgo de sangrado, cuadros de ICC por alto gasto cuando existen fístulas arteriovenosas y el embolismo pulmonar. Es una enfermedad esporádica asociada a la mutación del gen VG5Q que codifica para factores de crecimiento implicados en la angiogénesis. El diagnóstico diferencial debe ser planteado con entidades como las hamartomatosis múltiples y las facomatosis, de gran relevancia por su asociación con neoplasias malignas. De ahí la importancia del estudio genético, que fue solicitado y cuyos resultados se encuentran pendientes.

\section{ICTUS EN PACIENTE JOVEN: SÍNDROME DE MOYAMOYA}

Fernández Castro I, Paz Ferrín J, Sánchez Conde P, Gondar Barcala T, Álvarez Otero J, García Pouton N, de la Fuente Aguado J. MEDICINA INTERNA, POLCLIINICO POVISA.

INTRODUCCIÓN: La enfermedad de Moyamoya es una rara enfermedad cerebrovascular no oclusiva, que se caracteriza por una estenosis progresiva de la carótida interna y sus ramas desarrollo de circulación colateral compensatoria. Se aplica el término "síndrome de Moyamoya" cuando se identifica una etiología causante.

OBJETIVOS: Nuestro objetivo es describir un nuevo caso y realizar una revisión de la literatura mediante búsqueda bibliográfica en Pubmed.

MATERIAL Y MÉTODOS: Paciente varón de 37 años de edad, que acude a nuestro centro por episodio al despertarse de madrugada de disartria, agitación, inestabilidad de la marcha y caída al suelo sin pérdida de conocimiento. No tuvo cefalea, fiebre ni movimientos tónico-clónicos. Entre sus antecedentes padeció una meningitis tuberculosa en la infancia con hemiparesia derecha leve residual. En la exploración neurológica destacaba un leve borramiento del surco nasogeniano derecho y una hemiparesia residual con Babinski derecho La analítica no mostró alteraciones y la TC cerebral describió un infarto crónico localizado entre la cabeza del núcleo caudado y e brazo anterior de la cápsula interna izquierda y oclusión completa del segmento M1 izquierdo con recanalización distal a través de pequeñas colaterales, hallazgo confirmado por RM. El paciente fue dado de alta con tratamiento antiagregante, y permanece asintomático.

DISCUSIÓN: La enfermedad de Moyamoya consiste en una estenosis progresiva de carótida interna y sus ramas, con el desarrollo de circulación colateral compensatoria, lo que otorga un aspecto de "árbol en brote". Fue descubierta en Japón en 1957, y debe su nombre a la palabra "cigarrillo" en japonés, por su distribución angiográfica. La etiología es desconocida. Tiene mayo prevalencia en población asiática, y es más frecuente en el sexo femenino (1.8/1). Presenta dos picos de incidencia: uno en la infancia, entre los 5 y los 9 años y otro en la edad adulta, entre los 35 y los 45 años. Es importante hacer la diferenciación terminológica entre enfermedad de Moyamoya, idiopática, y síndrome de Moyamoya, secundaria a otras patologías, entre las que se encuentran etiologías infecciosas, trastornos hematológicos, patología autoinmnes, vasculopatías, enfermedades metabólicas, etc. Suele cursar con clínica de accidente isquémico transitorio ictus (más del 50\% hemorrágicos, por rotura de vasos colaterales frágiles 0 aneurismas), como hemorragia subaracnoidea por rotura de aneurismas, convulsiones o cefalea. Se diagnostica mediante técnicas de imagen, siendo la arteriografía el gold estándar aunque la angio- RM o el angio- TC han sustituído a la arteriografía convencional. El tratamiento es sintomático en e momento agudo; no está aceptada la prevención primaria y se utiliza tratamiento médico con antiagregantes como prevención secundaria además de tratamiento quirúrgico

CONCLUSIONES: El síndrome de Moyamoya es una rara patología causante de enfermedad cerebrovascular en gente joven.

\section{HEPATITIS AUTOINMUNE. REVISIÓN DE CASOS EN 6 AÑOS EN EL COMPLEXO HOSPITALARIO DE OURENSE}

Latorre Díez A, Lorenzo Vizcaya AM, Barreiro Rivas A, González Noya A, López Mato P. MEDICINA INTERNA, COMPLEXO HOSPITALARIO DE OURENSE.

INTRODUCCIÓN: La hepatitis autoinmune (HAl) es una enfermedad inflamatoria del hígado caracterizada por un infiltrado linfoplasmocitario de los espacios porta que se acompaña de autoanticuerpos y elevación de las inmunoglobulinas séricas.Según la clasificación existente se diferencian dos subtipos de HAl: tipo 1 con anticuerpos ASMA y/o tipo 2 con anticuerpos antiLKM.Se trata de una enfermedad con una gran variabilidad clínica,que incluye desde pacientes sintomáticos o presencia de síntomas debilitantes hasta pacientes con fallo hepático agudo. El tratamiento estándar para conseguir la remisión es la administración de inmunosuresores OBJETIVOS: Conocer las características epidemiológicas de los pacientes mayores de 18 años diagnosticados de HAl en Ourense en el período de enero 2009 a diciembre 2014; manejo diagnóstico, tratamiento y evolución.
MÉTODOS: Estudio descriptivo retrospectivo de los pacientes con HAl que han requerido ingreso por cualquier causa en el Complexo Hospitalario de Ourense. Se analiza los subtipos, evolución analítica,respuesta al tratamiento y evolución clínica.

RESULTADOS: De enero de 2009 a diciembre de 2014 se diagnosticaron 40 casos con HAl; de los cuales el $90 \%$ se trató de HAl tipo I el 10\% restante no hubo tipificación De los 40 pacientes 34 eran mujeres y 6 eran hombres. La mediana de edad al diagnóstico fue de 67,5 años[20 y 94 años]. En cuanto al motivo de ingreso de los pacientes estudiados:3 presentaban ictericia al ingreso 2 de ellos astenia,2 anemia hemolítica, 4 de los pacientes presentaban encefalopatía a ngreso se observó descompensación hidrópica en 4 pacientes y alteración de pruebas del perfi hepático en 1de los pacientes.Los 14 casos restantes ingresaron para la realización de biopsia hepática. En cuanto a la autoinmunidad,22 de los casos presentaron positividad para anticuerpos antinucleares ANA, 24 positividad para ASMA, 13 de los pacientes presentaban positividad para ANA y ASMA y 2 de los casos presentaron AMA positivos, ninguno de los pacientes presento anticuerpos antiLKM.Existía un aumento de gammaglobulinas séricas, principalmente lgG,en todos los casos.Se encontraron enfermedades autoinmunes asociadas en 8 (20\%): 2 casos de LES, hipotiroidismo Al, 1 enfermedad de Crohn y 3 casos de enfermedad celíaca.El tratamiento más frecuentemente administrado fue la azatioprina, seguido de prednisona, prednisona y azatioprina combinación de azatioprina y ácido ursodesoxicólico, ácido ursodesoxicólico y hubo 6 casos no tratados.A lo largo de este periodo fallecieron 5 pacientes, 1 por hepatitis aguda fulminante y 4 e ellos por insuficiencia hepática.

CONCLUSIONES: La HAl afecta más a las mujeres.El subtipo mayoritario de HAl es el subtipo I(ANA y ASMA positivos), no hubo ningún paciente que presentase el subtipo 2.El tratamiento de elección fueron los fármacos inmunosupresores, siendo la prednisona y la azatioprina los más usados.

\section{EOSINOFILIA EN RELACIÓN CON NEMATOSIS INTESTINAL POR ASCARIS LUMBRICOIDES}

Dalama López T, Lijó Carballeda C, García Alén D, Bravo Blázquez I, Martul Pego E, Fernández Bouza E, Sesma Sánchez P. MEDICINA INTERNA, COMPLEXO HOSPITALARIO UNIVERSITARIO DE FERROL (A CORUÑA).

INTRODUCCIÓN: Se presenta un caso de una paciente de 82 años con eosinofilia en relación con nematosis intestinal por Ascaris Lumbricoides.

CASO CLÍNICO: Paciente de 82 años que consulta por dolor abdominal difuso acompañado de síndrome general con pérdida de $5 \mathrm{Kg}$ de peso en 2 meses, así como estreñimiento crónico. La paciente vive en medio rural, tiene ganado porcino, bovino y perros, que están fuera de la vivienda. Ingresa en el Servicio de Medicina Interna para estudio. La exploración física al ingreso es anodina. Se realiza un análisis completo; en el hemograma se evidencia leucocitosis de 13470/mm3 con 47\% de eosinófilos; bioquímica, coagulación, sedimento urinario, hormonas tiroideas, perfil férrico y marcadores tumorales son normales. Se realiza tomografía computarizada (TC) tóraco-abdóminopélvica, viéndose quistes hepáticos simples sin otros hallazgos. La colonoscopia y la gastroscopia resultan sin alteraciones, tomándose biopsias en antro y duodeno que descartan gastroenteritis eosinofilica. Durante el ingreso el estudio de parásitos en heces fue negativo. Se procede al alta con el diagnóstico de síndrome general y eosinofilia pendiente de completar estudio ambulatorio. A los 7 días del alta la paciente expulsa por la boca un parásito tipo nematodo, el cual es remitido a Microbiología, siendo identificado como Ascaris Lumbricoides (hembra adulta). Se instaura tratamiento con Albendazol 400mg durante 3 días con resolución del cuadro.

DISCUSIÓN: El diagnóstico diferencial de eosinofilia incluye alergias, fármacos, vasculitis (ChurgStrauss), síndrome hipereosinofílico, parásitos y neoplasias. Dada la clínica de la paciente, con dolor abdominal y síndrome general, se intentó en un primer momento descartar malignidad. La prevalencia de infección por Ascaris es mayor en países con climas cálidos y húmedos que favorecen la transmisión, así como áreas donde las prácticas de saneamiento son subóptimas, conduciendo a un aumento de la contaminación del suelo y las aguas. En nuestro medio en la actualidad es poco común, debiendo aún así ser considerada. El diagnóstico de nematosis intestina por Ascaris Lumbricoides debe establecerse mediante el estudio microscópico de heces, con la visualización de los huevos característicos del helminto. Puede haber falsos negativos ya que hasta pasados al menos 40 días desde el inicio de la infección no se visualizarán en las heces, como presuponemos que sucedió con nuestra paciente, por lo que no son de gran utilidad en el diagnóstico precoz.

CONCLUSIONES: Las parasitosis deben ser consideradas en el diagnóstico de eosinofilia. Si existe una firme la sospecha se puede plantear instaurar tratamiento empírico, dada la baja sensibilidad de las pruebas diagnósticas en estadios precoces.

\section{FISTULA ARTERIOVENOSA TRAS ARTROPLASTIA DE RODILLA COMO CAUSA DE TROMBOSIS VENOSA PROFUNDA}

Vidal Blanco L, Ríos Prego M, Alves Pereira ED, Brea Aparicio R, Velo García A, Encabo González A, Chouza Piñeiro A, Míguez Silva F, Núñez Fernández Mu.

SERVICIO DE MEDICINA INTERNA. SERVICIO DE RADIOLOGÍA., COMPLEJO HOSPITALARIO UNIVERSITARIO DE PONTEVEDRA

INTRODUCCIÓN: Las lesiones vasculares después de la artroplastia de rodilla son muy raras. Las formas de presentación no agudas o diferidas tras la cirugía son: la isquemia, los aneurismaspseudoaneurismas y las fistulas arterio-venosas. La fístula arterio-venosa es la complicación iatrogénica menos frecuentes tras la artroplastia de rodilla, variando su presentación clínica, con dolor, tumefacción difusa de la pierna, masa pulsátil, hemartros e incluso isquemia. Presentamos un caso de fístula arterio-venosa a nivel de hueco poplíteo que debutó como trombosis venosa profunda

CASO CLÍNICO: Varón de 74 años, portador de factores de riesgo cardiovascular (obesidad, hipertensión arterial diabetes y dislipemia) y artroparía degenerativa intervenido de artroplastia en rodilla izquierda hacía 10 años, y artroplastia en rodilla derecha 5 meses antes de su atención en la consulta de Medicina Interna, donde había sido remitido con el diagnóstico de trombosis venosa profunda en pierna derecha. Había sido sometido a un ecodoppler que evidencia: vena femoral común, vena femoral superficial y cayado de la vena safena sin alteraciones; a nivel de la vena poplítea existe aumento de material ecogénico en su interior y ausencia de comprensibilidad. Se 
inicia tratamiento con heparina de bajo peso molecular ajustada a peso, con cambio a rivaroxaban a dosis habituales. En la ecografía vascular de control a los 4 meses de iniciado el tratamiento anticoagulante, no existen datos directos ni indirectos de trombosis venosa profunda a nivel poplíteo, y si la existencia de una pequeña fístula arteriovenosa a dicho nivel.

CONCLUSIONES: La afectación vascular diferida tras cirugía ortopédica de rodilla es muy infrecuente, siendo la fistula arteriovenosa la patología mas infrecuente de las descritas.

No tenemos constancia de la descripción de una trombosis venosa profunda como forma de presentación de una fístula arteriovenosa iatrogénica tras artroplastia.

\section{TASAS DE INCIDENCIA DE INGRESOS ASOCIADOS A SÍNDROME DE ABSTINENCIA ALCOHÓLICA EN GALICIA: ANALISIS DEL CMBD 1999-2010}

Ventura-Valcárcel P (1), Méndez-Gómez $R$ (1), Romay-Lema E (1), Pertega-Díaz S (2), Rabuñal-Rey $R(1)$, Monte-Secades $R(1)$.

SERVICIO DE MEDICINA INTERNA (1) Y SERVICIO DE EPIDEMIOLOGÍA Y ESTADISTICA (2), HOSPITAL UNIVERSITARIO LUCUS AUGUSTI, LUGO (1). COMPLEJO HOSPITALARIO UNIVERSTTARIO DEA CORUÑA (2).

INTRODUCCIÓN: las últimas encuestas sobre el uso de alcohol en España registran un descenso en la cantidad consumida en los últimos años. Sin embargo, no existen datos sobre la incidencia del síndrome de abstinencia alcohólica (SAA) en pacientes hospitalizados y su evolución en los últimos años.

OBETIV0: analizar la tendencia evolutiva y de las tasas de incidencia de los ingresos hospitalarios con SAA en Galicia en el periodo 1999-2010.

MATERIAL Y MÉTODO: se solicitó al Área de Información y Estadísticas Asistenciales del Instituto de Información Sanitaria del MSSSI de España, para extracción de la base de datos del CMBD de hospitales públicos, los ingresos hospitalarios con síndrome de abstinencia alcohólica (CIE9MC 291.81)/Delirio por abstinencia alcohólica (delirium tremens) (CIE9MC 291.0)/alucinosis po abstinencia alcohólica (CIE9MC 291.3), entre los años 1999 y 2010. Se analizaron las siguientes variables: edad, sexo, CCAA, fecha de ingreso y estado al alta. Se calcularon las tasas crudas ajustadas (x100.000 habitantes) de incidencia de ingresos asociados a SAA, totales y en función del sexo y los grupos de edad. Para el análisis estadístico se usó el programa SPSS

RESULTADOS: nn el periodo 1999-2010, se registraron en España 52951 ingresos de enfermos con diagnóstico principal o secundario de SAA, 87.86\% hombres. De estos, 7334 (13.85\%) se produjeron en Galicia, 83.3\% hombres, donde el número de ingresos anuales osciló entre un máximo de 695 en el año 2006 y un mínimo de 548 en 2010 (tabla 1). La tasa de incidencia ajustada global promedio de los 10 años fue 28.6 ingresos por 100.000 habitantes (50.4 en hombres y 8.5 en mujeres). La evolución de las tasas ajustadas de incidencia de ingresos asociados a SAA en Galicia a lo largo del periodo de estudio se muestra en la tabla2, en la que se aprecia 列 asociados a SAA según grupos de edad se muestran en la tabla3.

CONCLUSIONES: la incidencia de ingresos asociados a SAA en los hospitales del sistema sanitario público de Galicia presenta una tendencia a la disminución en la segunda mitad del periodo 19992010. Los ingresos se concentran en hombres y en la franja de edad 40-55 años.

\section{ESTUDIO DESCRIPTIVO DE HEMATOMAS EN PARTES BLANDAS NO TRAUMÁTICOS EN UN PERIODO DE DOS AÑOS}

Domínguez Rodríguez T, Piñeiro Parga P, Suárez Fuentetaja $R$, Verdeal Dacal $R$, Porto Pérez AB, Juane Cobián A, Doval Domínguez L, de la Iglesia Martínez F.

MEDICINA INTERNA, CHUAC, COMPLEXO HOSPITALARIO UNIVERSTTARIO DEA CORUÑA.

INTRODUCCIÓN: Los hematomas en partes blandas son un diagnóstico relativamente frecuente anto en pacientes procedentes de su domicilio como en pacientes ingresados en el hospital, principalmente en plantas de especialidades médicas. Suelen presentar factores predisponentes como el uso de fármacos anticoagulantes o antiagregantes o coagulopatías. La evolución clínica es muy variable, presentándose tanto como un hallazgo incidental como en situación de shock hemorrágico y muerte secundaria.

OBJETIVOS: El objetivo de este estudio es describir las características epidemiológicas de aquellos pacientes que desarrollan un hematoma de partes blandas no traumático así como los factores predisponentes y la mortalidad asociada a dicha patología en un hospital de tercer nivel.

MATERIAL Y MÉTODO: Se diseñó un estudio observacional retrospectivo incluyendo 73 pacientes que presentaron un hematoma en partes blandas no traumático como motivo de ingreso o durante su hospitalización por otra causa y cuya fecha de alta fue en los años 20140 2015. Se recogieron datos demográficos, clínicos, analíticos y terapéuticos y se analizaron con el paquete estadístico SPSS21. RESULTADOS: Los varones representaron el 43,8\% de la muestra ( $n=32$ ), presentando una edad media de 75,99 años. Entre sus antecedentes destacaban la presencia de hipertensión arteria $(75,3 \%)$, diabetes mellitus $(31,5 \%)$, dislipemia $(50,7 \%)$, sobrepeso/obesidad $(68,7 \%)$ y etilismo crónico (13,7\%). Un 21 9\% presentaba cardiopatía isquémica, un 34,2\% insuficiencia cardíaca, 23,3\% enfermedad cerebrovascular crónica el 9,6\% demencia y un 21,9\% enfermedad pulmona crónica. Resaltar también la presencia hepatopatía crónica en el 12,3\% de los casos, habiendo presentado en el 4,1\% del total complicaciones secundarias a la misma, y la presencia de neoplasia activa en los últimos 5 años en 10 pacientes. El 78,1\% ingresaron en Medicina Interna, el 13,7\% en otro servicio médico y solamente el $8,2 \%$ en un servicio quirúrgico. La localización más frecuente de los hematomas fue en abdomen y espalda (generalmente en músculos recto anterior y psoas ilíaco) hasta en el $47,9 \%$ de los casos, seguido de miembros interiores en el 31,5\% de los pacientes, siendo mucho menos frecuente en otras localizaciones como miembros superiores, axila o músculo pectoral. 19 pacientes habían estado ingresados en los últimos 30 días, 6 pacientes precisaron ingreso en una unidad de cuidados intensivos, 13 pacientes $(17,8 \%)$ fallecieron durante el ingreso ospitalario y $9(12,3 \%)$ en los primeros 30 días tras el alta.

CONCLUSIONES: Los hematomas en partes blandas no traumáticos: - Presentan una incidencia no desdeñable en las plantas de Medicina Interna. - Sus localizaciones más frecuentes son recto anterior, psoas iliaco y músculos de miembros inferiores. - En más del $25 \%$ de los caso se presentan en pacientes cuyo ingreso actual constituye un reingreso precoz - Presentan una mortalidad intrahospitalaria y precoz post-alta elevadas.

\section{MORTALIDAD Y FACTORES PRONÓSTICOS EN INFECCIONES URINARIAS POR PSEUDOMONAS AERUGINOSA}

Álvarez J, Lamas JL, González L, Arca A, Rodríguez I, Fernández M, Bermúdez JR, de la Fuente J. MEDICINA INTERNA, HOSPITALIZACIÓN A DOMICILIO, MICROBIOLOGÍA, POVISA.

INTRODUCCIÓN: Las infecciones del tracto urinario constituyen una de las patologías más prevalentes en los pacientes hospitalizados, suponiendo entre un 20 a un $49 \%$ de todas las infecciones nosocomiales. Dentro del ámbito hospitalario, el 7-10\% de las infecciones urinarias son producidas por Pseudomonas aeruginosa, con una mortalidad en aquellas asociadas a bacteriemia entre $5 \%-33 \%$.

OBJETIVOS: Analizar la mortalidad y factores pronósticos de las infecciones urinarias por Pseudomonas aeruginosa en pacientes hospitalizados.

MATERIAL Y MÉTODO: se incluyeron todos los pacientes ingresados en nuestro hospital entre Septiembre de 2012 y Septiembre de 2014 con diagnóstico de infección del tracto urinario por Pseudomonas aeruginosa. Se excluyeron los episodios repetidos en un mismo paciente y los casos de bacteriuria asintomática. Se creó una base de datos con diversas variables demográficas, clínicas y analíticas. Se evaluó la mortalidad por cualquier causa a los 30 días del diagnóstico. Se crearon curvas de Kaplan y Meier para el análisis de los factores asociados a mortalidad y se utilizó el test de Log-Rank para valorar la presencia de diferencias estadísticamente significativas entre los grupos. Se realizó un análisis multivariante mediante regresión de Cox.

RESULTADOS: se incluyeron 62 pacientes ingresados con diagnóstico de infección urinaria po Pseudomonas aeruginosa durante el tiempo de estudio, con una mediana de edad de 75 años, el $51 \%$ varones. El $27 \%$ de las infecciones fueron de adquisición comunitaria. El $8 \%$ presentaron criterios de sepsis grave o shock séptico en el momento del diagnóstico. El 27\% de las cepas de Pseudomonas aeruginosa fueron multirresistentes. La mortalidad por cualquier causa a los 30 días fue del $17,7 \%$. Los factores asociados a una menor supervivencia fueron la hepatopatía crónica con hipertensión portal $(P<0,01)$, la diabetes mellitus $(P=0,04)$, la insuficiencia renal crónica $(P=0,02)$, la presentación en forma de sepsis grave o shock séptico $(P<0,01)$, un índice de Charlson mayor de $3(\mathrm{P}=0,02)$ y el tratamiento antibiótico definitivo inadecuado $(\mathrm{P}<0,01)$. En el análisis multivariante los factores de riesgo de mortalidad con significación estadística fueron la hepatopatía crónica avanzada $(P<0,01)$, la diabetes mellitus $(P=0,04)$, la insuficiencia renal crónica $(P=0,03)$ y el tratamiento antibiótico definitivo inadecuado $(P=0,01)$.

CONCLUSIONES: las infecciones urinarias por Pseudomonas aeruginosa se asocian con una elevada mortalidad en pacientes hospitalizados, sobre todo en pacientes con importante comorbilidad como insuficiencia renal crónica, hepatopatía avanzada y diabetes mellitus. E tratamiento antibiótico inadecuado es un factor claramente asociado a un peor pronóstico en estos pacientes, por lo que es fundamental ajustar el tratamiento empírico inicial al antibiograma en el momento en el que esté disponible.

\section{ANÁLISIS DE LOS FACTORES PREDISPONENTES Y TRATAMIENTO DE LOS HEMATOMAS DE PARTES BLANDAS NO TRAUMÁTICOS EN UN HOSPITAL DE A CORUÑA}

Domínguez Rodríguez T, Verdeal Dacal R, Piñeiro Parga P, Suárez Fuentetaja R, Porto Pérez AB, Juane Cobián A, Doval Domínguez L de la Iglesia Martínez F. MEDICINA INTERNA, CHUAC, COMPLEXO HOSPITALARIO UNIVERSITARIO DEA CORUÑA.

INTRODUCCIÓN: Existen diversos factores predisponentes para cualquier tipo de hemorragia, entre los que destacan fármacos y diversas patologías como la hemofilia o la hepatopatía crónica. Sin embargo, no son muchos los estudios que evalúan los hematomas en partes blandas espontáneos ni analizan sus factores predisponentes.

OBJETIVOS: Describir la actitud diagnóstico-terapéutica realizada en pacientes adultos que desarrollaron un hematoma de partes blandas no traumático, así como su evolución clínica en un hospital de A Coruña.

MATERIAL Y MÉTODOS: Se diseñó un estudio observacional retrospectivo incluyendo 73 pacientes que presentaron un hematoma en partes blandas como motivo de ingreso o durante su hospitalización, y cuya fecha de alta fue en el año 20140 2015. Se recogieron datos demográficos, clínicos y terapéuticos. El análisis estadístico se realizó con SPSS21.

RESULTADOS: Los pacientes presentaban un índice de Charlson ajustado por edad medio de 5,4 y una estancia media de 17,2 días, teniendo el 49,3\% 80 o más años. 20 pacientes estaban antiagregados en su domicilio con AAS y solamente 2 con inhibidores 2PY12, ambos con clopidogrel. 36 estaban con tratamiento anticoagulante con acenocumarol, 1 con apixaban, otro con ribaroxaban y 9 con heparinas de bajo peso molecular (HBPM) (3 a dosis profiláctica, 5 a dosis anticoagulante y 1 dosis "intermedia"). En las 72 horas previas al sangrado, 22 estaban antiagregados con AAS, 6 con clopidogrel y 1 con prasugrel. Aumentaba entonces a 47 los pacientes que recibían tratamiento anticoagulante con HBPM ( 25 a dosis anticoagulante correcta 10 a dosis intermedias, 7 con dosis supraterapéutica y 5 a dosis profiláctica), reduciéndose a 23 los que estaban con acenocumarol y a 1 el que mantenía el inhibidor directo del factor Xa 4 episodios se produjeron con la reintroducción del acenocumarol tras terapia con HBPM y 8 durante la sustitución de acenocumarol por terapia puente con HBPM. El 71,2\% de los pacientes estaban con tratamiento al menos a dosis anticoagulante en las 72 horas previas al sangrado teniendo un HAS-BLED ( $\geq 3$ ) y CHA2DS2-VASc ( $\geq 2$ ) de alto riesgo el 42,3 y 98\% respectivamente. En el ámbito terapéutico, al $28,8 \%$ se les administró vitamina $K$ y al $11,0 \%$ complejo protrombínico. 35 pacientes precisaron transfusión de concentrados de hematíes $(\mathrm{CH})$, con una mediana de 4 $\mathrm{CH}$ administrados, 2 pacientes requirieron concentrados de plaquetas y otros 2 de plasma fresco congelado. El tratamiento del hematoma fue conservador en el $82,2 \%$, en el $11,0 \%$ se realizó embolización percutánea, en el 5,5\% cirugía y en 1 paciente embolización percutánea y cirugía. CONCLUSIONES: Los pacientes con hematomas en partes blandas no traumáticos: - Presentan ingresos con una estancia media prolongada. - El 16,4\% de los eventos se producen en las transiciones entre acenocumarol y HBPM. - El tratamiento conservador es el más utilizado, aunque la embolización percutánea es una alternativa terapéutica cada vez más empleada. 


\section{DÉFICIT DE VITAMINA D EN MÉDICOS INTERNOS RESIDENTES DEL COMPLEJO UNIVERSITARIO DE SANTIAGO DE COMPOSTELA}

Alende Castro V, Macia Rodríguez C, Garcia Villafranca A, Páez Guillán E, Beceiro Abad C, Carballo Fernández I, Vázquez Agra N, Pernas Pardavila H, González Quintela A. MEDICINA INTERNA, COMPLEXO HOSPITALARIO UNIVERSITARIO DE SANTIAGO DE COMPOSTELA.

INTRODUCCIÓN: El déficit subclínico de vitamina D (que cursa en ausencia de hipocalcemia e hipofosfatemia) se asocia a osteoporosis, aumento del riesgo de caídas y fracturas. El nivel óptimo de 25-hidroxivitamina D es controvertido, aunque se postula entre 20 y $40 \mathrm{ng} / \mathrm{ml}$. En el National Health and Nutrition Examination Survey (NHANES) de 2005 a 2006, el 42,6\% de los adultos mayores de 20 años presentaban niveles de hidroxivitamina D inferiores a $20 \mathrm{ng} / \mathrm{ml}$.

OBJETIVOS: Analizar los niveles de vitamina D en el colectivo de médicos internos residentes de Santiago de Compostela.

MÉTODOS: Estudio prospectivo en el que se incluyeron médicos internos residentes que desempeñan su labor asistencial en el Complexo Hospitalario Universitario de Santiago de Compostela. Se recogieron variables epidemiológicas y analíticas.

RESULTADOS: Se incluyeron 32 médicos internos residentes (81,2\% mujeres) con una edad media de 27,80 + 2,09 años. Las especialidades a las que pertenecían fueron: Medicina Interna Reumatología, Oncología Médica, Oncología Radioterápica, Reumatología, Psiquiatría, Cardiología Neurología, Medicina de Familia, Cirugía Vascular, Cirugía General, Otorrinolaringología, Neumología Digestivo, Pediatria y Medicina Intensiva. El 100\% presentó niveles de 25 hidroxivitamina D menor o igual a $20 \mathrm{ng} / \mathrm{ml}$. En dos de los casos, los niveles de 25 hidroxivitamina D fueron indetectables. En los 30 casos restantes, la media fue de 10,3 $\pm 4,6 \mathrm{ng} / \mathrm{ml}$

CONCLUSIONES: el 100\% de los Médicos Internos Residentes de Santiago de Compostela presentaron niveles deficientes de vitamina $\mathrm{D}$, dato superior a la prevalencia descrita para la población genera.

\section{ALTERACIONES ANALITICAS SECUNDARIAS A LA INFECCIÓN POR EL VIRUS INFLUENZA}

Vázquez Agra N, Alende Castro V, Macía Ríos C, García Villafranca A, Páez Guillán EM, Novo Veleiro I, González Quintela A.

MEDICINA INTERNA, COMPLEJO HOSPITALARIO UNIVERSITARO DE SANTIAGO DE COMPOSTELA.

INTRODUCCIÓN: La infección por las cepas del virus de la gripe suelen causar un cuadro de vías respiratorias superiores en forma de brotes epidémicos, asociando síntomas de afectación sistémica como son la cefalea, la fiebre, las mialgias o la afectación del estado general. Aunque descritas, no existe literatura acerca de manifestaciones como la elevación de enzimas hepáticas en relación a daño hepatocelular y alteraciones analíticas como la leucopenia, descritas para otras infecciones víricas.

OBJETIVOS: Analizar la frecuencia y grado de afectación hepática en pacientes infectados por el virus de la gripe, así como otras alteraciones analíticas relevantes y su relación con la cepa detectada a lo largo de un ciclo epidémico.

MÉTODOS: Estudio retrospectivo en el que se incluyeron pacientes ingresados desde el 1 de enero al 31 de marzo de 2016 con diagnóstico de infección por virus Influenza en el Hospital de Santiago de Compostela. Se recogieron variables epidemiológicas, clínicas, analíticas y microbiológicas. Se realizó un análisis descriptivo y se determinó la asociación entre las alteraciones encontradas y la cepa detectada.

RESULTADOS: Se incluyeron 53 pacientes (56,6\% mujeres) con una edad media de 58,42 \pm 15,26 años. El 98,1\% de los pacientes presentaba un Índice de Barthel mayor de 20 puntos. Un 3,8\% de los pacientes requirió ingreso en UCl y ninguno de los pacientes falleció. En cuanto a comorbilidades, observamos: exfumador $45,3 \%$, obesidad 45,3\%, EPOC/ASMA en el 32,1\%, insuficiencia renal crónica $18,9 \%$, insuficiencia cardiaca $7,5 \%$ y hepatopatía $5,7 \%$. En cuanto a la microbiología en el 96,2\% la infección fue causada por el virus Influenza A y en el 3,8\% po el virus Influenza B. En cuanto a las alteraciones analíticas, el 64,2\% presentaron alteraciones en cuanto a los valores de transaminasas o bilirrubina(Si GOT > $37 \mathrm{U} / \mathrm{l} 0 \mathrm{GPT}>31 \mathrm{U} / \mathrm{l}$ o GGT $>$ $38 \mathrm{U} / \mathrm{l}$ o FAL > $263 \mathrm{U} / \mathrm{l}$ o Bilirrubina total $>1,2 \mathrm{mg} / \mathrm{dl}$ ). El 84,9\% presentó alguna alteración de hemograma. Los hallazgos fueron: 28,8\% plaquetopenia $(<130.000), 69,8 \%$ linfopenia $(<1.000)$ y 3,8\% leucopenia (< 4.000). En ningún paciente se objetivó neutropenia. En el análisis univariante se demostró una asociación estadísticamente significativa entre la cifra mínima de linfocitos y la cepa Influenza A $(p=0,039)$

CONCLUSIONES: La infección del virus de la gripe cursó en el 84,9\% con alteraciones en e hemograma y en el 64,2\% con algún dato de daño hepático. La cepa Influenza A mostró asociación significativa con la linfopenia. Ninguna de las cepas se asoció a mortalidad o necesidad de ingreso en UCl.

\section{LA BRUCELOSIS DE SANTA TERESA DE JESÚS Y ANTONI GAUDÍ: DOS MISTICOS Y UNA ENFERMEDAD}

Montes-Santiago J.

MEDICINA INTERNA, COMPLEJO HOSPITALARIO UNIVERSITARIO. VIGO

INTRODUCCIÓN: La brucelosis está producida por el género Brucella y cursa con un cuadro febril y afectación articular, con posible compromiso del sistema nervioso. No tratada puede ser mortal y con frecuencia sigue un curso crónico. Aquí se estudia su repercusión en las vidas de 2 figuras señeras en tiempos cuyo tratamiento no era posible.

MÉTOD0: Estudio patobiográfico de 2 eminentes figuras en la cultura de España.

RESULTADOS: Santa Teresa de Jesús (1527-1582). Tras profesar en el convento de la Encarnación en Ávila presentó a los 23 años un episodio brusco de pérdida de conciencia durante 4 días, dándosela incluso por muerta. Durante su vida, padeció de dolores múltiples, desvanecimientos, fiebres, parálisis, anemia... que la llevaron con frecuencia al borde de la muerte. "Arsenal de enfermedades" según su médico Antonio Aguiar de Burgos. No obstante fue una persona con agudo sentido del humor, admirada por personajes como el Duque de Alba, la Princesa de Éboli 0 el mismo Felipe II. No se arredró incluso ante la Inquisición -fémina inquieta y andariega la tildaron sus enemigos- $y$, a pesar de sus achaques, desarrollo una infatigable actividad reformadora literaria y mística. Analizadas sus dolencias por ilustres médicos -Nóvoa Santos, García-Albea, Alonso Fernández, Marañón, Barbado etc. las conclusiones son diversas: histeria, depresión, epilepsia, infarto de miocardio, Parkinson... Pero el episodio de desvanecimiento y achaques posteriores se han argumentado como debidos a neurobrucelosis (A. Senra). Tal enfermedad era endémica en Castilla.

Antoni Gaudí (1852-1926). El universalmente reconocido arquitecto fue un niño frágil diagnosticado de reumatismo a los 6 años. Ello y la influencia de su padre le inclinaron, tras una fase de dandy en su juventud, a seguir una vida natural con dieta vegetariana y ejercicio físico intenso. Tal pensamiento inspiró siempre su vida pues estimaba que la originalidad era estudiar y copia la naturaleza. Probablemente ello también estuvo en el riesgo de consumir leche natural sin pasteurizar, mecanismo probable de adquisición de la brucelosis (1911). Tras realizar obras como EI Capricho (Comillas), el Parque y Colonia Güell, la casa Milá y La Pedrera, tal enfermedad le hizo retirarse a la montaña y fue determinante en retomar una vida más ascética y dedicar el resto de su vida al Proyecto de la Sagrada Familia. Falleció en el Hospital de San Pau, 3 días después de ser arrollado por un tranvía.

CONCLUSIONES: La supuesta brucelosis introdujo profundos cambios en las vidas de ambos personajes. En Teresa de Jesús se sitúa en el comienzo de su actividad reformadora y sus secuelas estarán presentes -y para algunos serán determinantes- de su frenética actividad posterior. En Gaudí, tras su recuperación, condicionará de forma preeminente su decisión de una vida ascética y su compromiso casi exclusivo con el proyecto de la Sagrada Familia.

\section{ESTUDIO DESCRIPTIVO SOBRE PERITONITIS BACTERIANA ESPONTÁNEA (PBE) EN PACIENTES CON HEPATOPATÍA CRÓNICA DURANTE EL PERIODO COMPRENDIDO ENTRE 2011-2015 EN EL COMPLEJO HOSPITALARIO UNIVERSITARIO DE A CORUÑA}

Suárez Fuentetaja R, Yáñez González-Dopeso L, Suárez López F, Verdeal Dacal $R$ SERVICIO DE MEDIIINA INTERNA. SERVICIO DE DIGESTIVO, COMPLEJO HOSPITALARIO UNIIERSITARIO DEA CORUÑA.

INTRODUCCIÓN: La PBE es una entidad de gran relevancia en la práctica clínica por su elevada prevalencia en los pacientes cirróticos hospitalizados, con una alta tasa de recurrencia y mortalidad en el primer año tras su diagnóstico.

OBJETIVOS: Describir las características epidemiológicas de los pacientes con PBE en una muestra de pacientes cirróticos ingresados por cualquier causa en una planta médica.

MATERIAL Y MÉTODO: Estudio observacional transversal sobre una muestra de 76 pacientes con PBE ingresados por cualquier causa en un hospital de tercer nivel entre el 1 de Enero de 2011 y el 31 de Diciembre de 2015. Se recogieron datos demográficos, clínicos, analíticos y terapéuticos a través de la historia clínica informatizada. Las variables fueron analizadas mediante el paquete estadístico SPSS21.

RESULTADOS: Se ha analizado una población de 76 pacientes de los cuales el el 55,3\% eran hombres ( $n=42)$, con una edad media de 63 años (DT 14,5). El 43,4\% ( $n=33)$ ingresó en el Servicio de Digestivo, el 39,5\% ( $n=30)$ en Medicina Interna y el 13,2\% $(n=10)$ en UCl. Se trata de una muestra con mucha comorbilidad asociada reflejado a través de un Índice de Charlson medio de $5,46 \%$ (DT 2,541). La cirrosis era conocida previamente al ingreso en el $86,8 \%$ de los casos. Etiología alcohólica en el $56 \%$ ( $n=42)$, mixta en el $14,5 \%$ de los casos $(n=11)$, secundaria a infección crónica por VHC en el $20 \%(n=15)$ y autoinmune en el $4 \%(n=3)$. Referían consumo de alcohol de forma activa el 28,9\% $(n=22)$ de los pacientes, exbebedor crónico el 40,8\% ( $n=31)$ y nunca bebedor el $30,3 \%(n=23)$. El 56,6\% de la muestra se encontraba en estadio $C$ en la clasificación de Child-Pugh La puntuación media en la escala MEI D fue de 20 (DT 9,5).En relación con las complicaciones en el contexto de su hepatopatía crónica, el 17,1\% $(n=13)$ presentaban hepatocarcinoma al diagnóstico de la PBE, hemorragia digestiva en los 7 días previos a la PBE el $19,7 \%(n=15)$ e insuficiencia renal aguda el $64 \%$. No presentaba antecedentes de PBE previa e $96,1 \%(n=73)$ ni recibían profilaxis con Norfloxacino el 92,1\% $(n=70)$. En términos de mortalidad, el $72,4 \%$ había fallecido en el momento de la recogida de datos; de ellos, el $43,6 \%$ presentaban PBE no resuelta en el momento del fallecimiento.

CONCLUSIONES: Se trata de una patología que afecta a una población jóven,con predominio por el sexo masculino. La etiología alcohólica es la más frecuente. Son pacientes pluripatológicos, con una hepatopatía severa manifiesta por medio de la escala de CHILD- PUHG y MELD. La PBE se relaciona con un elevado número de complicaciones intrahospitalarias y, secundario a ello, una alta mortalidad tanto en el momento agudo de la PBE, como tras la resolución de la misma. Estos hallazgos se encuentran en concordancia con la bibliografía consultada.

\section{ESTUDIO DESCRIPTIVO SOBRE PERITONITIS BACTERIANA ESPONTÁNEA (PBE) DESDE EL PUNTO DE VISTA MICROBIOLOGICO}

Suárez Fuentetaja R, Yáñez Gonzalez-Dopeso L, Suárez López F, Verdeal Dacal $R$ SERVICIO DE MEDICINA INTERNA. SERVICIO DE DIGESTIVO. COMPLEJO HOSPITALARIO UNIVERSTTARIO DEA CORUNA.

INTRODUCCIÓN: La PBE es una de las complicaciones infecciosas más graves de la cirrosis y una de las causas más frecuentes de morbimortalidad en estos pacientes. El adecuado y rápido manejo de la misma ha disminuído de forma drástica la mortalidad observada en las últimas décadas. OBJETIVOS: Describir las características epidemiológicas desde el punto de vista infeccioso de los pacientes cirróticos con PBE ingresados por causa médica.

MATERIAL Y MÉTODOS: Estudio observacional retrospectivo sobre una cohorte de 76 pacientes con PBE ingresados por cualquier causa entre el 1 de Enero de 2011 y el 31 de Diciembre de 2015, en un hospital de tercer nivel. El diagnóstico de PBE se hizo al documentar la presencia de $\mathrm{PMN}>250 / \mathrm{mm} 3$ en el líquido ascítico (LA). Se recogieron datos demográficos, clínicos, analíticos 
y terapéuticos a través de la historia clínica informatizada. Las variables fueron analizadas mediante el paquete estadístico SPSS21.

RESULTADOS: Analizamos variables relacionadas con riesgo para infección por microorganismos resistentes (MR): el 98,7\%\% ( $n=74$ ) no presentaron colonización por (MR) los 3 meses previos a la PBE. El 22,7\% había recibido betalactámicos en los 3 meses previos a la PBE $(n=58)$ y el 14,7\% de los pacientes había recibido otro tipo de antibioterapia diferente a este grupo de antibióticos en ese mismo periodo. El 51,3\% (=39) habían sido sometidos a paracentesis previamente, pero sólo el 3,9\% de ellos presentaron PBE con anterioridad, tratada con ceftriaxona en todos los casos. Adquisición comunitaria en el $53,9 \%(n=41)$, asociada a cuidados sanitarios en el $23,7 \%$ $(n=18)$, y nosocomial en el 22,4\% ( $n=17)$. Se recogió cultivo de LA en el $90,5 \%(n=67)$. De ellos, el $41,8 \%$ presentaron hallazgos microbiológicos positivos para microorganismos sensibles a antibioterapia empírica, el $6 \%$ fue positivo para microorganismos resistentes, y en el $52,2 \%$ no se aisló microorganismo causal. Escherichia coli representa el aislamiento microbiológico más frecuente $(46,5 \%, n=20)$, seguido por Estreptococcus sp en el 20,9\% $(n=11,8)$ y Stafilococcus sp en el $4,7 \%$ (n=2). Al 36\% se le retiraron hemocultivos de forma simultánea, presentando bacteriemia el 29,6\%. Como antibioterapia de primera línea se admnistró ceftriaxona en el 74,6\% $(n=53)$, carbapenémicos en el $7 \%(n=5)$, quinolonas también en el $7 \%(n=5)$ y piperacilinatazobactam en el $5,6 \%(n=4)$. El $72,4 \%$ habían fallecido en el momento de la recogida de datos; de ellos, el 43,6\% presentaban PBE no resuelta en el momento del fallecimiento.

CONCLUSIONES: Resaltar la importancia de la antibioterapia empírica precoz frente a microorganismos habituales causantes de PBE inmediatamente después de su diagnóstico, así como la adecuación de dicha antibioterapia en función de resultados microbiológicos y antibiograma. Para ello es imprescindible la toma de muestras para cultivo.

\section{HIPERGLUCEMIA BASAL AL INGRESO COMO FACTOR PREDICTOR DE MORTALIDAD EN PACIENTES MÉDICOS HOSPITALIZADOS}

Conde S, Mena A, Seoane B, Nicolás R, Penado S, Ramos V, de la Iglesia F. UNIDAD DE CORTA ESTANCIA MÉDICA SERVICIO DE MEDICINA INTERNA.

HOSPITAL UNIVERSTTARIO DEA CORUÑA.

INTRODUCCIÓN: La hiperglucemia basal al ingreso (HBI) es un factor pronóstico independiente caracterizado en diversas patologías médicas como cardiopatía isquémica, enfermedad cerebrovascular o sepsis

OBJETIVOS: Evaluar la asociación entre HBI y la mortalidad intrahospitalaria y a largo plazo en pacientes médicos hospitalizados

MATERIALES Y MÉTODOS: Estudio retrospectivo, observacional, que incluyó pacientes consecutivos hospitalizados durante el año 2015 en una unidad de corta estancia médica. Se definió hiperglucemia como glucemia $\geq 126$. Las variables cualitativas se compararon mediante chi cuadrado y las cuantitativas mediante t de Student. Se utilizó regresión logística para evalua las variables asociadas a mortalidad.

RESULTADOS: Se incluyeron un total de 1000 pacientes (56,9\% varones, edad media $73,8 \pm 13,0$ ). Los principales diagnósticos fueron: infección respiratoria/neumonía (17,3\%), insuficiencia cardiaca (16\%), y cardiopatía isquémica (12,0\%). El 92,2\% de los ingresos procedían del servicio de Urgencias . El 28 , $8 \%$ eran diabéticos (HbA1c $6.35 \pm 1,38$ ). Presentaron $\mathrm{HBl}$ un $34.2 \%$. La mortalidad intrahospitalaria fue del $2,5 \%$ y la mortalidad total del $21,0 \%$, con un seguimiento medio de 1 año. Respecto a la mortalidad intrahospitalaria, un $64,0 \%$ de los pacientes presentaban HBI (OR 3,55, IC 1,55-8,12; p 0,002), sin alcanzarse significación estadística en el análisis multivariante. Los factores asociados de manera independiente a mortalidad durante el seguimiento fueron (OR, IC95\%; p): HBI $(3,05,2,06-4,48 ;<0,001)$, índice de Charlson $(1,58,1,41-1,77 ;<0,001)$ y albúmina $(0,35,0,22-0,55 ;<0,001)$. La estancia media fue de $6,1 \pm 5,4$ en pacientes con glucemias $<126$ al ingreso frente a 7,2 $\pm 7,1$ en pacientes con $\mathrm{HBI}$.

CONCLUSIONES: La HBI es predictor de mortalidad en los pacientes hospitalizados en una unidad de corta estancia médica. Se relaciona además con estancias medias más prolongadas.

\section{HIPOTIROIDISMO POSTHEMITIROIDECTOMÍA: FACTORES DE RIESGO}

García Poutón N, Boente Varela R, Trigo Barros C, Lamas Ferreiro JL, Álvarez Otero J, Gondar Barcala T, Fernández Castro I de la Fuente Aguado J.

MEDICINA INTERNA. ENDOCRINOLOGÍA, POVISA.

INTRODUCCIÓN: El hipotiroidismo es la complicación más frecuente en los pacientes sometidos a hemitiroidectomía. Se han descrito factores de riesgo asociados, como la presencia de autoinmunidad o el valor de la TSH previa. El tiempo de desarrollo de hipotiroidismo después de la cirugía no está del todo definido, y en general se trata precozmente lo cual impide la valoración de su evolución natural.

OBJETIVOS: Descripción de la prevalencia y de los factores de riesgo de desarrollo de hipotiroidismo en pacientes sometidos a hemitiroidectomía en nuestro hospital y análisis de su manejo clínico y terapéutico.

MATERIAL Y MÉTODOS: Estudio retrospectivo en el que se incluyen a 89 pacientes sometidos a hemitiroidectomía desde 2010 a 2014. Los parámetros registrados para el riesgo de desarrollo de hipotiroidismo fueron sexo, edad, presencia de autoinmunidad, TSH previa a la cirugía e histología Evaluamos el tratamiento implementado y el tiempo de seguimiento en cada caso.

RESULTADOS: Incluímos a 89 pacientes, $86.5 \%$ mujeres y $13.5 \%$ hombres. El diagnóstico previo más frecuente fue el de adenoma nodular (58.4\%) seguido de bocio multinodular (32.6\%). El tiempo medio de seguimiento fue de 28.5 meses, durante el cual 35 pacientes de los 89 totales del estudio desarrollaron hipotiroidismo postcirugía (39.3\%). De esos pacientes, 29 presentaron hipotiroidismo subclínico y 6 hipotiroidismo franco. El tiempo medio hasta el desarrollo del hipotirodismo fue de 8.67 meses. Se trataron al 80\% de los pacientes con TSH por encima del límite alto de la normalidad. En el análisis univariante resulta significativa para la aparición de hipotiroidismo el sexo femenino (OR 0.115; IC 95\% IC 0.14-0.938: $p=0.018$ ) y la TSH previa a la cirugía mayor de 2.0 U/ml (OR 3.15; IC 95\% 1.235-7.857; $p=0.014$ ); el resto de parámetros no fueron significativos. En el análisis multivariante el único factor de riesgo independiente de desarrollo de hipotiroidismo fue la TSH mayor de 2 U/ml (OR 3.029; IC 95\% 1.199-7.651; $p=0.019$ )
CONCLUSIONES: El hipotiroidismo postquirúrgico está descrito entre el 5.6 y el $48.9 \%$ de lo casos sometidos a hemitiroidectomía, y en nuestro estudio se objetivó una prevalencia de $39.32 \%$. Se han relacionado como factores de riesgo de una manera significativa el sexo femenino y la TSH mayor de $2 \mathrm{U} / \mathrm{ml}$, en comparación con otros descritos como la presencia de tiroiditis de Hashimoto previa o la presencia de autoanticuerpos. Estudios recientes especulan acerca de la importancia de evitar el tratamiento precoz (TSH $<10 \mathrm{U} / \mathrm{ml}$ ) y un tiempo de seguimiento largo hasta 9 meses, debido a la demostración de casos con resolución de hipotiroidismo pasada la fase aguda postintervención. En nuestro trabajo hemos visto que se realiza un tratamiento precoz del hipotiroidismo subclínico en pacientes asintomáticos. Ante la evidencia descrita puede ser beneficioso prolongar el tiempo de seguimiento sin tratamiento y permitir la recuperación natural de la hormona.

\section{BALANCE POSITIVO DE FÓSFORO COMO FACTOR DE RIESGO VASCULAR EN PACIENTES CON ENFERMEDAD}

Verdeal Dacal R, Suárez Fuentetaja R, Porto Pérez AB, Pérez Piñeiro A, Domínguez Rodríguez T, Arévalo Gómez A, Barbagelata López C, Rodríguez González A, Llinares García D. Freire Castro S. SERVICIO DE MEDICINA INTERNA., COMPLEJO HOSPITALARIO UNIVERSITARIO DEA CORUÑA, A CORUÑA.

INTRODUCCIÓN: Los pacientes con Enfermedad Renal Crónica (ERC) están expuestos a una elevada morbimortalidad cardiovascular no atribuible únicamente a los factores de riesgo tradicionales. Entre los factores de riesgo no clásicos cada vez tienen más peso las alteraciones del Metabolismo Óseo Mineral (MOM). En estos enfermos, y desde las fases tempranas de su enfermedad, existe un balance positivo de fósforo, a pesar de que los niveles séricos apenas sufren alteraciones hasta los estadíos finales de la enfermedad.

OBJETIVOS: En este estudio pretendemos retratar las alteraciones del MOM en pacientes con ERC estadíos 3 y 4 que ingresan en una Unidad de Medicina Interna, poniendo el foco en las alteraciones que presentan en el fósforo sérico y en el Índice de Excreción de Fósforo (IEP).

MATERIAL Y MÉTODO: Estudio observacional transversal de 76 eventos en 72 pacientes con ERC estadíos 3 y 4 de la K/DOQI que motivaban su ingreso en una Unidad de Medicina Interna del Complexo Hospitalario Universitario A Coruña de forma consecutiva entre los meses de abril y noviembre de 2015. Documentamos datos demográficos, clínicos, analíticos y terapéuticos. Las variables han sido analizadas con el paquete estadístico SPSS2

RESULTADOS: Los varones representaron el 43,3\% de los ingresos. De todos ellos, 63 pacientes (82,9\%) eran hipertensos, 30 (39,5\%) diabéticos, 49 (64,5\%) dislipémicos y 26 (34,2\%) fumadores 0 exfumadores. Su comorbilidad, analizada con el Índice de Charlson modificado por edad, era de 6,84 de media. Según su estadio K/DOQI un 30,3\% de los eventos se dio en pacientes estadio 3a, un $53,9 \%$ en estadio 3 b y un $15,8 \%$ en estadio 4 . A medida que se reduce el Filtrado Glomerular Estimado (FGe) se observa una tendencia a aumentar la fosforemia, pero especialmente cuando cae por debajo de $20 \mathrm{ml} / \mathrm{min}$. Los niveles se mantienen en la normalidad hasta en el 85,53\% de Ios casos. Por su parte, el análisis del IEP en orina muestras un progresivo incremento ya desde estadios más precoces de la enfermedad, reflejando el mayor esfuerzo de las nefronas remanentes para aclarar el fósforo del organismo.

CONCLUSIONES: - El balance positivo de fósforo que se da desde las fases precoces de la ERC es un reconocido promotor y acelerador del daño endotelial a través del eje Fósforo-FGF23/KlothoPTH. Los niveles de fósforo sérico no son útiles para detectar de forma temprana estas alteraciones. El sobreesfuerzo glomerular por aclarar este balance de fósforo se refleja analíticamente en e IEP desde estadios precoces de la enfermedad. - Los pacientes con ERC que ingresan en Servicios de Medicina Interna presentan desde fases tempranas de su enfermedad alteraciones del MOM. Aconsejamos implementar las guías de práctica clínica e incluir un estudio dirigido en este sentido desde el estadío 3 (K/DOQI).

\section{EXPERIENCIA CON BEVACIZUMAB \\ EN TELANGIECTASIA HEMORRÁGICA HEREDITARIA}

Gondar Barcala T, Cid Gómez D, González Vázquez L, Martínez Egido I (1), Fernández Villaverde A (2). Vázquez López S (2), González González L, de la Fuente Aguado J.

MEDICINA INTERNA, ORL (1) Y APARATO DIGESTIVO (2).. POVISA.

OBJETIVOS: describir las características clínicas y evolutivas de 2 pacientes con THH con indicación de tratamiento con Bevacizumab como uso compasivo por la imposibilidad de controlar su sintomatología con tratamientos locales o con otros fármacos sistémicos, por los altos requerimientos transfusionales.

MATERIAL Y MÉTODOS: presentación de los casos clínicos y revisión de la literatura.

RESULTADOS: Caso 1: varón de 54 años con antecedentes de EPOC severo, TEP, HTA y miocardiopatía hipertensiva; epixtasis de repetición con anemia ferropénica varios años de evolución. Cumplía 4 criterios de Curaçao de enfermedad de Rendu Osler con múltiples ingresos por anemia severa con angor e insuficiencia cardiaca, precisando en 5 años la transfusión de un total de 166 concentrados de hematíes y la realización de 10 endoscopias. Se solicitó uso compasivo de Bevacizumab a dosis de $5 \mathrm{mg} / \mathrm{kg}$ cada 2 semanas. Dese entonces solo precisó la transfusión de 5 concentrados de hematíes, el último hace 35 meses. No ha vuelto a presentar episodios de insuficiencia cardiaca y la última hemoglobina es de $15.5 \mathrm{~g} / \mathrm{dl}$. Se ha disminuido la dosis a 2.5mg/kg manteniendo la eficacia. Caso 2: mujer de 80 años con antecedentes de epixtasis de repetición desde la infancia y varios ingresos desde los 72 años por anemia severa ferropénica. Cumple 3 criterios de Curaçao de enfermedad de Rendu Osler. Precisó los últimos dos años la transfusión de 44 concentrados de hematíes y la realización de 12 endoscopias. Se solicitó uso compasivo de Bevacizumab a dosis de $2.5 \mathrm{mg} / \mathrm{kg}$ cada dos semanas con muy buena evolución. Desde el inicio del tratamiento hace 5 meses, solo se han transfundido dos concentrados de hematíes.

CONCLUSIONES: el Bevacizumab permitió la reducción de las necesidades transfusionales de forma drástica en nuestros pacientes, cuando otros tratamientos locales y sistémicos se mostraron inefectivos. La tolerancia del fármaco a las dosis administradas ha sido muy buena sin efectos secundarios relevantes. 


\section{FACTORES ASOCIADOS A MORTALIDAD PRECOZ EN PACIENTES FALLECIDOS DURANTE EL INGRESO EN UNA UNIDAD DE CRÓNICOS DE MEDICINA INTERNA}

Sardina-Ferreiro R, Gómez-Buela I, Vázquez-Vigo R, Caínzos-Romero T, Sánchez-Trigo S, Gómez-Gigirey A, Ferreira-González L.

SERVICIO DE MEDICINA INTERNA., COMPLEJO HOSPITALARIO UNIVERSITARIO DE FERROL.

OBJETIVO: Descubrir posibles factores relacionados con la mortalidad precoz en pacientes ingresados en una Unidad de Crónicos de Medicina Interna.

MATERIAL Y MÉTODOS: Estudio de cohortes retrospectivo. Población: pacientes fallecidos durante el ingreso en la Unidad de Crónicos del Servicio de Medicina Interna del CHU de Ferrol. Período de estudio: 15/3/2015 a 15/3/2016. Grupos: Mortalidad precoz: aquellos pacientes que fallecieron en las primeras 72 horas tras el ingreso. Objetivo principal: causas de mortalidad precoz. Objetivos secundarios: tiempo hasta la muerte durante el ingreso. T-student para comparación de variables cuantitativas, Chi2/Fischer para cualitativas. Curvas de Kaplan-Meier para supervivencia. Regresión de Cox para análisis multivariante. Análisis con Stata 13.0 para Mac.

RESULTADOS: Se analizaron 114 pacientes de los que $34(29,9 \%)$ murieron precozmente. No encontramos relación estadísticamente significativa entre mortalidad precoz y edad, sexo institucionalización, demencia, polifarmacia o número de ingresos en el año previo. Tampoco la administración de sedación paliativa se asoció con mortalidad precoz Existió una mayor mortalidad precoz en aquellos pacientes en los que la sedación la indicó el médico de guardia en lugar del médico de planta ( $20 \%$ vs $41 \%$; $p=0.09$ ) y sin embargo en aquellos con indicación de rescates sedantes no pautados la mortalidad precoz fue menor ( $19,2 \%$ vs $45 \%$; $p=0.06$ ). De los pacientes con mortalidad precoz en el 34\% estaban recogidos en la HC los síntomas para sedación, frente al $25,8 \%$ en que no constaban. Por otro lado, en un $40 \%$ constaba información a la familia frente al $28,8 \%$ que no constaba. En cuanto a comorbilidad, los pacientes con mortalidad precoz presentaban un IC mayor pero sin diferencias estadísticamente significativas $(9,9 \pm 11,7$ vs 7,7 $\pm 2,1 ; p=0.1)$. En el análisis multivariante y tras ajustar por comorbilidad y sexo, los pacientes institucionalizados presentaron un menor tiempo hasta la muerte (Hazard ratio: 2.04 (IC 95\%:1.053.97).

CONCLUSIONES: No hemos encontrado factores que se asocien a una mortalidad precoz. Los pacientes institucionalizados tienen una menor supervivencia durante su ingreso final.

\section{DIFERENCIAS EN EL METABOLISMO CALCIO-FÓSFORO EN PACIENTE INGRESADOS POR EVENTO VASCULAR 0 TROMBÓTICO FRENTE A OTROS DIAGNÓSTICOS}

Verdeal Dacal R, Pérez Piñeiro A, Suárez Fuentetaja R, Porto Pérez AB, Piñeiro Parga P, Arévalo Gómez A, Barbagelata López C, Rodríguez González A, Llinares García D, Freire Castro S. MEDICINA INTERNA, COMPLEJO HOSPITALARIO UNIVERSITARIO DE LA CORUÑNA.

INTRODUCCIÓN: Los pacientes con Enfermedad Renal Crónica (ERC) están expuestos a un elevado resgo vascular que justifica en gran medida su elevada morbimortalidad. Las alteraciones de Metabolismo Óseo Mineral (MOM) en el eje Fósforo-GFG23/Klotho-PTH se han convertido en protagonista principal en la fisiopatología de su enfermedad vascular. Las alteraciones en calcio, fósforo, 25(OH)vitamina D, FGF23 y PTHi se presentan como marcadores pronósticos en la literatura.

OBJETIVOS: El objetivo de este estudio es describir los factores de riesgo vascular y las principales determinaciones del MOM en una población con Enfermedad Renal Crónica (ERC) estadios 3 y 4 que ingresa en una Unidad de Medicina interna por un evento vascular o trombótico. MATERIAL Y MÉTOD0: Estudio observacional transversal de 76 ingresos (en 72 pacientes) con ERC estadíos 3 y 4 (K/DOQl) ingresados por causa vascular o trombótica, insuficiencia cardíaca y enfermedad pulmonar crónica en una Unidad de Medicina Interna del Complexo Hospitalario Universitario A Coruña de forma consecutiva entre los meses de Abril y Noviembre de 2015. Documentamos datos demográficos, clínicos, analíticos y terapéuticos y las variables fueron analizadas mediante el paquete estadístico SPSS21.

RESULTADOS: Los pacientes del grupo que ingresaban por eventos vasculares o trombóticos enían con mayor frecuencia diabetes mellitus ( $46,7 \%$ vs $37,7 \%$ ), dislipemia ( $80,0 \%$ vs $60,7 \%$, hiperuricemia (93,3\% vs $86,9 \%$ ) y enfermedad vascular establecida (arteriopatía periférica $20,0 \%$ vs $9,8 \%$, cardiopatía isquémica $46,7 \%$ vs $23,0 \%$, enfermedad cerebrovascular $26,7 \%$ vs $18,0 \%$ ). Estos pacientes son más jóvenes ( 79,08 vs 81,14 años) e ingresaron con un Filtrado Glomerula Estimado (FGe) menos reducido. De ahí que en esta muestra se obtenga una menor alteración en I MOM: valores de PTH (102,87 vs 179,88), fosfatemia $(3,44$ vs 3,90) e índice de excreción de fósforo $(0,73$ vs 1,15$)$ menores, manteniéndose la calcemia $(8,97$ vs 9,03$)$ y los niveles de $25(\mathrm{OH})$ vitamina $\mathrm{D}(13,4$ vs 12,38$)$ similares.

CONCLUSIONES: En nuestra muestra los pacientes cuyo diagnóstico principal es un evento vascular o trombótico no presentan una función renal basal más deteriorada ni tampoco un mayor balance positivo de fósforo. Probablemente sea al ampliar la muestra cuando se pueda observar cambios significativos en el perfil de función renal y MOM de los pacientes que ingresan por eventos vasculares en planta de hospitalización de Medicina Interna.

\section{SARCOIDOSIS-LIKE COMO REACCIÓN PARADÓJICA A TRATAMIENTO CON ADALIMUMAB: A PROPÓSITO DE UN CASO}

González Vázquez L, Gondar Barcala T, Fernández Villaverde A (1), Valle Feijoó L, Álvarez Otero J García Pouton N, Fernández Castro I, de la Fuente Aguado J. MEDICINA INTERNA, Y APARATO DIGESTIVO (1)., POVISA.

INTRODUCCIÓN: existe un número creciente de pacientes que reciben tratamientos biológicos para enfermedades autoinmunes. Entre los efectos adversos de estos fármacos están las reacciones paradójicas como reacciones psoriasiformes, uveítis, enfermedad inflamatoria intestinal, vasculitislike y sarcoidosis-like.

OBJETIVOS: comunicar un caso de sarcoidosis-like en un paciente tratado con Adalimumab por enfermedad de Crohn.
MATERIAL Y MÉTODOS: descripción del caso clínico y revisión de la literatura.

RESULTADOS: varón de 33 años con enfermedad de Crohn diagnosticada quince años antes y que había recibido prednisona y azatioprina; desde hacía dos años en tratamiento con Adalimumab. Acude a urgencias por fiebre de hasta $38^{\circ} \mathrm{C}$, sudoración profusa, tos seca y dolor centrotorácico opresivo con la tos. La exploración física no mostró alteraciones. El hemograma, y bioquímica fueron normales. En las pruebas hepáticas presentaba una GOT de 89U/L, GPT de 104 U/L, con normalidad de GGT, FA y Bb. En la radiografía de tórax se observó aumento de hilios pulmonares con ocupación de la ventana aorto-pulmonar. Una TC mostró múltiples adenopatías homogéneas en cadena paratraqueal inferior derecha, izquierda, región subcarinal y ambos hilios pulmonares. La ECA fue de 86 U/L. En la broncoscopia no se obtuvo material para el diagnóstico. Se realizó una mediastinoscopia con exéresis de adenopatías: linfadenitis granulomatosa no necrotizante compatible con sarcoidosis. Inicialmente se suspendió el Adalimumab y se pautó solo tratamiento sintomático con paracetamol e ibuprofeno. Ante la persistencia de fiebre, malestar y tos, se decidió iniciar tratamiento esteroideo con prednisona a dosis de 30 mgrs al día y suplementos con calcio y vitamina D. Los síntomas desparecieron a los pocos días y un mes después el paciente suspendio el tratamiento por su cuenta, con reaparición de los síntomas. Se reiniciaron los corticoides a dosis de $15 \mathrm{mgrs}$ al día, con pauta descendente de 5 mgrs cada 2 semanas y se mantuvo con 5 mgrs al día durante 6 meses. Se suspendieron y tras 18 meses permanece asintomático, sin datos de recidiva y con normalización de la radiografía de tórax.

DISCUSIÓN: hasta el 2015 se han descrito unos 71 casos de sarcoidosis-like asociada a fármacos anti TNF: 41 con etanercept, 14 con infliximab y 18 con adalimumab. Con respecto a este último, la mayoría eran mujeres (13 vs 5), edad media: 47 años (rango: 27-66) y con artritis reumatoidea 0 artropatía psoriásica de base. El tiempo transcurrido entre el inicio del tratamiento y de los síntomas es muy variable, desde un mes hasta 6 años. La mayoría presentaron resolución al suspender el tratamiento y sólo cinco de ellos precisaron esteroides.

CONCLUSIONES: Es importante para los clínicos conocer esta posible complicación que deberá incluirse en el diagnóstico diferencial de las diversas formas de afectación pulmonar que pueden observarse en pacientes con enfermedades reumáticas inflamatorias, especialmente la AR.

\section{USO DE NACO EN MEDICINA INTERNA EN EL COMPLEXO HOSPITALARIO UNIVERSITARIO DE OURENSE}

Barreiro Rivas A (1), Fernández González MP (2), Latorre Díez A (1), González Noya A (1), López Mato $P$ (1), Lorenzo Vizcaya A (1), de Toro Santos M (1).

(1) SERVICIO DE MEDICINA INTERNA. COMPLEXO HOSPITALARIO UNIVERSITARIO DE OURENSE (2) SERVICIO DE FARMACIA HOSPITALARIA. COMPLEXO HOSPITALARIO UNIVERSTTARIO DE OURENSE, COMPLEXO HOSPITALARIO UNIVERSTTARIO DE OURENSE.

INTRODUCCIÓN: El uso de nuevos anticoagulantes orales ha ido aumentando en los últimos años. Se plantea un estudio sobre el uso de los mismos en pacientes ingresados en Medicina Interna en nuestro hospital.

OBJETIVO: Analizar las características de una muestra de pacientes a tratamiento con NACO en el Servicio de Medicina Interna del CHUO, con el fin de conocer las indicaciones con las que se prescriben, las preferencias de fármacos y dosis y su adecuación a las caraceterísticas de los pacientes, además de registrar eventos isquémicos y hemorrágicos.

MATERIAL Y MÉTODOS: Estudio descriptivo retrospectivo en el que se recogieron datos de pacientes con al menos un ingreso en Medicina Interna en el CHUO durante 2014 que recibieron dispensación intrahospitalaria de un NACO. Esta información se obtuvo a través del Servicio de Farmacia Hospitalaria del CHUO

RESULTADOS: Se incluyeron 25 pacientes (18 recibían dabigatran, 4 rivaroxaban y 3 apixaban), con una media de 79,2 años. Todos menos uno lo recibían para prevención de ictus en FA. La mayoría de ellos habían recibido sintrom y el cambio se había hecho por INR lábill. Entre los 18 pacientes que recibían dabigatran, 15 recibían la dosis de $110 \mathrm{mg}$ cada $12 \mathrm{~h}$, de ellos 2 tenían disfunción renal grave y 3 tenían disfunción renal moderada; 11 de ellos eran mayores de 80 años. Se encontraron 3 pacientes menores de 80 años sin disfunción renal moderada grave $n$ otras indicaciones aparentes que recibían dosis de $110 \mathrm{mg}$. En cuanto al rivaroxaban, de los 4 pacientes uno recibían dosis de $20 \mathrm{mg}$ cada $24 \mathrm{~h}$, otro de $15 \mathrm{mg}$ y otros 2 dosis de $10 \mathrm{mg}$ cada $24 \mathrm{~h}$ (uno por disfunción renal, y el otro porque la recibía como profilaxis tromboembólica). La dosis de apixaban era de $5 \mathrm{mg}$ cada $24 \mathrm{~h}$ en dos casos y de 2,5mg cada $24 \mathrm{~h}$ en el otro, que tenían disfunción renal moderada. Se registraron un total de 3 eventos isquémicos. Dos de estos pacientes estaban recibiendo rivaroxaban; uno de ellos recibía dosis plena y el otro dosis de 15 $\mathrm{mg} / 24 \mathrm{~h}$. Observamos 3 sangrados importantes, los tres hemorragias digestivas bajas, en pacientes con dabigatran a dosis de $110 \mathrm{mg}$

CONCLUSIONES: EI NACO más utilizado en pacientes ingresados en Medicina Interna durante 2014 fue el dabigatran, con preferencia por la dosis de 110 mg cada 12h, elección que se justifica por la avanzada edad de los pacientes (se recomienda en mayores de 80 años) y por disfunción renal en varios casos. No obstante se encontraron dos pacientes con disfunción renal grave en los que estaría más indicado otro NACO y tres pacientes sin motivo aparente para no recbir la dosis de $150 \mathrm{mg} / 12 \mathrm{~h}$. Se observa igual prevalencia de eventos isquémicos y hemorrágicos en este grupo de pacientes (12\% del total en ambos casos). En el caso de los ACV la proporción fue mayor para rivaroxaban (50\%). Se observa la importancia de adecuar el tipo de anticoagulante y su dosis a cada paciente y la pertinencia de futuros estudios para evaluar riesgo isquémico y hemorágico de cada fármaco.

\section{HIPOACUSIA NEUROSENSORIAL BILATERAL Y ANTICUERPOS ANTICARDIOLIPINA POSITIVOS}

Vilas B, Freire MC, Boveda D, Suárez MM, Sousa A, Lorenzo R, Rivera A, Argibay A, Crespo M. SERVICIO MEDICINA INTERNAVIGO, EOXIVIGO.

INTRODUCCIÓN Y OBJETIVOS: presentamos el caso de una mujer de 25 años con antecedente de neurosensorial bilateral progresiva con anticuerpos anticardiolipina (ACLAs) y anticuerpos anti beta2glicoproteina I (AntiB2GPI) positivos en dos determinaciones.

MATERIAL Y MÉTODOS: revisión de historia clínica y literatura.

RESULTADOS: Mujer de 25 años, GOPOA0, sin exposición a tóxicos, con menstruaciones irregulares, que presenta desde los 15 años hipoacusia neurosensorial (HN) en oído izquierdo 
progresiva hasta cofosis de etiología no filiada (ANA negativos y Ac. Anti68kDaAg negativo) que en Enero de 2016 comienza con HN en oído derecho, con ANA positivos a título 1/80 y antiDNAds positivo $22 \mathrm{Ul} / \mathrm{mL}$ en una determinación. Además se hizo RNM de peñasco, sin alteraciones. Fue valorada en consulta de medicina interna siendo tanto la anamnesis dirigida a autoinmunidad y la exploración física normales. Destacaba analíticamente una hemoglobina de $9.9 \mathrm{mg} / \mathrm{dL}$ de perfil ferropénico. Se solicitaron ACLAs y AntiB2GPI que fueron positivos en dos determinaciones a título intermedio, anticoagulante lúpico negativo, factor V Leiden y mutación 20210A de factor II negativos, coagulacion normal,C3 $56 \mathrm{mg} / \mathrm{dL}, \mathrm{C} 48.6 \mathrm{mg} / \mathrm{dL}$. ANAs y antiDNAds se negativizaron. CONCLUSIONES: La HN es considerada idiopática en la mayor parte de los casos, aunque se ha visto que en algunos casos está asociada a autoanticuerpos circulantes frente a antígenos específicos del oído interno y el sindrome antifosfolípidico (SAF). En este, se cree que es debida a microtrombosis de repetición en la vasculatura laberíntica por disfunción endotetelial. Actualmente nuestra paciente no cumple criterios clasificatorios de SAF, pero el perfil de autoanticuerpos y la presentación clínica es muy sugestiva. En el momento actual está en tratamiento con aspirina e hidroxicloroquina.

\section{MORTALIDAD EN UNA UNIDAD DE CRÓNICOS DE MEDICINA INTERNA. ANÁLISIS DESCRIPTIVO}

Gómez-Buela I, Sardina-Ferreiro R, Vázquez-Vigo R, Caínzos-Romero T, Sánchez-Trigo S, Gómez-Gigirey A, Ferreira-González L.

SERVICIO DE MEDICINA INTERNA., COMPLEJO HOSPITALARIO UNIVERSITARIO DE FERROL.

OBJETIVO: Realizar un estudio descriptivo de mortalidad de los pacientes ingresados en una Unidad de Crónicos de Medicina Interna.

MATERIAL Y MÉTODOS: Estudio de cohortes retrospectivo. Población: pacientes fallecidos durante el ingreso en la Unidad de Crónicos del Servicio de Medicina Interna del CHU de Ferrol. Período de estudio: 15/3/2015 a 15/3/2016. Se revisaron los informes y comentarios médicos y de enfermería recogidos en la historia clínica $(\mathrm{HC})$ electrónica. Objetivo principal: tasa de mortalidad durante el ingreso. Objetivos secundarios: causas de ingreso, causas de éxitus, comorbilidad basal, polifarmacia, complicaciones durante el ingreso y uso de fármacos sedantes. Variables cuantitativas expresadas como media y DE, cualitativas como $n$ (\%). Análisis con Stata 13.0 para Mac.

RESULTADOS: Durante ese periodo ingresaron en nuestra unidad 781 pacientes, 114 de los cuales fallecieron, suponiendo una tasa de mortalidad del 14,6\%. La media de duración de la hospitalización hasta el fallecimiento fue de 9,2 (1-35) días. En un 29,8\% de los casos el éxitus se produjo en las primeras 72 horas de ingreso. La edad media fue de $85,5(D E 6,6)$ años. El $50 \%$ fueron varones. El $11 \%$ de los pacientes estaba institucionalizado antes del ingreso y un $50 \%$ presentaba deterioro cognitivo. La media del número de ingresos en el año previo fue de 1,2 (0-8). La media del número de fármacos antes del ingreso fue de 8,2 (0-17). La media del índice de Charlson fue de 7,75 (3,5-14,9). La causa más frecuente de ingreso fue la infección respiratoria (44,7\%), seguido de ICC (10,5\%), ictus (8,8\%), ITU (7,9\%) y neoplasia avanzada $(7 \%)$. El diagnóstico principal final de éxitus fue infección respiratoria (47,4\%), ICC en un $14,7 \%$, ictus $(9,7 \%$ y neoplasia avanzada (7\%). El 83,3\% se consideró éxitus previsible al ingreso aunque solo en el 18,4\% constaba indicación explícita de "no RCP" en la HC.

Se administró sedación paliativa en un 76,3\% de los casos (un 22,8\% mediante rescates sin pauta fija), siendo indicada por el médico de planta en el 38,6\% y por el de guardia en el 14,9\%. Se realizó una retirada progresiva de tratamiento antes de la sedación en un $42,1 \%$. En un $54,4 \%$ de los casos constaban recogidos en la HC los síntomas por los que se indicaba sedación y en un $91,2 \%$ que se había informado a la familia. El $43,9 \%$ de los pacientes presentaron alguna complicación pre-éxitus y el 13,2\% presentaron más de 1. Las más frecuentes fueron delirium (12,3\%), broncoaspiración $(5,3 \%)$ y RAO $(4,4 \%)$.

CONCLUSIONES: Los pacientes hospitalizados en la Unidad de Crónicos del CHUF son pacientes de edad muy avanzada, con comorbilidad elevada y una alta tasa de mortalidad que suelen ingresar y fallecer por infección respiratoria e insuficiencia cardíaca. Con frecuencia reciben sedación durante el ingreso y en la gran mayoría sus familiares estaban informados del probable desenlace. A pesar de que en porcentaje elevado el éxitus era esperable, la tasa de indicación explícita de "no RCP" fue baja.

\section{MANEJO Y COMPLICACIONES DEL TRATAMIENTO DEL TROMBOEMBOLISMO PULMONAR EN PACIENTES MUY ANCIANOS}

Barbagelata C, Vares M, Llinares D, Piñeiro P, Clavero E, Blanco C, Bouza L, Arévalo A. MEDICINA INTERNA, COMPLEJO HOSPITALARIO UNIVERSITARIO DEA CORUÑA.

INTRODUCCIÓN: La evidencia científica sobre el tratamiento del tromboembolismo pulmonar (TEP) en los pacientes de edad avanzada es escasa pese al aumento de su incidencia y del riesgo de sangrado. Es por ello necesario ampliar los estudios que permitan definir mejor el manejo del TEP en este grupo.

OBJETIVOS: Registrar el tratamiento del TEP en la fase inicial y a largo plazo, así como las complicaciones.
MÉTODOS: Estudio descriptivo retrospectivo en pacientes con edad mayor o igual a 80 años, con diagnostico de TEP entre 01/01/2013 y 31/12/2013 en el CHUAC, realizándose seguimiento del tratamiento y de las complicaciones hasta enero del 2016.

RESULTADOS: Se incluyeron 70 pacientes. En el 100\% la anticoagulación se inició con HBPM (97\% enoxaparina), la dosis no se ajustó por función renal en 15\% (10 casos), aunque sólo 11 casos tenian MDRD inferior a 30. Se realizó paso a antivitamina K en $80 \%$ (44 pacientes acenocumarol y uno warfarina); en el $20 \%$ se mantuvo el tratamiento con HBPM ( $81 \%$ con cancer). El INR estuvo bien controlado al inicio del tratamiento en la mitad de los pacientes, en aquellos que prolongaron tratamiento más de 6 meses el INR fue lábil los últimos 6 meses en el 57,5\%. El tratamiento se suspendió en algún momento en el 85\% de los casos. Los motivos de la suspensión fueron: fin del tratamiento (63.6\%), aparición de complicaciones (30.3\%-10 casos, siendo la más frecuente el sangrado, 7 casos), decisión del paciente (6.1\%). Presentaron complicación por sangrado el $12.9 \%$, tratándose de sangrado mayor $5,7 \%$, clínicamente relevante $2,9 \%$ y de sangrado menor $4.3 \%$. Un $15.4 \%$ de los pacientes se encontraban antiagregados y anticoagulados en el momento del sangrado. En el momento del sangrado se encontraban con acenocumarol 5 casos, 3 con INR en rango en ese momento y otros 3 casos se encontraban con HBPM. Sorprendentemente, el sangrado no se asoció con mal control de INR, probablemente por el bajo tamaño de la muestra. La complicación hemorrágica más frecuentes fue la digestiva. La duración media del tratamiento fue de 189 días (6 meses), aunque el análisis de duración de tratamiento excluyendo a los pacientes fallecidos aumentó la media a 259 días (8 meses). Fueron exitus el 51,7\%, ninguno por causa de sangrado.

CONCLUSIONES: En los pacientes mayores de 80 años es necesario suspender el tratamiento en el $30 \%$ de los casos por aparición de complicaciones siendo la más frecuente el sangrado. Presentarón INR lábil durante el tratamiento entre el 50-57\% de los pacientes, aunque no encontramos relación entre el INR hábil y el sangrado, el tamaño muestra era pequeño. La duración media del tratamiento fue de 6 meses, suspendiendo el mismo en el 85\% de los casos. Destacar que no se ajustó HBPM por función renal en el 90\% de los MDRD menor 30.

\section{ANÁLISIS DE MORTALIDAD (M) EN UNA COHORTE DE HEMATOMAS EN PARTES BLANDAS NO TRAUMÁTICOS (HPBNT)}

Verdeal Dacal $R$, Suárez Fuentetaja R, Domínguez Rodríguez T, Piñeiro Parga P, Porto Pérez AB, González Vigo V, Doval Domínguez L, De la Iglesia Martínez F

MEDICINA INTERNA, CHUAC. COMPLEXO HOSPITALARIO UNIVERSITARIO DEA CORUÑA

INTRODUCCIÓN: Los HPBNT son un problema no inusual en Medicina Interna. Con el envejecimiento de la población, con más pacientes pluripatológicos, se prevé que su frecuencia pueda elevarse en los próximos años. Presentan una M importante lo que aumenta el interés por variables que pueden advertir una mala evolución.

OBJETIVOS: Describir las variables que pueden favorecer la M en pacientes con HPBNT en un hospital de A Coruña.

MATERIAL Y MÉTODO: Se diseñó un estudio observacional retrospectivo incluyendo 73 pacientes con un HPBNT como motivo de ingreso o durante su hospitalización, y cuya fecha de alta fue en Ios años 20140 2015. Se recogieron datos demográficos, clínicos, analíticos y terapéuticos y se utilizó SPSS21 para el análisis estadístico.

RESULTADOS: La mediana de edad del grupo (G) de los 13 fallecidos en el ingreso (G2), y de los 22 éxitus entre el ingreso y 30 días postalta (G3) era 4 años superior (83 frente a 79 años) a la de la cohorte total (G1). Destacaba una mayor presencia en los $\mathrm{G}$ de éxitus de diabetes mellitus, neoplasia activa en los últimos 5 años, hepatopatía crónica y sobrepeso/obesidad (38,46\%, 23,1\%, $15,4 \%$ y $83,3 \%$ en el G2, $45,5 \%, 22,7 \%, 18,2 \%$ y $91,7 \%$ en el G3 frente a $34,2 \%, 13,7 \%$, $13,7 \%$ y $68,4 \%$ en el G1 respectivamente). Resaltar la presencia de un coeficiente muy cercano a la significación de éxitus durante el ingreso 0 en los 30 días postalta (G3) en los pacientes con sobrepeso/obesidad, con casi 8 veces más probabilidad de muerte. Además los G2 y G3 también presentaban un mayor porcentaje de enfermos transfundidos con concentrados de hematíes, anemización significativa ( $\geq 2 \mathrm{~g} / \mathrm{dl}$ de hemoglobina) e inestabilidad hemodinámica $(77,9 \%, 68,2 \%$, $38,5 \%$ en el G2, $77,3 \%, 69,2 \%, 36,4 \%$ en el G3 y $47,9 \%, 58,9 \%, 28,8 \%$ en el G1). Dentro de los pacientes anticoagulados en cada G, los del G2 y G3 presentaban un mayor porcentaje de pacientes con HAS-BLED de alto riesgo ( $\geq 3$ ) que los del $G 1$ ( $50,0 \%$ y $55,6 \%$ frente a $42,3 \%$ ). Analizando la función renal, destacaba un mayor deterioro del filtrado glomerular estimado por MDRD-4 media de más de $4 \mathrm{~mL} / \mathrm{min} / 1,73 \mathrm{~m} 2$ antes del sangrado en el G2 y G3 respecto al G1. Sin embargo, no se encontraron diferencias relevantes en otras variables como etilismo, ingreso en los últimos 30 días, estancia media, localización y número pacientes anticoagulados antes de la hemorragia. En el ámbito terapéutico, 2 pacientes del G3 estaban con dosis supraterapéuticas de heparina y 3 combinaban al menos 2 tratamientos anticoagulante/antiagregante. Se realizó en menos ocasiones un abordaje conservador en los pacientes fallecidos, optándose por la embolización percutánea en 4 y la cirugía en 2 de los 22 pacientes del G3.

CONCLUSIONES: La edad, el deterioro de la función renal y/o hepática, un HAS-BLED de alto riesgo y sobretodo la obesidad son factores determinantes en el pronóstico de los HPBNT que pueden advertirnos la posibilidad de realizar un manejo más prudente de los fármacos si existe riesgo o sospechamos esta patología 